Portland State University

PDXScholar

Environmental Science and Management

Professional Master's Project Reports

Fall 2021

\title{
Closed Canopies Crowd Out Bats: Planning Artificial Gap Creation
}

Alana Simmons

Portland State University

Follow this and additional works at: https://pdxscholar.library.pdx.edu/mem_gradprojects

Part of the Environmental Indicators and Impact Assessment Commons, and the Environmental Monitoring Commons

Let us know how access to this document benefits you.

\section{Recommended Citation}

Simmons, Alana, "Closed Canopies Crowd Out Bats: Planning Artificial Gap Creation" (2021).

Environmental Science and Management Professional Master's Project Reports. 70.

https://pdxscholar.library.pdx.edu/mem_gradprojects/70

https://doi.org/10.15760/mem.73

This Project is brought to you for free and open access. It has been accepted for inclusion in Environmental Science and Management Professional Master's Project Reports by an authorized administrator of PDXScholar. Please contact us if we can make this document more accessible: pdxscholar@pdx.edu. 


\section{Portland State}

\section{Closed Canopies Crowd Out Bats: Planning Artificial Gap Creation}

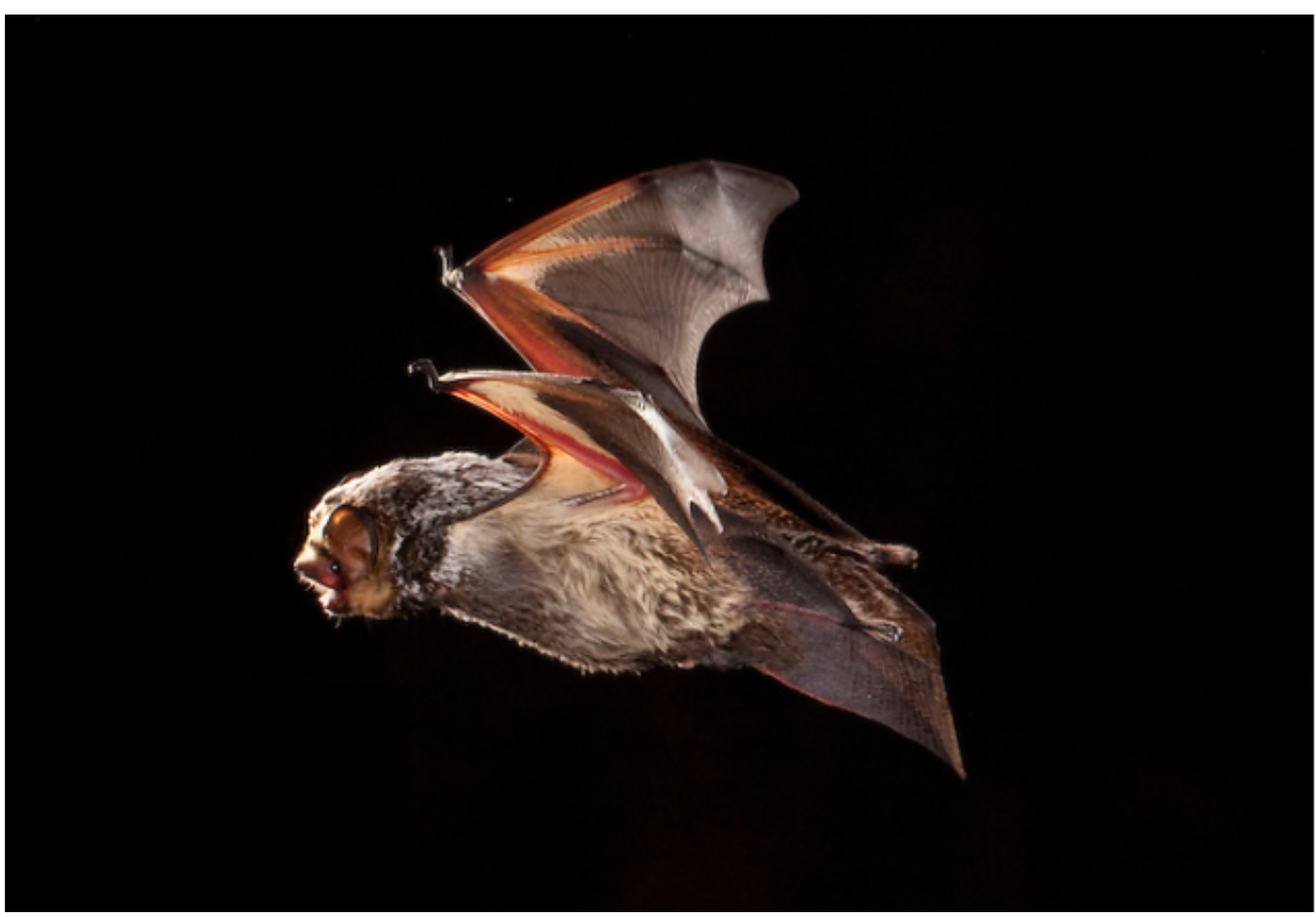

Alana Simmons

Master's in Environmental Management

Environmental Science and Management (ESM)

Academic Advisor: Dr. Catherine de Rivera, ESM

Community Partners: DeAnna Williams, USFS; Jason Kirchner, ODFW; Gregory Reed, ODFW; Raymond Dodd, ODFW; Jennifer Ringo, ODFW

Committee Members: Dr. Sarah Carvill, ESM; Dr. Thomas Rodhouse, National Park Service \& Oregon State University-Cascades; Rogelio Rodriguez, Oregon State University-Cascades

Photo Credit: Michael Durham Photography 


\section{Table of Contents}

$\begin{array}{lr}\text { Statement of Purpose } & 4\end{array}$

$\begin{array}{lr}\text { Executive Summary } & 5\end{array}$

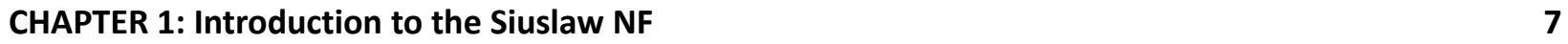

History of Management $\quad 11$

Regional Native American History 11

Establishment of the Forest and Other Designated Areas 13

US Forest Service Management $\quad 13$

Dominant Vegetation Zones and Plant Associations 15

$\begin{array}{ll}\text { Prominent Fauna } & 19\end{array}$

Bat Community $\quad 21$

Forest Succession $\quad 23$

$\begin{array}{ll}\text { Disturbance Regime } & 24\end{array}$

CHAPTER 2: Bats of the Siuslaw NF and the Importance of Forest Gaps 27

$\begin{array}{ll}\text { Insectivorous Bats and Energy Conservation } & 27\end{array}$

Bat Morphogroups and the Roles of Forest Gaps $\quad 29$

Importance of Forest Gaps $\quad 31$

Types of Forest Gaps $\quad 33$

Timber Harvest Gaps $\quad 33$

Meadows, Grasslands, and Herbaceous Gaps 36

Gaps from Fire $\quad 37$

Gaps from Windthrow and Disease $\quad 37$

Water-Associated Gaps 38

Roads and Trails $\quad 40$

Role of Edge Habitat Created by Gaps

Role of Forest Interiors $\quad 42$

Transition from Gap to Forested Habitat $\quad 44$

CHAPTER 3: Artificial Gap Creation and Parameters Influencing Bat Activity 46

Literature Review Methods $\quad 47$

Important Gap Parameters $\quad 47$

Gap Size and Shape $\quad 47$

Forest Type $\quad 50$

Proximity to Roosting Habitat $\quad 52$

Proximity to Source of Drinking Water 55

Proximity to Highways $\quad 57$

Regenerating Plant Structure $\quad 59$

$\begin{array}{ll}\text { Elevation } & 60\end{array}$ 
Additional Managerial Concerns for the Siuslaw NF 61

Siuslaw NF Gap Parameter Table $\quad 62$

Parameters in Need of Further Research $\quad 65$

$\begin{array}{ll}\text { Insect Availability } & 65\end{array}$

$\begin{array}{ll}\text { Wind } & 66\end{array}$

$\begin{array}{ll}\text { Plant Composition, Slope Aspect, and Soil Type } & 67\end{array}$

$\begin{array}{ll}\text { Connectivity via Commuting Pathways } & 67\end{array}$

CHAPTER 4: Case Study of the Siuslaw NF: Identifying Locations for Gap Creation 68 $\begin{array}{ll}\text { Methods } & 68\end{array}$

$\begin{array}{ll}\text { Dataset Preparation } & 69\end{array}$

Weighted Overlay Analysis $\quad 72$

$\begin{array}{ll}\text { Results and Discussion } & 74\end{array}$

$\begin{array}{lr}\text { Conclusions } & 81\end{array}$

$\begin{array}{lc}\text { References } & 83\end{array}$ 


\section{Statement of Purpose}

Managed even-aged forest stands often lack small to medium-sized canopy gaps that help to increase habitat diversity and, in turn, wildlife diversity. A large body of literature suggests that this habitat diversity is especially important for bat communities and that bat activity and diversity can be depressed in closed canopy, even-aged stands. Open- and edge-adapted bats have evolved specific wing morphologies and echolocation call structures that make them reliant upon forest gaps as energy efficient foraging grounds in otherwise structurally cluttered forests. Artificial gap creation projects that increase habitat diversity have been implemented to benefit ungulates, and a similar approach could also be applied to support foraging activity of bats in even-aged forests that lack dynamic natural disturbances. However, little consideration has been given to the use of gaps by bats and no comprehensive approach for artificial gap creation for the benefit of bats has been proposed.

In response to this lack of guidance for forest managers in the Pacific Northwest region, this document provides a focused review of existing literature regarding bats and gaps. This information was used to create specific management recommendations regarding physical characteristics of gaps and their spatial context on the landscape. To identify ideal locations for gap creation on the ground according to these recommendations, a weighted overlay method is suggested. This document has been written for the use of forest managers throughout the entire Pacific Northwest region. However, the Siuslaw National Forest (NF), a Late-Successional Reserve on the coast of Oregon, was used as a specific case study to demonstrate how the proposed approach can be applied to a specific management unit.

The document is broken into the four following chapters. Chapter 1 introduces the Siuslaw NF and briefly describes the forest's bat community, major vegetation zones, forest succession, disturbance regime, and management. Using previous research from the region as a guide, Chapter 2 provides background information regarding bat biology and ecology and it details the importance of gaps, forest edges, and interior stands as habitat for forest-dwelling bats. Different types of forest gaps common to the Pacific Northwest are discussed including both artificially created and naturally occurring gaps. Chapter 3, again guided by review of existing literature, highlights important gap parameters including physical characteristics and spatial context to promote bat activity as well as provides specific gap management recommendations. Chapter 4 provides an example of how to input management recommendations into a Geographic Information System (GIS) to pinpoint ideal locations for gap creation within a management unit. A weighted overlay analysis, a common GIS tool, was conducted in the Siuslaw NF following the management guidelines, and resulting maps are discussed.

The ultimate goal of this document is to provide forest managers in the Pacific Northwest region with the knowledge and planning tools necessary to promote foraging activity of specialized open- and edge-adapted species. While other management units may have different or additional managerial constraints than those of the Siuslaw NF, thIS proposed approach can be easily adapted to meet the varied needs of different forests. By following this approach, forest managers can provide the habitat 
diversity and complexity necessary to promote high levels of bat activity and diversity within even-aged, closed canopy forests.

\section{Executive Summary}

Creating canopy gaps can help support the diverse community of bats in the Pacific Northwest region. Though all local species are insectivorous, they inhabit a wide range of habitat types and have different structural habitat requirements. 13 out of the 15 species of bats found in Oregon are associated with forests and primarily roost in large diameter snags. Based upon their wing morphology and echolocation call structure, bats fall within one of three morphogroups. On one end of the spectrum, large-bodied bats with long narrow wings are termed open-adapted bats. These species are built for fast, straight-line flight and are aerial hawkers, catching their insect prey out in the open air often within canopy gaps. On the opposite end of the spectrum, small-bodied bats with short, wide wings are referred to as clutter-adapted bats. These species exhibit slow but highly maneuverable flight and glean insects off of foliage sometimes within the interior of forest stands. Bats of intermediate wing morphology are called edge-adapted bats. These species are typically slow aerial hawkers and forage at the interface of gaps and forest stands.

Many studies have shown that levels of overall bat activity as well as activity of open- and edge-adapted species is greatest within forest gaps and at the edges of gaps. Even clutter-adapted bat species often utilize the edges of forest gaps. Open- and edge-adapted bats have very limited plasticity in the types of habitats that can be used for foraging. Use of structurally cluttered habitat is energetically costly for these morphogroups and can be highly detrimental as bats are physiologically constrained by tight energy budgets. Thus, open forest gaps are highly important resources for open- and edge-adapted forest-dwelling bat species. A forest gap supporting bat foraging is defined as an opening of any size and shape sufficiently devoid of vegetation that allows for unobstructed fast, straight-line flight. Several types of forest gaps are created naturally by disturbances including fire, windthrow, and disease. Other natural gaps can be created by landscape features such as water bodies, meadows, grasslands, and herbaceous areas. In some cases forest gaps are created by human activity such as timber harvest, and open space above trails or forest roads with minimal traffic may be used as foraging grounds by bats.

Closed canopy, even-aged forests relatively devoid of forest gaps have the potential to negatively impact overall bat diversity and the activity of open- and edge-adapted species. As such, forest managers have the opportunity to create artificial gaps for the benefit of bats. To best plan gap creation, several gap parameters must be considered. Perhaps the most influential is gap size; open- and edge-adapted species are unable to forage effectively within very small gaps while clutter-adapted bats are excluded from large gaps. Even open-adapted species may avoid large gaps created by intense disturbances such as commercial clear-cuts. Review of existing literature indicates that gaps from 0.075-0.5 ha in size are likely to support the activity of all three morphogroups. Gap shape may also be important as elongated or irregularly shaped gaps provide a greater availability of edge habitat compared to circular gaps. 
Another highly important parameter to incorporate when planning gap creation is the distance between a gap and suitable roosting habitat. For a gap to function as viable foraging grounds, it must be within a reasonable distance from forest stands with high densities of large diameter snags. Previous studies indicate that males, juveniles, and non-reproductive females are less constrained in their nightly commutes than reproductive females. Pregnant females typically use resources near roosts due to energetic constraints and, in addition, lactating females must be available to nurse their young throughout the night. Gaps situated within $1 \mathrm{~km}$ of suitable roosting habitat are likely to accommodate the needs of reproductive females. The proximity of gaps to water should also be considered. Though bats in the Pacific Northwest region consume water-laden insect prey, they require additional drinking water. Artificial forest gaps created within 2-3 km of still or slow-moving water bodies will help bats meet drinking water needs.

Just as the proximity of artificial gaps to beneficial resources should be considered, so too should the proximity of gaps to potentially disrupting anthropogenic activity. Major roadways with high traffic volume are known to dampen nearby bat activity and can cause the mortality of bats by vehicle collision. Several studies have shown that road effects can pervade into forest stands and disrupt foraging bats. At a minimum, high traffic roadways are likely to influence the activity of all three bat morphogroups up to $350 \mathrm{~m}$ into forests, though some studies suggest that clutter-adapted bat activity can be affected up to $1.6 \mathrm{~km}$ away from roads. As such, gaps created beyond the zone of influence of roads are expected to promote the highest diversity of bat activity.

Plant structure and forest type are also parameters in need of evaluation when planning gap creation. The structure of early colonizing vegetation post gap creation has the potential to determine a gap's functional longevity. Once trees have regenerated in a gap and especially once the difference in canopy height between the regenerated trees and surrounding forest has been diminished, the area no longer functions as a gap. Thus, the creation of gaps in areas that support dense early colonizing shrubs that suppress tree growth will result in foraging grounds with extended functional life. When comparing the results of studies regarding forest type preferences of bats throughout the entire Pacific Northwest region, no strong patterns are found. However, there is evidence that creating artificial forest gaps within specific forest types may be important in some local regions. Different forest types provide varied insect resources, which leads to differences in insect abundance and diversity and could influence foraging habitat selection of bats.

The elevation at which an artificial gap is created can influence its suitability as foraging grounds for reproductive females. While males, juveniles, and non-reproductive females readily utilize torpor as a means of energy conservation when experiencing cold temperatures, reproductive females avoid torpor as it slows fetal growth rates and delays timely parturition, ultimately decreasing their youngs' chances of survival. Regional studies indicate that reproductive females roost and forage at low, warm elevations. As such, artificial gaps created at elevations less than $700 \mathrm{~m}$ are likely to better meet the foraging habitat needs of reproductive females.

The above list of gap parameters is not comprehensive; as existing literature indicates that habitat structure is the driving force behind forest gap preferences of bats, parameters related to physical structure were prioritized. However, many additional gap parameters are likely influential and 
are in need of future research. It is suggested that parameters including the influence of insect availability, wind, plant composition, slope aspect, soil type, connectivity of gaps via commuting pathways, and other variables be further explored. Though additional research on the nuanced gap preferences of bats are necessary, forest managers can utilize results from existing research along with geospatial tools to better plan the creation of artificial gaps to promote bat diversity and the activity of edge- and open-adapted bat species in closed canopy forests.

\section{CHAPTER 1: Introduction to the Siuslaw NF}

Prior to delving into the proposed artificial gap creation approach, the Siuslaw NF is characterized as it is used as a case study throughout the document. This characterization provides necessary context for understanding possible and appropriate management decisions within this particular forest. Located on the coast of Oregon along the Pacific Ocean (Figure 1), the Siuslaw National Forest encompasses over 630,000 acres of land between the cities of Tillamook and Coos Bay. The forest is relatively long with the northernmost tip at a latitude of approximately $45.9^{\circ} \mathrm{N}$ and the southernmost tip at $43.4^{\circ} \mathrm{N}$, a 135 mile span. The forest spans across the following 8 counties (listed by greatest acreage): Lane, Lincoln, Tillamook, Douglas, Yamhill, Benton Coos, and Polk (USDA Forest Service, n.d.a). Approximately 604,000 acres consist of mixed forests and 27,000 acres are made up of sand dunes and wetlands (USDA Forest Service, 1990). The Alsea, Nestucca, Siuslaw, and Umpqua Rivers flow through the forest into the Pacific Ocean. Managed by the U.S. Forest Service, the forest is divided into the Hebo Ranger District to the north (Figure 2) and the Central Coast Ranger District to the south (Figure 3).

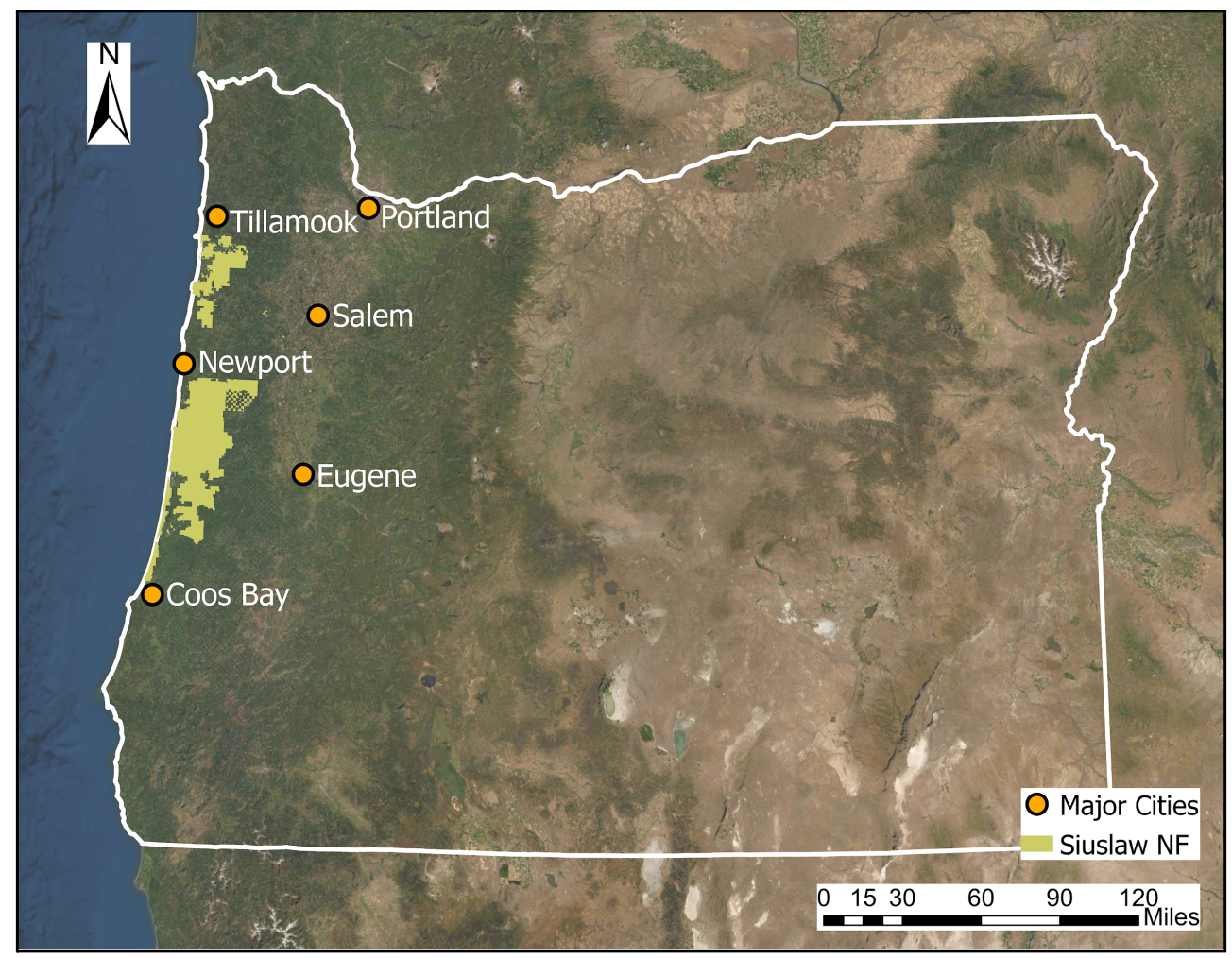

Figure 1: Location of the Siuslaw NF within the state of Oregon. 


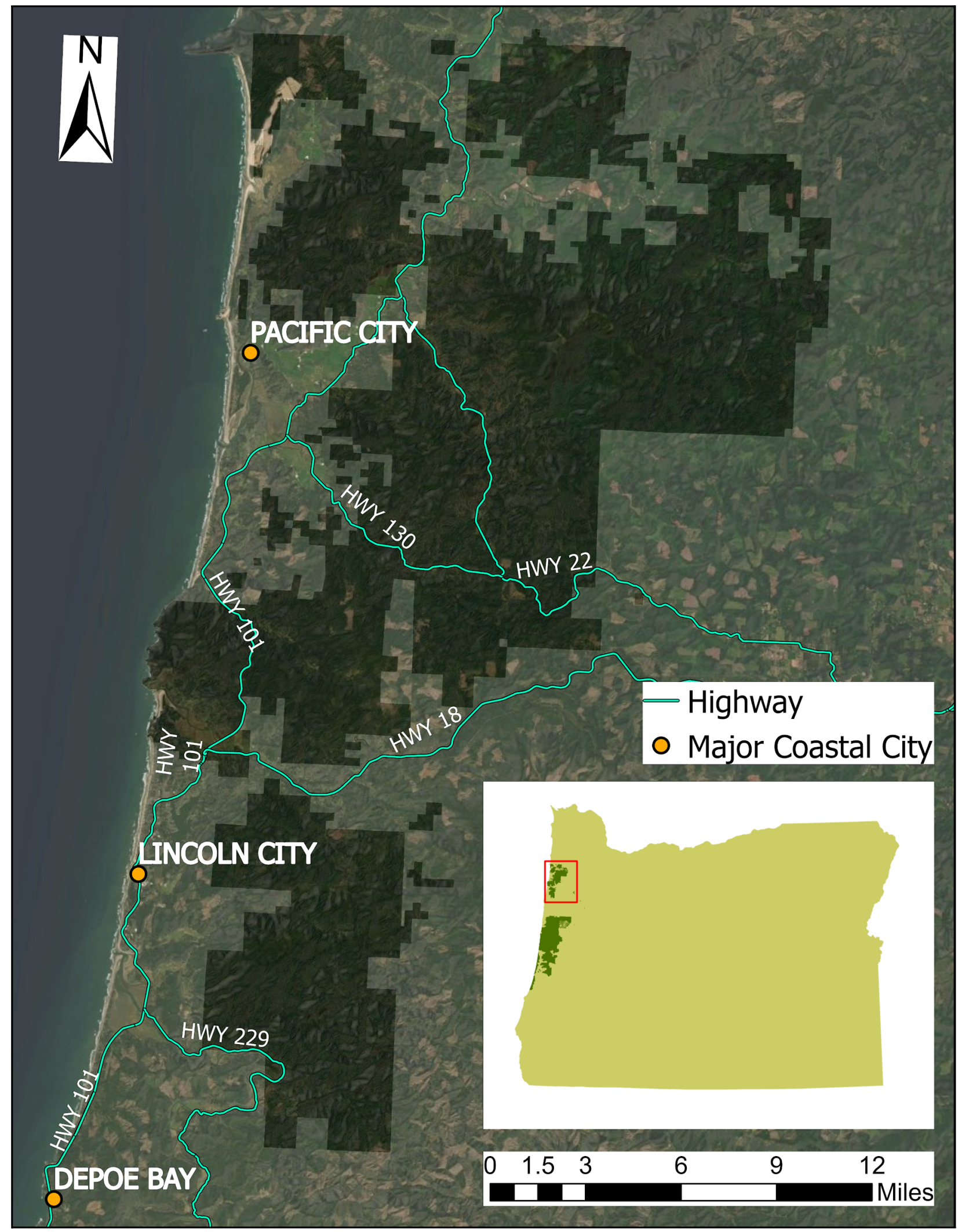

Figure 2: Map of the northern Hebo District of the Siuslaw NF. 


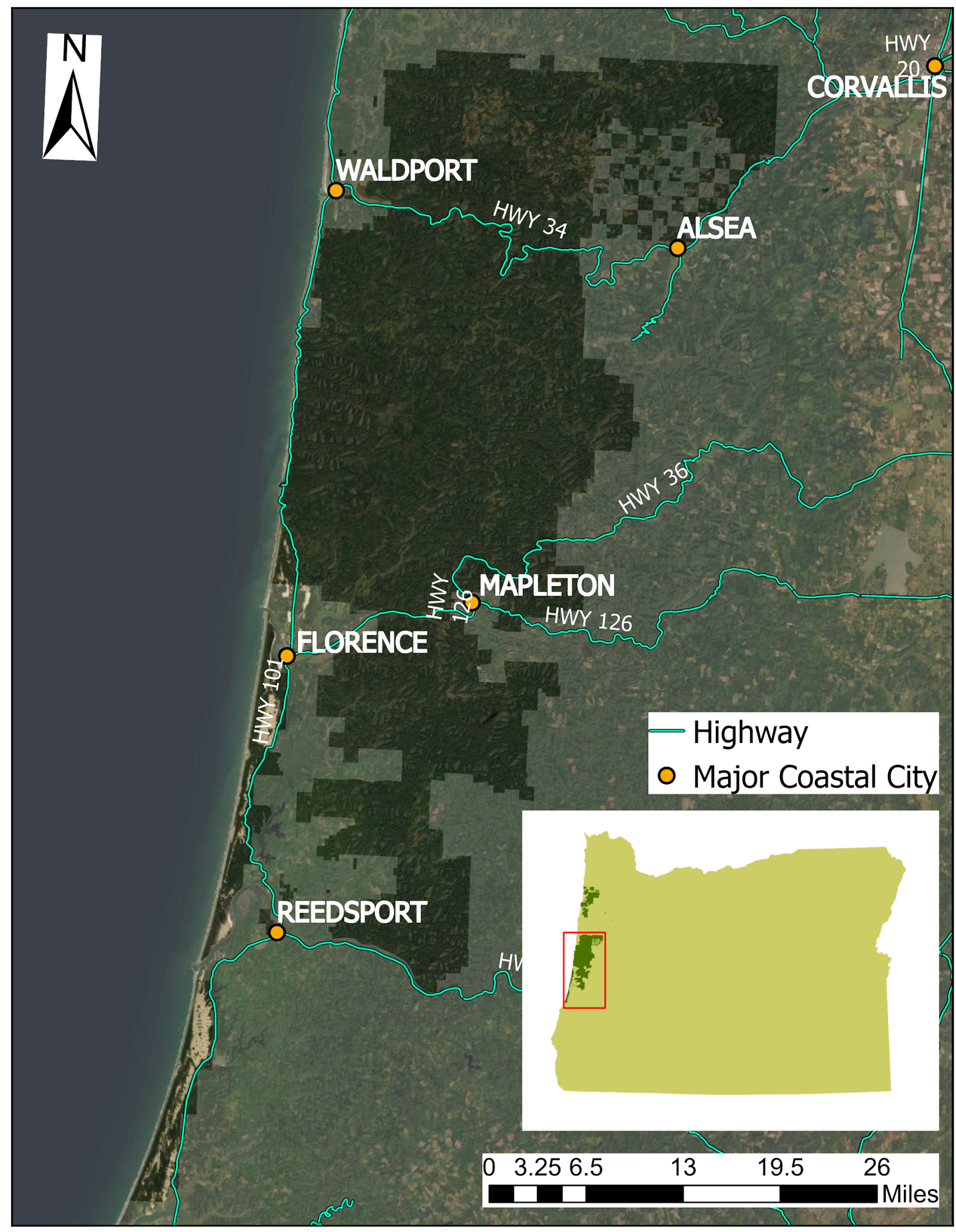

Figure 3: Map of the southern Central Coast Ranger District in the Siuslaw NF. 
Elevations range from sea level along the coast to 1,249 $\mathrm{M}$ at Mary's Peak (USDA Forest Service, n.d.a) Orographic effects are strong with high elevation ridges experiencing higher levels of precipitation than neighboring low elevation locations (Hemstrom \& Logan, 1986). Inland locations receive up to 40 inches more rain per year than coastal locations (Hemstrom \& Logan, 1986) with some inland locations of the forest receiving up to 100 inches of rain annually (USDA Forest Service, n.d.a). Temperatures are mild throughout the year along the coast; winter months average between $30-40^{\circ} \mathrm{F}$ and summer months remain around $60^{\circ} \mathrm{F}$ (USDA Forest Service, n.d.a). The further away from the coast, the more extreme temperatures become; however, temperatures remain relatively moderate.

The Siuslaw NF lies within the Central Pacific Coastal Forest ecoregion, one of eight ecoregions in the Pacific Northwest. The Central Pacific Coastal Forest ecoregion accounts for almost $17 \%$ of the entire Pacific Northwest (Strittholt, Dellasala, \& Jiang, 2006). Historically, the lands of this ecoregion were comprised of an estimated $85 \%$ old conifer forests ( $>150$ years old) but, as of 2006 , the reach of old conifer forests had been minimized to only $18 \%$ (Strittholt, Dellasala, \& Jiang, 2006). The remaining old-growth forest has been fragmented and lies scattered in a matrix of stands at varied early and middle successional stages. Discussed further in the below management section, the Siuslaw NF is a federally designated Late-Successional Reserve intended to preserve the remaining old-growth and to promote the creation of late-successional habitat.

\section{History of Management}

\section{Regional Native American History}

Long before the Siuslaw NF was established, the region was inhabited by the Tillamook, Nestucca, Salmon River, Siletz, Yaquina, Alsea, Siuslaw, and Kuitsh (Kalawatset, Lower Umpqua, or Quuiich) peoples (Loy, 2001). Although estimates of when civilization first appeared on the coast of Oregon are continually changing in accordance with new discoveries, it is currently thought that the region was first inhabited between 6,000 and 10,000 years ago (Wilkinson, 2010). Culture, language, and ways of life differed between these diverse groups despite their close proximity to and contact with one another. Communities living along the coast relied upon the ocean for food with sea lion, whale, shellfish, marine fishes, and salmon being common food items (Confederated Tribes of Siletz Indians, n.d.). The diets of tribes living further inland consisted of other foods including deer, elk, salmon, and acorns (Confederated Tribes of Siletz Indians, n.d.). Tribes often lived in plank houses constructed from cedar or sugar pine during harsher seasons and some moved to and from seasonal camps (Confederated Tribes of Siletz Indians, n.d.).

There is substantial evidence that tribes in the Pacific Northwest utilized fire as a management tool (Boyd, 1999). A less prevalent practice among coastal tribes than those further inland, burning was used to the benefit of deer hunters and to encourage growth of berry-bearing bushes including salal, red huckleberry, and salmonberry (Boyd, 1999). As a part of the natural world, these communities gave 
thanks to the land and their foods. Prior to salmon runs the first salmon ceremony was conducted to show respect and appreciation to their preferred food (Wilkinson, 2010).

It is debated when the first colonial ship arrived on the Native American peoples' shorelines and could have been as early as the 1520s (Wilkinson, 2010). In the late 18th century, American, British, and Russian trade ships began frequenting the coast bringing with them waves of disease including smallpox, whooping cough, influenza, and measles among others (Mcnaughton, 2020). Having no prior exposure to European diseases, Native American populations experienced mass mortalities with declines up to 95\% (Macnaughtan, 2020). The Lewis and Clark Expedition arrived in the area in 1805 and noted that villages along the lower Columbia River were all but decimated with only bodies and buildings left at sites of major villages (Confederated Tribes of Siletz Indians, n.d.).

Fur trade was prevalent in the area with the Hudson Bay Co. and the Pacific Fur Co. controlling trade by the mid 1820's; their large outposts foreshadowing the permanence of outsiders on the landscape. The European settlers in the region transitioned from fur trade to farming by the late 1830's with missionaries and settlers moving into the area in increasing numbers (Confederated Tribes of Siletz Indians, n.d.). With the U.S congress passing of the Oregon Donation Land Act of 1850, large swathes of Native American land were promised to white settlers emigrating to the west. This immigration led to the enactment of many treaties throughout the 1850's between the U.S. government and Native American tribes, some of which were respected though many were left unfulfilled by the U.S. government.

An Executive Order signed in 1855 established the Coast Reservation, which encompassed 1.1 million acres of land from Cape Lookout to Siltcoos River (Confederated Tribes of Siletz Indians, n.d.; Lewis \& Kentta, 2010). Another Executive Order signed in 1865 removed 200,000 acres of land around Acquinna Bay from the reservation, and the Annual Appropriations Bill for Fulfilling Treaty Stipulations of 1875 reduced the reservation by approximately 700,000 acres leaving only around 225,000 acres for Native American use (Confederated Tribes of Siletz Indians, n.d.; Lewis \& Kentta, 2010). Between 1892 and 1894, the Dawes Allotment Act of 1887 was implemented, which further fragmented and reduced tribal lands. All tribal members were awarded 80 acre land allotments. Moreover, the 191,000 acres of tribal lands remaining after that allotment were removed from tribal control and opened for homesteading (Lewis \& Kentta, 2010). With the Western Oregon Indian Termination Act of 1954 the federal status of the Confederated Tribes of the Siletz Indians was revoked; at this time all but 39 acres of the reservation were sold (Confederated Tribes of Siletz Indians, n.d.).

In 1977 the Confederated Tribes of the Siletz Indians' federal status was returned and, in 1980, the Siletz Reservation Act restored around 3,660 acres of land as a reservation (Confederated Tribes of Siletz Indians, n.d.). The modern reservation sits on Siletz River within the Siuslaw National Forest. A much more complete history and characterization of the 28 confederated tribes and their reservation can be found using the online resources provided by the Confederated Tribes of Siletz Indians and in Charles Wilkinson's book "The People are Dancing Again". In no way does the above extremely condensed and selective history adequately describe the brutal and unfair treatment of Native Americans in this region or across the United States. 


\section{Establishment of the Forest and Other Designated Areas}

In 1908, the Siuslaw NF as well as the Hebo and Central Coast Ranger Districts, were officially established by the U.S. Federal Government. In the forest's early days, activity within its boundaries looked much different than what happens in the forest today. From its inception till the early 1930's, homesteaders were allowed on National Forest lands. However, the landowners were bought out and all land within forest boundaries was brought under the management of the US Forest Service of the United States Department of Agriculture (USDA Forest Service, n.d.b). After 1933, during the Great Depression, there were multiple Civilian Conservation Corps (CCC) camps located throughout the forest. At this time, roads, bridges, fire lookout towers, and campgrounds were being created by members of the CCC (USDA Forest Service, n.d.b). The now popular scenic Highway 101 was constructed around this time.

In 1960, the Cape Perpetua Scenic Area was established to preserve a unique tract of land that transitions from temperate spruce rainforest to sea (USDA Forest Service, n.d.c; La Follette \& Deur, 2020). In 1972, the Oregon Dunes National Recreation Area was created ensuring the continuation of recreational enjoyment and unique ecology of one of the largest temperate coastal sand dunes areas (USDA Forest Service, n.d.d). In 1974, a portion of the Siuslaw National Forest in between Neskowin and Lincoln City was designated as the Cascade Head Experimental Forest by President Ford (USDA Forest Service, n.d.e). The land was set aside to ensure future enjoyment of the scenic landscape as well as for research of Sitka spruce-western hemlock forests (USDA Forest Service, n.d.e). In the following years, the Rock Creek, Drift Creek, and Cummins Creek Siuslaw Wilderness Areas were also established.

\section{US Forest Service Management}

From the late 1800's to the present, Pacific Northwest forests have been commercially logged (USDA Forest Service, n.d.b). With the start of WWI in 1914, enormous amounts of timber were harvested for the construction of military airplanes and large logging operations continued after the end of the war. With the invention and availability of better transportation and the gas-powered chainsaw in the late 1950s, a wave of intense commercial logging washed over federal forests in the region. At the time, European forest management practices of the day including clearcutting, removal of biomass post-harvest, and replanting of harvested areas with monocultures were thought to be ecologically sound means to obtain a fast-growing crop (Curtis et al., 2007)

During this time, old-growth and late-successional stands were thought to hold no ecological value and older forests were seen only as prime locations for timber harvest. It wasn't until the 1970s and 1980s when innovative research revealed that old-growth forests are dynamic and unique ecosystems that support a particular suite of wildlife. By this time in the 1980s, Pacific Northwest forests had been reduced to, "...a highly fragmented mosaic of recent clearcuts, thinned stands, and young plantations interspersed with uncut natural stands" (Forest Conference Executive Committee, 1993). Models have estimated that old-growth stands historically accounted for $39-55 \%$ of the Oregon Coast Range forests but by the year 2000 , old-growth accounted for only approximately $5 \%$ (Wimberly et al., 2000). Old-growth researchers of the 1980 s reported that the forest management strategies of the time 
did not support the continuation of biodiversity of old-growth communities or associated aquatic ecosystems.

In the late 1980s, what is now known as the Timber Wars began when scientists, government workers, loggers, environmentalist organizations, and the public became divided in their opinions as to how dwindling old-growth stands of the region should be managed. The US Forest Service became responsible for a highly complicated balancing act. Some stakeholders expected the Siuslaw NF along with other forests in the region to be managed in a way that favored the economy over the forest's ecology. The Siuslaw NF has the highest productivity per acre of any U.S. National Forest and revenue generated by timber sales far outweighs the money spent on timber and road management (USDA Forest Service, 1990). Other stakeholders recognized that logging practices of the day threatened the continued existence of old-growth forests, the region's biodiversity, and associated ecosystem provisioning and regulating services.

In 1990, an old-growth obligate species, the northern spotted owl (Strix occidentalis caurina), was listed under the Endangered Species Act (ESA) spurring protection of old-growth habitat. These protections were supported by subsequent listings of the marbled murrelet (Brachyramphus marmoratus) and several fish species. In 1994, the Northwest Forest Plan (NWFP) was adopted by the USDA Forest Service to guide management of diverse forest resources in an ecologically sound manner while meeting economic demands (USDA Forest Service \& Bureau of Land Management, 1994). The NWFP remains in compliance with the National Forest Management Act, the ESA, and the National Environmental Policy Act. Specifically addressed by the NWFP are acceptable practices regarding the management of late-successional forests. Since 1994, the Siuslaw NF has been designated as a Late-Successional Reserve to serve the following purposes (USDA Forest Service \& Bureau of Land Management, 1994a).

"First, they provide a distribution, quantity, and quality of old-growth forest habitat sufficient to avoid foreclosure of future management plans. Second, they provide habitat for populations of species that are associated with late-successional forests. Third, they will help ensure that late-successional species diversity will be conserved."

The Siuslaw NF is still currently managed in accordance with the NWFP and the special standards and guidelines for Late-Successional Reserves. While recreation is still a large part of the forest, timber harvest has been greatly reduced in the interest of habitat conservation. Silvicultural concerns are the main driver of these guidelines though many other concerns including development, fire suppression, and nonnative species management are addressed by these guidelines as well. Current management policy and guidelines can be viewed on the US Forest Service website and some specific guidelines pertinent to artificial gap creation are discussed below in Chapter 3. 


\section{Dominant Vegetation Zones and Plant Associations}

Two drastic geographic shifts occur within the Siuslaw NF. First, the coastal west forest transitions to inland regions in the east. Second, conditions change with the decrease in latitude from the north to south of the forest. Due to the diverse range of environmental conditions resulting from these gradiental shifts, many different plant associations are found within the Siuslaw NF. For the purposes of this document, two major zones of dominant vegetation occur within the Siuslaw NF: the western hemlock (Tsuga heterophylla) zone and the Sitka spruce (Picea sitchensis) zone (Hemstrom \& Logan, 1986; USDA Forest Service, 1990) (Table 1, Figure 4, Figure 5). Modeled plant associations of the Coast Range show that the western hemlock zone covers approximately $77 \%$ of the Siuslaw NF and approximately $23 \%$ falls within the Sitka spruce zone (Table 1) (Henderson \& McCain, 2011). However, very small portions of the forest have been classified as Douglas fir (Pseudotsuga menziesii), Pacific silver fir (Abies amabilis), and grand fir (Abies grandis) zones (Table 1, Figure 4, Figure 5). Note that plant associations for small portions of the Central Coast District have not been modeled (Figure 5).

Table 1: Dominant vegetation zones and plant associations of the Siuslaw NF and their respective percentages based on the Oregon Coast Modeled Plant Associations (Henderson \& McCain, 2011).

\begin{tabular}{|c|c|c|c|}
\hline Vegetation Zone & $\%$ of Siuslaw NF & Plant Association & $\%$ of Siuslaw NF \\
\hline \multirow{9}{*}{ Western hemlock } & \multirow{9}{*}{$76.8 \%$} & sword fern, moist & $45.24 \%$ \\
\hline & & salmonberry, wet & $18.90 \%$ \\
\hline & & swordfern, Oregon grape, salal (mesic) & $10.01 \%$ \\
\hline & & rhododendron & $1.818 \%$ \\
\hline & & red huckleberry, oxalis & $0.699 \%$ \\
\hline & & transition to Douglas-fir zone (warm) & $0.001 \%$ \\
\hline & & nonforest (dry) & $0.001 \%$ \\
\hline & & nonforest (wet) & $0.001 \%$ \\
\hline & & devil's club or skunk cabbage (very wet) & $<0.001 \%$ \\
\hline \multirow{4}{*}{ Sitka spruce } & \multirow{4}{*}{$22.5 \%$} & salmonberry (wet) & $11.09 \%$ \\
\hline & & oxalis, sword fern (moist) & $9.673 \%$ \\
\hline & & salal (mesic) & $1.583 \%$ \\
\hline & & nonforest (wet) & $0.160 \%$ \\
\hline Douglas-fir & $0.4 \%$ & black oak, poison oak & $0.347 \%$ \\
\hline
\end{tabular}




\begin{tabular}{|c|l|l|c|}
\hline & & poison oak (warm) & $0.018 \%$ \\
\cline { 3 - 4 } & & nonforest (dry) & $<0.001 \%$ \\
\hline \multirow{2}{*}{ Pacific silver fir } & \multirow{2}{*}{$\mathbf{0 . 3 \%}$} & oxalis (high precipitation) & $0.287 \%$ \\
\cline { 3 - 4 } & & nonforest (wet) & $0.004 \%$ \\
\hline Grand fir & $<\mathbf{0 . 0 1 \%}$ & oceanspray, poison oak & $0.004 \%$ \\
\hline
\end{tabular}




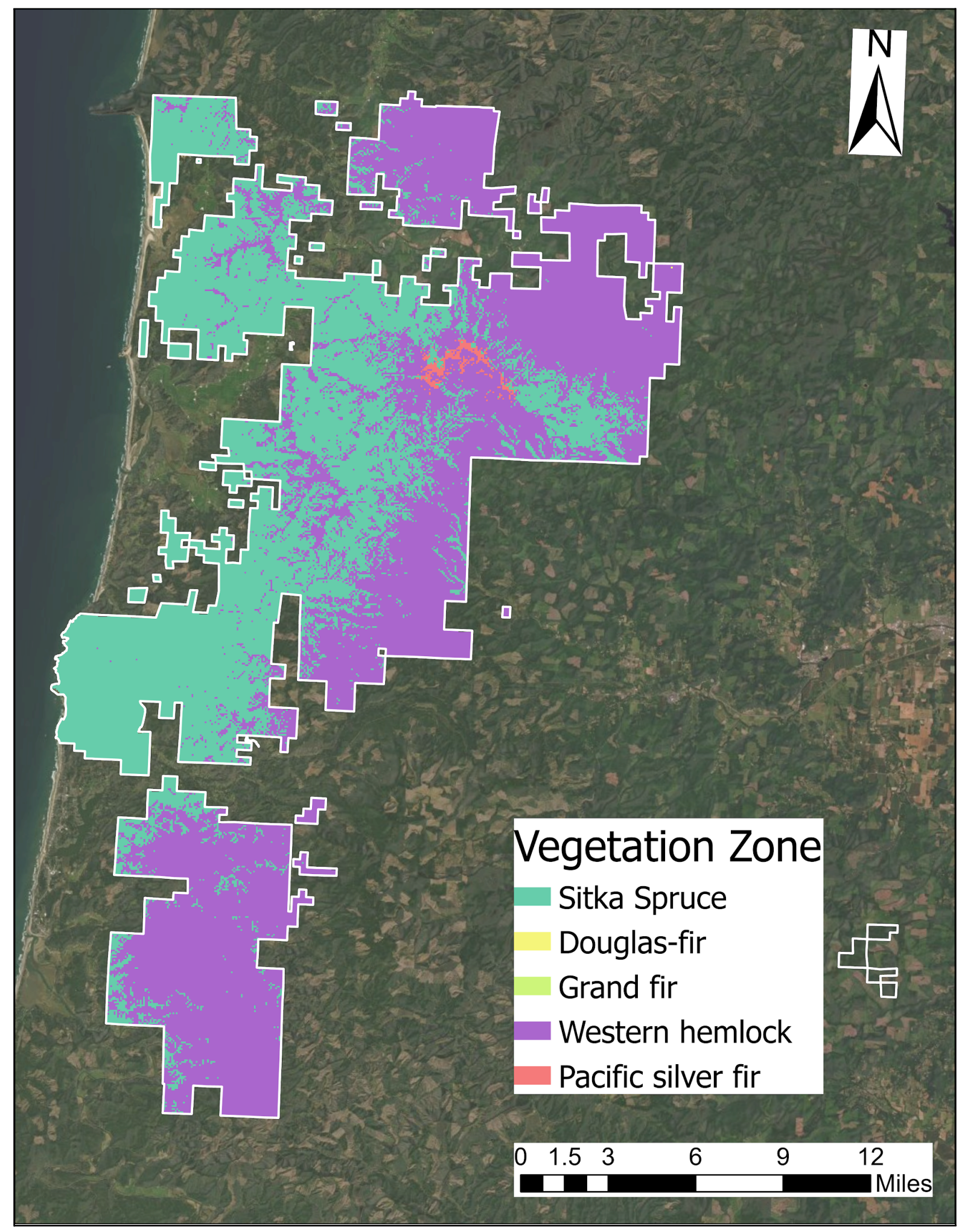

Figure 4: Major vegetation zones of the Hebo Ranger District within the Siuslaw National Forest based upon the Oregon Coast Modeled Plant Association Groups (Henderson \& McCain, 2011). 


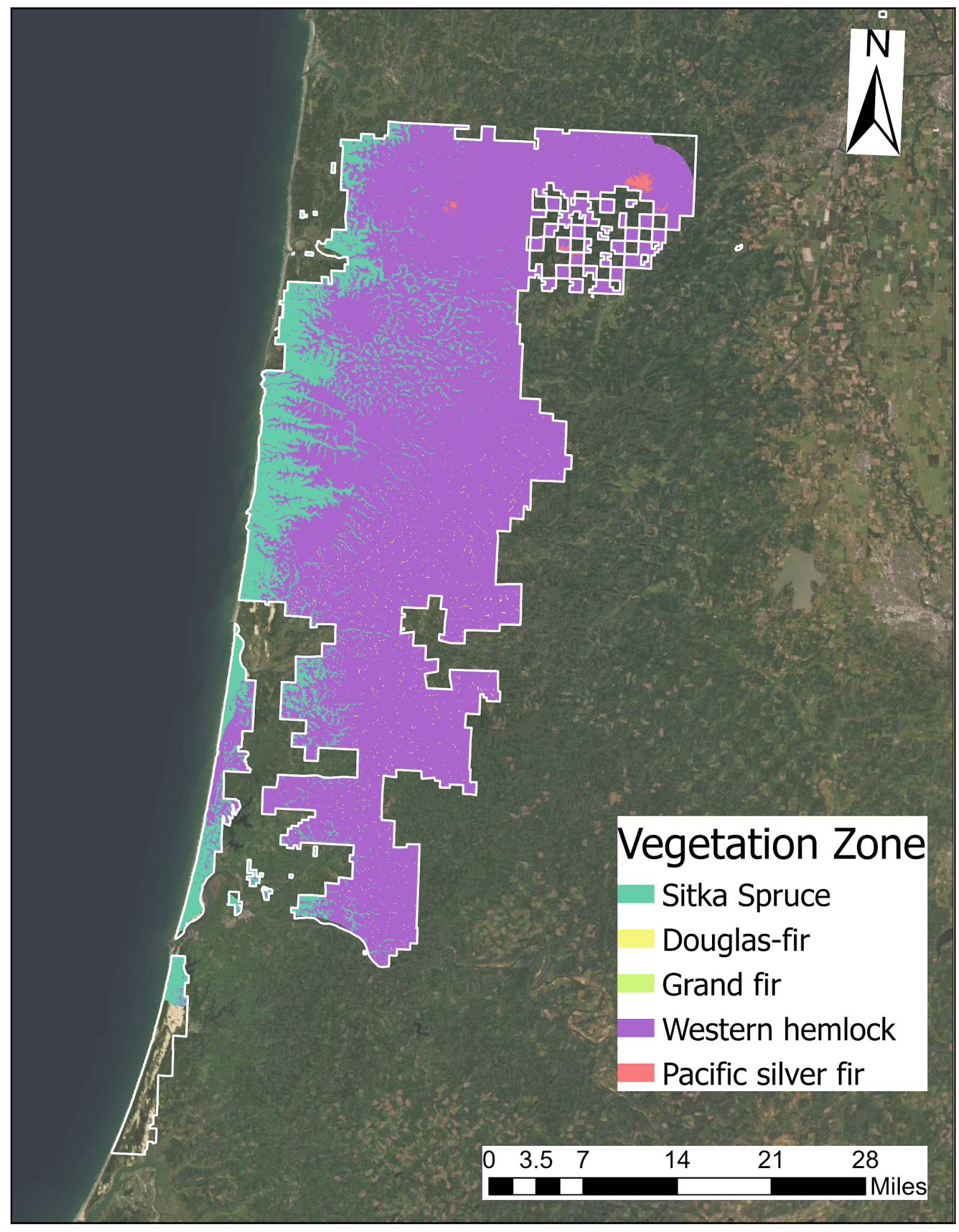

Figure 5: Major vegetation zones of the Central Coast Ranger District within the Siuslaw National Forest as characterized by the Oregon Coast Modeled Plant Association Groups (Henderson \& McCain, 2011). 
The western boundary of the forest, flanked by the Pacific Ocean, falls within the Sitka spruce zone and is characterized by relatively consistent temperatures throughout the year. These coastal areas are often covered in a blanket of fog preventing moisture stress that is experienced by plants further inland (USDA Forest Service, 1990). Unimpeded by thick fog, high salinity, and strong coastal winds, Sitka spruce thrive along and near the coast. Salal (Gaulthoria shallon), salmonberry (Rubus spectabilis) and swordfern (Polystichum munitum) are common understory counterparts of Sitka spruce and are tolerant to salt spray (USDA Forest Service, 1990). While Sitka spruce are the dominant tree species in these coastal areas, Douglas fir (Pseudotsuga menziesii) and red alder (Alnus rubra) are also common. Generally, Sitka spruce only superficially penetrate inland following rivers for a few short miles though can be found further inland within the Hebo District (Figure 4).

Moving to the east, conditions change rapidly beyond the first few high ridges. No longer in the fog belt and as highly influenced by the Pacific Ocean, summers are drier and temperatures more variable throughout the year at inland locations (USDA Forest Service, 1990). Slopes become steeper and soils generally drain quickly. As Sitka spruce fades out, western hemlock dominates inland landscapes though Douglas fir and red alder remain common. Salal, salmonberry, and swordfern persist in the understory and are joined by vine maple (Acer circinatum), rhododendron (Rhododendron spp.), and Oregon grape (Mahonia spp.) (USDA Forest Service, 1990; Hemstrom \& Logan, 1986). At very moist sites, understories may be dominated by skunk cabbage (Symplocarpus foetidus) or devil's club (Oplopanax horridus) (USDA Forest Service, 1990).

At the northern end of the forest where the climate is cooler and moister, slopes are less steep and soil conditions more fertile compared to the warmer and drier southern end of the forest where slopes are much steeper and soils are poor (USDA Forest Service, 1990). The variable combinations of these environmental factors including climate, soil type, salinity, elevation, aspect, and many other conditions as well as the influence disturbance regimes and successional processes determine the occurrence and composition of plant associations found throughout the region (Hemstrom \& Logan, 1986). All plant associations and their respective prevalence in the Siuslaw NF are listed in Table 1.

\section{Prominent Fauna}

The Siuslaw NF is home to a diverse suite of wildlife including 69 species of mammals, 26 species of amphibians and reptiles, 235 species of birds, and more than 200 species of fish (USDA Forest Service, n.d.a). As previously noted, the Siuslaw NF is a Late-Successional Reserve in which the remaining old-growth stands are preserved and provide refuge for old-growth obligates and associated species. Likely the most famous and controversial of this suite of species is the federally threatened Northern spotted owl (Strix occidentalis caurina) which still resides within old-growth stands of the Siuslaw NF though must compete with the nonnative barred owl (Strix varia). Other famous old-growth dependent species include the federally threatened marbled murrelet (Brachyramphus marmoratus) and a candidate species for threatened status, the red tree vole (Arborimus longicaudus). Another threatened bird species, the Western snowy plover (Charadrius alexandrinus nivosus) can be found on some 
southern portions of the Siuslaw NF's sandy beaches during most of the year but a subset of individuals breed slightly inland along cobble river reaches within the forest.

Along with serving the purposes of a Late-Successional Reserve, the Siuslaw NF offers many recreational opportunities to the public including hunting and fishing activity. Several big game species draw visitors to the forest including blacktail deer (Odocoileus hemionus columbianus), Roosevelt elk (Cervus canadensis roosevelti), cougar (Puma concolor), and American black bear (Ursus americanus). The forest also boasts some 1,200 miles of anadromous streams and 30 natural lakes, which support an extensive fish community (USDA Forest Service, n.d.a). Notably, many of the fish species that have made the region famous including the threatened Oregon coast coho salmon as well as steelhead and cutthroat trout have historically traveled through the Siuslaw NF, and several restoration projects have been conducted to ensure their successful passage for years to come (USDA Forest Service, n.d.f)

In addition to the previously mentioned carnivores, many mustelids inhabit the forest including the striped skunk (Mephitis mephitis), western spotted skunk (Spilogale gracilis), American marten (Martes americana), and coastal marten (Martes caurina) as well as other carnivores such as coyote (Canis latrans) and red fox (Vulpes vulpes). Oftentimes prey items for these carnivores, many species of rodents can be found in throughout the forest including representatives of the sciurid family such as Townsend's chipmunk (Neotamias townsendii), Douglas squirrel (Tamiasciurus douglasii), northern flying squirrel (Glaucomys sabrinus), and the recently described species Humboldt's flying squirrel (Glaucomys oregonensis). Larger rodents including mountain beaver (Aplodontia rufa) and American beaver (Castor canadensis) are also prevalent.

The moist coastal forest also hosts many amphibians including the coastal tailed frog (Ascaphus truei), Northern red-legged frog (Rana aurora), Northwestern salamander (Ambystoma gracile), long-toed salamander (Ambystoma macrodactylum), Cope's giant salamander (Dicamptodon copei), and rough skinned newt (Taricha granulosa). The coastal tailed frog and northern red-legged frog are federally listed as a species of concern and are listed at the state level as sensitive species. Cope's giant salamander also has a state listing as a sensitive species. The coastal fog belt and the high density of streams and other water bodies found in the Siuslaw NF provide the mesic conditions needed by these amphibians threatened by desiccation. Many invertebrates also are at home within the Siuslaw NF, notably the threatened Oregon silverspot butterfly (Speyeria zerene hippolyta).

Of course this short list of organisms barely scratches the surface of the biodiversity found within the boundaries of the Siuslaw NF. In addition to the above wildlife, there is a great diversity of marine organisms including crustaceans and marine mammals such as pinnipeds and whales, which can be seen off the coast of the forest. Fauna of the Siuslaw NF can be further characterized by using resources such as the US Geological Survey's Gap Analysis Project Species Viewer (USGS, 2018), the Oregon Department of Fish and Wildlife (ODFW) website, or Oregon field guides. 


\section{Bat Community}

Eleven of Oregon's fifteen bat species can be found within the Coast Range during warm spring and summer months (Perkins, Barss, \& Peterson, 1990; Maser \& Cross, 1981) (Table 2). All eleven of these species are known to reside within the Siuslaw NF, although some are restricted to only more southern portions of the forest (USGS, 2018). Unsurprisingly, all of these bat species are associated with forest habitat, although some species, like the little brown bat and big brown bat, are not exclusively forest-dwelling and will utilize variable habitat in other regions of the state (ODFW, n.d.). Some species, like the long-legged myotis (Myotis volans), live in Oregon's forests year-round (Miller, Arnett \& Lacki, 2003) while others make short-distance migrations $(10-500 \mathrm{~km})$ to suitable winter hibernacula such caves, mines, bridges, or buildings (Perkins, Barss, Peterson, 1990; Christy \& West, 1993). Due to their small size, cryptic nocturnal nature, and relatively low level of activity during cold months, the overwintering habits of these species are not well documented (Perkins, Barss \& Peterson, 1990). Two species, the hoary bat (Lasiurus cinereus) and silver-haired bat (Lasionycteris noctivagans), only reside in Oregon's coastal forests during part of their life cycle and make long-distance seasonal migrations (Perkins, Barss, \& Peterson, 1990; ODFW, n.d.). Some hoary bats travel distances greater than 1,000 km round-trip annually (Weller et al., 2016).

Table 2: Bat species of the Siuslaw NF: scientific and common names, species status, flight adaptations and feeding guild. Status includes least concern (LC), Oregon Conservation Strategy Species (OCSS), threatened, and under review. Generalized flight adaptations and feeding guilds were determined according to Norberg \& Rayner (1987) unless otherwise noted (*Kunz, 1982; **Holloway \& Barclay, 2001).

\begin{tabular}{|c|c|c|c|c|}
\hline Scientific Name & Common Name & $\begin{array}{c}\text { Species } \\
\text { Status }\end{array}$ & Flight Adaptation & Feeding Guild \\
\hline Corynorhinus townsendii & $\begin{array}{c}\text { Townsend's } \\
\text { big-eared bat }\end{array}$ & OCSS & Clutter-adapted & Hover gleaning \\
\hline Eptesicus fuscus & Big brown bat & LC & Open-adapted & Slow hawking \\
\hline Lasionycteris noctivagans & Silver-haired bat & OCSS & Edge-adapted* & Slow hawking* \\
\hline Lasiurus cinereus & Hoary bat & OCSS & Open-adapted & Fast hawking \\
\hline Myotis californicus & California myotis & OCSS & Clutter-adapted & $\begin{array}{c}\text { Slow hawking, } \\
\text { Gleaning }\end{array}$ \\
\hline Myotis evotis & Western long-eared & Threatened & Clutter-adapted & $\begin{array}{c}\text { Gleaning, Slow } \\
\text { hawking }\end{array}$ \\
\hline Myotis lucifugus & Little brown myotis & Under Review & Edge-adapted & Slow hawking \\
\hline Myotis thysanodes & Fringed myotis & OCSS & Clutter-adapted & $\begin{array}{c}\text { Gleaning, } \\
\text { Hovering }\end{array}$ \\
\hline
\end{tabular}




\begin{tabular}{|c|c|c|c|c|}
\hline Myotis volans & Long-legged myotis & OCSS & Edge-adapted & $\begin{array}{c}\text { Slow hawking, } \\
\text { Gleaning }\end{array}$ \\
\hline Myotis yumanensis & Yuma myotis & LC & Open-adapted & Slow hawking \\
\hline Tadarida brasiliensis & Brazilian free-tailed bat & LC & Open-adapted & Fast hawking \\
\hline
\end{tabular}

Whether a year-round resident, short-distance migrant, or long-distance migrant, all 13 of these species reside in the Siuslaw NF during warm spring and summer months when reproductive females give birth. Although there are many differences in the life histories of Pacific Northwest bats, their reproductive strategies and timing are relatively similar (Christy \& West, 1993). Bats are gregarious in fall and winter months when breeding occurs but fertilization is delayed until the spring and parturition generally occurs in late May to mid-July (Christy \& West, 1993; Barbour \& Davis, 1969; Maser et al., 1981; Racey, 1982). The number of offspring per female varies among species, with small-bodied bats like Myotis spp. having only one offspring while larger-bodied bats like the big brown bat, hoary bat, and silver-haired bat have an average of two offspring (Barbour \& Davis, 1969). Bats nurse their young until juveniles are weaned in late summer (van Zyll de Jong, 1985; Anthony, Stack \& Kunz, 1981).

During the day, bats of the Siuslaw NF are relatively inactive and remain within day roosts. Different bat species are known to roost in several different natural and man-made structures including snags, tree foliage, tree stumps, rock crevices, caves, mines, bridges, and buildings (Christy \& West, 1993; Zabel \& Anthony, 2003). However, considering the lack of caves along the Oregon coast (Zabel \& Anthony, 2003) and low densities of buildings and bridges in the Siuslaw NF, it is likely that bats primarily use snags with suitable crevices and cavities as roosting habitat. Several bat species will use alternative roosts if faced with an absence of snags on the landscape. For example, the long-eared myotis is known to use logs, rocks, and stumps as roosts in addition to snags (Arnett \& Hayes, 2009) and the hoary bat is known to roost within foliage of conifers (Kunz, 1982).

Preferred snag characteristics are thought to be generally ubiquitous among temperate bat species (Vonhof \& Barclay, 1996; Arnett \& Hayes, 2009; Hayes, 2003). Snags utilized by bats are generally greater than $60 \mathrm{~cm}$ in diameter and $18 \mathrm{~m}$ in height (Zabel \& Anthony, 2003), although not all usable snags conform to these parameters (Arnett $\&$ Hayes, 2009). High quality roosts such as large diameter snags with crevices and cavities are integral to the success of highly sensitive life stages including pregnancy and pup-rearing and availability of suitable roosts is often cited as a limiting factor of bat populations (Arnett \& Hayes, 2009; Hayes \& Loeb, 2007; Hayes, 2003, Kunz, 1982; Lewis, 1995). Females of some species form communal maternity roosts and others roost solitarily (Christy \& West, 1993).

At night bats become active and commute from their day roosts to foraging grounds where they seek their prey. While bats around the world have evolved to exploit many different food resources, bats in the temperate regions of North America are all primarily insectivorous. Although they may occasionally take other invertebrates. Different bat species prefer different foraging habitats and display different modes of foraging; these topics are discussed in detail in Chapter 2. Insectivorous bats navigate using echolocation and use this ability to locate and secure their insect prey. Bats often use night roosts to rest and digest food in between bouts of foraging then either return to a previously used day roost or locate a new day roost before the morning light (van Zyll de Jong, 1985; Anthony, Stack, \& Kunz, 1981, 
1981; Adams \& Hayes, 2000). While bats hunt throughout the night, activity first peaks in the hours after sunset and again in the hours before sunrise (van Zyll de Jong, 1985).

All temperate bat species are relatively small with Myotis spp. weighing only 3-9.5 g and larger bodied non-Myotis spp. weighing 9-30 g (Christy \& West 1993). Due to their small body size, bats are without substantial fat reserves and must feed daily to meet energy demands (Strobel et al., 2013). As such, the inactivity of insects in winter months and their lack of energy reserves necessitates that bats either migrate to regions where food sources are available or remain inactive for the winter. After juveniles have been weaned and temperatures begin to drop, bats will begin their reproductive cycle again. Species that stay in Oregon become relatively dormant in hibernacula while migrating bats fly where food resources are available. Common among all of these bat species is their dependence upon forests like the Siuslaw NF for roosting and foraging habitat necessary for reproduction and survival. However, bats do not have a one-sided relationship with forests and provide natural pest control services by consuming insects and redistributing nutrients (Duchamp et al., 2010). Bats are known to feed on a wide range of insect families including moths and beetles and reduce the abundance of many forest pests helping to prevent devastating insect outbreaks (Ghanem \& Voigt, 2012; Jones et al., 2009).

\section{Forest Succession}

As with any forest, the structure and composition of the plant community of the Siuslaw NF is dynamic. The following description of the typical stages of forest succession within the Siuslaw NF is adapted from descriptions by Hemstrom and Logan (1986) (Figure 6). After a stand-leveling disturbance such as a high intensity fire, succession begins with the herbaceous phase lasting from 0-5 years post-disturbance. The herbaceous phase progresses to the shrub phase, typically lasting 5-15 years post-disturbance. Dense shrub species, most notably salmonberry, suppress the growth of tree saplings and can cause seed mortality especially within the first three years of competition. Under certain conditions, the shrub stage may last for more than 20 years (USDA Forest Service, 1990). However, red alder is a fierce, fast-growing competitor in open canopy conditions and in recently distrubed areas sometimes go through a red alder-dominated stage. Only after 100-150 years do shade tolerant conifers begin to break through the deciduous canopy. 


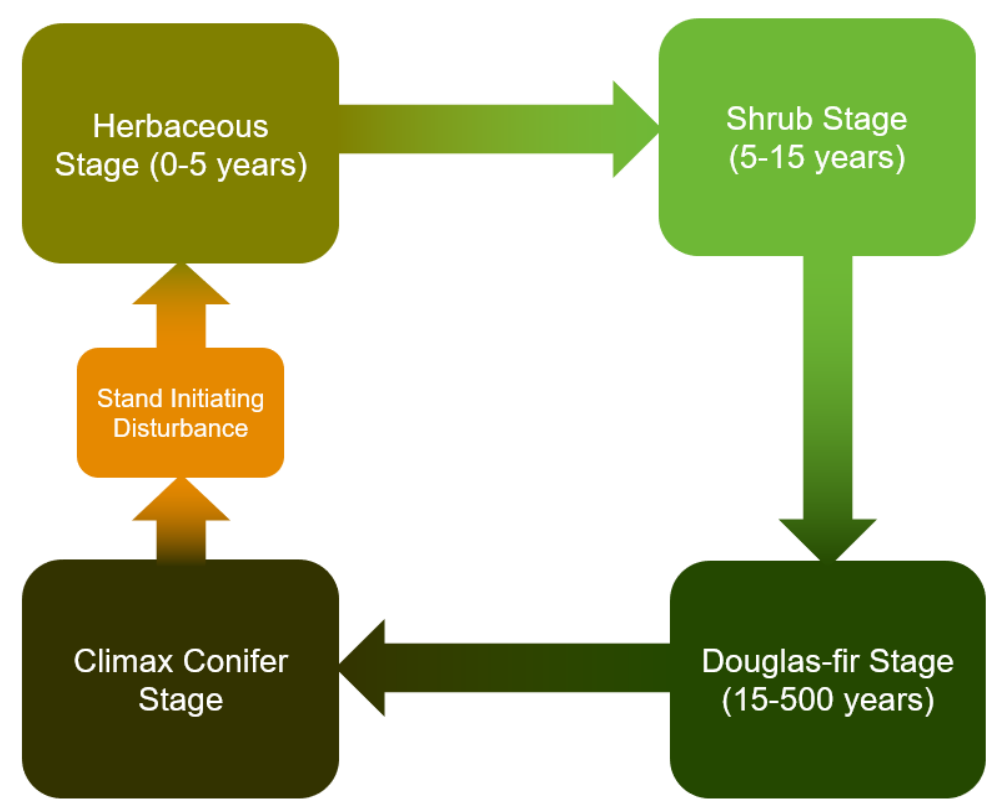

Figure 6: Common successional trajectory found within the Siuslaw NF as defined by Hemstrom and Logan (1986).

A more likely successional pathway after the shrub stage is the Douglas fir stage lasting 15-500 years which progresses to the climax conifer stage. At 10-15 years post-disturbance, Douglas fir canopies become closed effectively shading out many understory species until around the 50 year mark when canopies open to an extent allowing for regrowth of the understory. Historically, fire has been a major disturbance in the area (see further discussion below). Due to these major disturbances, stands over 500 years old in the climax conifer stage are relatively uncommon within the Siuslaw NF.

However, it is important to note that there are different definitions of late-successional and old-growth stands and that these conditions are reliant upon certain characteristics, not just stand age. For example, several Forest Ecosystem Management Assessment Team reports from the 1990s define late-successional stands as being principally composed of trees $>53 \mathrm{~cm}$ in diameter breast height (DBH) and that stands generally reach these conditions between 80-140 years (Moeur et al., 2005). Old-growth stands may be defined by additional characteristics including number of canopy layers and accumulation of woody debris with these conditions occurring in stands older than 150 years (Moeur et al., 2005). For the purposes of this bat-centric report, the terms mature and old-growth are used to describe stands greater than 120 years old that are often documented as having optimal roosting characteristics as described in Chapter 2. 


\section{Disturbance Regime}

While the coastal forests of Oregon do not have an especially dynamic disturbance regime, fire, windstorms, fungal disease, and insect pests all play a role. The two main drivers of disturbance in the forest, fire and windstorms, have varied temporal and spatial effects and leave different biological legacies (Harmon \& Pabst, 2019). Fungal disease and insect pests generally operate on a smaller scale but can still play an important role in tree mortality across the landscape. As logging activity is no longer prevalent in the Siuslaw NF, these disturbances are the main processes by which forest gaps are created in the dominantly closed-canopy forest. While each of these disturbance types are capable of creating canopy gaps, there is interplay among all four affecting the susceptibility of trees to mortality as well as impacting forest productivity.

\section{Fire}

The fire regime of forests within the Oregon Coast Range has been described as "...consisting of widespread, infrequent, stand-replacing fires" (Long, Whitlock \& Barlien, 2007). Fires generally occur in the summer when temperatures and fuel loads are high, moisture is low, and winds are strong. Like many regions, the most common natural source of ignition in the Coast Range is lightning (Long, Whitlock \& Barlien, 2007). Western hemlock forests of the Coast Range have had an estimated fire interval between 150-300 years (Agee, 1991; Impara, 1997). According to charcoal records from the Coast Range, the mean fire interval for the past 2,700 years to the present has been estimated at 210 $(+/-30)$ years (Long, Whitlock \& Barlien, 2007). However, human activity in the region for the past century has proven to have severe consequences on the natural fire regime.

In 1933, disaster struck on a hot and dry August day when a logging operation started what is now called the Tillamook Burn. Loggers, CCC members, farmers, and volunteers worked together to control the fire but with little success. In total, the Tillamook Burn scorched a total of 355,000 acres of coastal Oregon forests (Decker, 2018). This initial fire of 1933 set the stage for future fires that occurred at 6-year intervals as dead trees and other tinder left from logging activities built up in the forest. This accelerated cycle didn't end till 1951 after three more human-caused fires had devastated the landscape (Decker, 2018). This was the last major fire that has caused significant damage in the region to date. Little of the Siuslaw NF has been left untouched by high intensity fires within the last 200 years leaving few old-growth stands (Hemstrom \& Logan, 1986). Today the US Forest Service participates in fire suppression activity in an effort to allow existing stands to mature to desired late-successional and old-growth stages. Though infrequent, fire remains a force of change and can create forest gaps across the landscape of the Siuslaw NF.

\section{Windstorms}

While fire is relatively uncommon in the Siuslaw NF today, windstorm events strong enough to cause timber mortality generally occur yearly and events with hurricane force winds ( $>74$ miles per hour) have occurred every 25 years (Harmon \& Pabst, 2019). Windthrow is likely the most dynamic process by which canopy gaps are created in the mesic coastal forests of Oregon. Storms with hurricane force winds 
can impact large areas extending even beyond the Oregon Coast Range though timber mortality associated with windstorms is usually concentrated in small patches on the landscape (Harmon \& Pabst, 2019). Harmon and Pabst (2019) explored the long-term impacts of windstorms on plots of timberland in the Cascade Head Experimental Forest, located within the Siuslaw NF. Data showed that windstorm events typically only have a localized impact affecting less than 2 ha of land though the impact of multiple events are cumulative and can cause long-term changes to forest structure (Harmon \& Pabst, 2019). Over 83 years, stands 0.4 ha in size experienced $16-59 \%$ tree mortality due to windstorms; $80 \%$ of tree mortalities were immediate, although some wind damaged trees persisted for up to 35 years postdisturbance (Harmon \& Pabst, 2019).

Both Douglas fir and Stika spruce are more windfirm than the dominant western hemlock, but mortality rates of all species depend upon age and diameter at breast height (DBH) (Harmon \& Pabst, 2019; Ruth \& Yoder, 1953). In Harmon and Pabst's study (2019), Sitka spruce with large DBH were more windfirm than those with intermediate $\mathrm{DBH}$, whereas windthrow mortality of western hemlock increased with increasing $\mathrm{DBH}$. However, regardless of species, small diameter trees were often not affected by wind events due to protection by surrounding larger trees and boundary layer effects. The openness of an area can also affect mortality rates; forest stands with high tree density may be less susceptible to wind disturbance than stands with canopy gaps (Harmon \& Pabst, 2019).

\section{Fungal Disease}

Though less influential than fire and windstorms, fungal diseases also play a role in succession within the Siuslaw NF. The particularly moist conditions along the Pacific Coast are ideal for the germination of fungi and thus mesic forests are more susceptible to fungal infection than dry forests (Hagle, 2009). Fungal disease generally does not immediately cause tree mortality and the process may take more than 30 years (Hagle, 2009). Two common fungal diseases in the coastal forests of Oregon include laminated root rot caused by Phellinus weirii and Swiss needle cast caused by Nothopaecryptopus gaeumannii.

Laminated root rot, most prevalent on the western side of the Cascade Range, causes necrosis of roots leading to either direct tree mortality or weakening of roots, making trees susceptible to mortality by windthrow (Hagle, 2009; Goheen \& Willhite, 2006). It is estimated that between $5-11 \%$ of Douglas fir trees in western Oregon and Washington forests are infected yearly and that 32 million $\mathrm{ft}^{3}$ of Douglas fir forest are lost annually to the disease (Kastner, Goheen, \& Edmonds, 1994; Lawson, Berg \& Hansen, 1983; Hadfield, 1985; Childes \& Shea, 1967). Mortality rates of infected Douglas fir, grand fir, and western hemlock are $26 \%, 31 \%$, and $12 \%$ respectively while all other conifers, including western redcedar, generally have mortality rates around 5\% (Hagle, 2009). Patterns of infection are not obvious as some trees do not outwardly show symptoms; expansive stands of trees can be infected and host inoculum sources or infection can be dispersed throughout the forest (Hansen, 1976; Hagle, 2009). The fungus can live saprophytically in remains of dead trees for as long as 50 years and can infect surrounding trees through the spread of mycelium (Hagle, 2009). 
Swiss needle cast, a foliage disease, usually does not directly cause tree mortality but does affect succession and productivity in Douglas fir forests (Black, Shaw, \& Stone, 2010). Specific to Douglas fir, the disease causes a $23-50 \%$ decrease of growth in infected stands (Maguire et al., 2002) and affected an estimated 433,992 acres of Oregon forests in 2018 (Navarro \& Norlander, 2018). The fungus blocks foliar gas exchange causing a halt or reduction in photosynthesis activity and, in turn, the tree drops its needles (Black, Shaw, \& Stone, 2010; Oregon State University College of Forestry, n.d.). The fungus releases ascospores in late spring and early summer infecting only newly formed foliage by wind and water dispersion (Mulvey et al., 2013). Disease intensity is increased by warm spring and summer temperatures (Black, Shaw, \& Stone, 2010). Douglas fir within 18 miles of the coast are especially susceptible to infection due to high levels of moisture but infection rarely occurs more than 30 miles inland (Mulvey et al., 2013).

\section{Insect Pests}

Several insect pest species impact forest succession by causing tree mortality or reducing tree productivity in the coastal forests of Oregon. While some pest species only infest recently dead or nearly dead trees, primary pests can cause mortality of healthy trees. Depending upon the species, pest outbreaks can be facilitated by conditions such as overcrowding of trees and drought (Goheen \& Wilhite, 2006). Some primary bark beetle species prevalent in Oregon include the following: mountain pine beetle (Dendroctonus ponderosae), spruce beetle (Dendroctonus rufipennis), and western pine beetle (Dendroctonus brevicomis) among others (Goheen \& Willhite, 2006).

\section{CHAPTER 2: Bats of the Siuslaw NF and the Importance of Forest Gaps}

\section{Insectivorous Bats and Energy Conservation}

Prior to diving into the importance of forest gaps to bats, some knowledge of bat biology is required. As previously mentioned Pacific Northwest bat species are relatively miniscule with the smallest species west of the Cascades Range, the western small-footed myotis, weighing only 3-6 g and by far the largest species, the hoary bat, weighing 25-30 g (Christy \& West, 1993). Being a small-bodied flying mammal presents several energy conservation challenges, particularly in temperate regions. Mass-specific energy requirements are highest for small mammals and their capacity to store fat is directly proportional to body mass (Jonasson \& Willis, 2012; Capellini, Venditti \& Barton, 2010). Flight is an incredibly energy intensive activity and is the main method of locomotion for bats (Strobel et al., 2013). Thus, bats have highly limited fat reserves but also have high energy demands. Bats have evolved specialized physiological systems to cope with steep energetic demands including efficient circulatory systems and gas exchange mechanisms (Jürgens et al., 1981; Makanya \& Mortola, 2017). Bats have extremely efficient digestive systems to meet energetic needs (Strobel et al., 2013) and must consume about two-thirds of their body weight in insects daily (Ghanem \& Voigt, 2012). The act of foraging itself is 
energy intensive as it requires acrobatic flight to catch prey and flight on a full stomach after successful foraging requires elevated energetic output (Boyles et al., 2016).

In winter months when temperatures are low and insect prey is unavailable, bats in temperate regions must either migrate to warmer locations or remain inactive in hibernacula; both methods require carefully budgeted energy expenditure. Two bat species in Oregon, the hoary bat and the silver-haired bat, are long-distance migrants and evade the challenges of winter by migrating south (Zabel \& Anthony, 2003). Long-distance migrant species must frequently refuel at stop-over sites before continuing on their route (McGuire, Jonasson, \& Guglielmo, 2014). All other species of bats in Oregon are thought to be year-round residents or short-distance migrants, although little is known about the overwintering habits of these species (Perkins, Barss, Peterson, 1990; Christy \& West, 1993). Some species stay in forests year-round, using tree cavities or space under tree bark as hibernacula (Zabel \& Anthony, 2003). Within the Coast Range, where winter conditions are relatively forgiving, there has been evidence of some minimal winter activity among forest-dwelling bats (Pearson et al., 1952; Gellman \& Zielinski, 1996; Hayes, 1997; Zabel \& Anthony, 2003). Some species may migrate relatively short distances (10-500 km) to caves with low enough temperatures to promote hibernation (Christy \& West, 1993), although caves with these characteristics are rare in the region (Zabel \& Anthony, 2003). Hibernation can decrease daily energy requirements by up to two orders of magnitude (Speakman \& Rowland, 1999).

Another strategy used by many bat species to survive harsh environmental conditions is facultative heterothermy, otherwise known as torpor, in which bats experience reduced metabolic rates, heart rates, and body temperatures (Otto, Becker \& Encarnação, 2016, Geiser, 2004). Both migrating and non-migrating species are known to go into torpor and some may do so on a nightly basis (Geiser, 2004). This thermoregulatory process enables bats to balance tight energy budgets by maintaining heterothermy at low body temperatures (Boyles et al., 2016) and is one of the most energy-efficient temperature coping mechanisms in bats (Geiser, 2004). Daily energy expenditure is reduced by $50-90 \%$ when torpor is utilized daily (Geiser, 2004). Non-migrating bats may also go into full hibernation during winter months and use torpor during active months. While males and nonreproductive females may readily go into torpor when warranted by cold conditions, torpor is avoided by pregnant females as the process can slow fetal development rates and delay parturition dates (Hoying \& Kunz, 1998; Racey, 1973; Racey \& Swift, 1981; Racey, 1982). These females must rely on more energetically costly methods to maintain adequate body temperatures in order to increase the chances of survival of their young and thus are more reliant upon roosts with specific thermal properties (Barclay, 1991; Boyles et al., 2016).

Reproductive females face even more constrained energy budgets than males and nonreproductive females. Lactating female brown long-eared bats (Plecotus auritus) have half the available energy for respiration and fat storage as non-reproductive females (McLean \& Speakman, 1999). Prior to giving birth, pregnant females have the added weight of their young, which increases the strenuousity of flight. Postpartum little brown bats (Myotis lucifugus) in peak lactation expend double the amount of energy as nonreproductive females and males (Kurta et al., 1989 Barclay, 1991). Depending upon the species, pups can weigh $40 \%$ of their mother's body weight at birth and are solely reliant upon their mothers to provide nourishment until they are capable of flight (Jones, 2001). Bats are income breeders; in order for a mother to meet the energetic demands of milk production and her own metabolic costs, she must forage daily (Kurta et al., 1989; McLean \& Speakman, 1999; Racey \& Speakman, 1987) as her small fat reserves would not even cover the combined food and water demands of a single day (Jönsson, 1997; Henry et al., 2002). 
It is likely that reproductive females require greater amounts of food than males and nonreproductive females to satisfy their elevated energetic demands during motherhood (Kunz, 1974; Anthony \& Kunz, 1977). A study of little brown bats found that females increased their food consumption by $45 \%$ between pregnancy to lactation (Anthony \& Kunz, 1977) and a separate study found that Brazilian free-tailed bats increase their food consumption by $82 \%$ between the early and late stages of lactation (Kunz, Whitaker, \& Wadanoli, 1995). Water requirements of lactating females are also greater than that of pregnant and non-reproductive females (Kurta, Kunz, \& Nagt, 1990; McLean \& Speakman, 1999; Adams \& Hayes, 2008) and the loss of water increases throughout the period of lactation (Adams \& Hayes, 2008). A study in an arid zone of Colorado found that lactating fringed myotis females traveled to a water source 13 times more than non-reproductive females and exhibited significantly more drinking passes when at the water source (Adams \& Hayes, 2008).

The above paragraphs barely brush the surface of the interesting biology of insectivorous bats. For the purposes of this document, the key takeaway is that, due to their unique biology, insectivorous bats are in a constant battle to meet energy demands for flight, for reproduction, and to withstand seasonal changes. To survive and successfully reproduce, bats must take advantage of any opportunity to reduce energy expenditure and to conserve their limited fat reserves. As foraging activities often account for the greatest amount of daily expended energy (Kurta et al., 1989), special attention should be paid to the specific habitat needs of bats for foraging. Discussed below is one particularly important method of energy conservation for bats; the utilization of habitats suited to species-specific wing morphology and echolocation call structure.

\section{Bat Morphogroups and the Roles of Forest Gaps}

Clutter such as dense vegetation can present several issues for insectivorous bats when foraging. First, as nocturnal animals, bats rely primarily on echolocation to identify and avoid obstacles as well as to locate their insect prey. Bats must be able to distinguish between echos returning from clutter in the environment and echoes returning from their prey (Brigham et al., 1997; Fenton, 1990). A high volume of interfering clutter can decrease a bat's ability to locate small insects. Second, bats must maneuver around clutter which can reduce flight speed required to secure their elusive prey (Fenton, 1990). Third, having to avoid clutter when foraging causes bats to expend additional energy (Aldridge \& Rautenbach, 1987; Fenton, 1990; Sleep \& Brigham, 2003; Voigt et al., 2017).

Bats have evolved a variety of wing morphologies and echolocation call structures, each best suited to a different foraging habitat type (Loeb \& O'Keefe, 2011; Norberg \& Rayner, 1987; Aldridge \& Rautenbach, 1987; Fenton, 1990; Denzinger \& Schnitzler, 2013). While wing morphology certainly impacts foraging, it also impacts commuting behavior between resources which is another energy intensive activity undertaken by all bats (Wunder \& Carey, 1996). Insectivorous bat species can be placed into one of three generalized morphogroups associated with the habitats to which they are best adapted: open-adapted, clutter-adapted, or edge-adapted.

Bat species in the open-adapted morphogroup have long wings with pointed tips that create high wing aspect ratios and high wing loading (Norberg \& Rayner, 1987; Fenton, 1990). Bats belonging to this morphogroup are often heavier and larger bodied compared to the other morphogroups (Norberg \& Rayner, 1987). Open-adapted species are generally fast aerial hawkers, catching their prey mid-air and relying upon flight speed rather than agility for a successful capture. Echolocation calls of open-adapted 
bats tend to be long and narrowband with low frequency but high intensity (Fenton, 1990). Species belonging to this morphogroup are often referred to as constant frequency or CF bats (Fenton, 1990).

Both the wing morphology and echolocation call structure of open-adapted bats make foraging in cluttered environments challenging. While fast aerial hawking is energetically inexpensive in open environments, this method of foraging is inefficient in cluttered environments as bats must expend unnecessary energy avoiding clutter while pursuing prey (Fenton, 1990; Norberg \& Rayner, 1987). Additionally, as open-adapted wings are built for speed, not maneuverability, species belonging to this morphogroup are likely more effective hunters in open environments. In a cluttered space the high intensity calls of open-adapted bats bounce off of vegetation making it difficult to distinguish prey from objects to be avoided (Fenton, 1990). Thus, as their name implies, open-adapted bats are best suited to open foraging grounds, such as gaps in forests. However, some open-adapted species including the hoary bat, big brown bat, and silver-haired bat are also known to feed in open areas above forest canopy, not only in forest clearings (Kalcounis et al., 1999; Menzel et al., 2005).

At the opposite end of the morphogroup spectrum are the clutter-adapted species. Clutter-adapted bats have wings that are short to intermediate in length with rounded wingtips that create low wing aspect ratios and low wing loading (Norberg \& Rayner, 1987; Fenton, 1990). Clutter-adapted species generally have low body mass and are slow fliers compared to open-adapted species (Norberg \& Rayner, 1987). This morphogroup relies on agility to capture prey rather than speed and tend to use gleaning and hovering as modes of foraging. These bats will often slowly pick through vegetation and pluck insects from the surfaces of plants but do display more generalized flight behavior at times (Fenton, 1990; Norberg \& Rayner, 1987; Loeb \& O'Keefe, 2011; Sparks et al., 2005; Faure \& Barclay, 1994; Ratcliffe \& Dawson, 2003). Echolocation calls of clutter-adapted bats are generally short and broadband with high frequency but at low intensities (Fenton, 1990). Species belonging to this group are often referred to as frequency modulated or FM bats (Fenton, 1990).

In contrast to open-adapted bats, clutter-adapted species prefer to forage in densely vegetated habitats. Despite their specialized wing morphology, foraging in cluttered environments is still relatively energy intensive for clutter-adapted bats (Fenton, 1990). However, species belonging to this morphogroup are relatively small in size, making flight in both cluttered and open environments less energy intensive in comparison to larger-bodied open-adapted species (Norberg \& Rayner, 1987). The short, low intensity calls of clutter-adapted bats have given them the nickname of "whisperers" (Hackett, Korine, \& Holderied, 2014). Their quiet calls minimize the amount of interfering echos returning from clutter making them adept at differentiating prey from vegetation (Fenton, 1990; Fullard, 1987). However, clutter-adapted species may also be somewhat reliant upon audible and visual cues from their prey (Fenton, 1990; Tuttle \& Ryan, 1981; Bell et al., 1984).

Some species are intermediate in their wing morphology and call structure between the clutterand open-adapted morphogroups and belong to the edge-adapted morphogroup. Edge-adapted species have relatively long wings with short, rounded wingtips that create high wing aspect ratios but low wing loading (Fenton, 1990). Edge-adapted bats are often slow aerial hawkers, taking insects mid-air but at slower speeds than open-adapted species. Their echolocation calls are generally short and high intensity but can range from broadband to narrowband and some have components of both frequencies (Fenton, 1990) As their name suggests, edge-adapted species are commonly found foraging around the edges of forests (Blakey et al., 2019; Loeb \& O'Keefe, 2011). Their flight in relatively uncluttered environments at forest edges is inexpensive in terms of energetic output like that of open-adapted bats but their slow speed makes them more maneuverable like the clutter-adapted bats (Fenton, 1990). Their varied echolocation call structure allows edge-adapted bats to identify the linear forest edge next to which they 
are foraging enabling them to avoid obstacles but their high intensity calls are also effective in locating prey (Fenton, 1990).

These three morphogroups are generalized and each one displays a certain amount of plasticity in the environments they use for foraging. Clutter-adapted bats are the most versatile and are known to utilize open and edge habitat in addition to cluttered habitat (Fenton, 1990). For example, northern long-eared bats (Myotis septentrionalis), tricolored bats (Perimyotis subflavus), and Indiana bats (Myotis sodalis), all small-bodied clutter-adapted species, utilize both open forest gaps and densely forested areas (Ellis et al., 2002; Loeb \& O'Keefe, 2011; Sparks et al., 2005). Although these three specific species do not occur in the Pacific Northwest region, these findings are suggestive of the flight capabilities of bats within the clutter-adapted morphogroup. Long-eared bats, little brown bats, and northern long-eared bats are capable of gleaning insects from vegetation as well as aerial hawking (Faure \& Barclay, 1994; Ratcliffe \& Dawson, 2003). Edge-adapted bats readily use both forest edges and open areas as foraging grounds but tend to avoid cluttered habitats (Fenton, 1990; Crome \& Richards. 1988). Open-adapted bats are arguably the most specialized morphogroup and exhibit limited plasticity in utilizing anything other than open habitat for foraging (Fenton, 1990; Crome \& Richards, 1988).

Despite the plasticity of the species belonging to these morphogroups, results of many studies support these proposed morphological groupings of insectivorous bats across a wide range of settings from temperate areas to the tropics (Brooks et al, 2017; Morris, Miller, \& Klcounis-Ruppell, 2010; Humes, 1996; LaVal et al., 1977; Aldrige \& Rautenbach, 1987; Bender et al., 2015; Brooks, 2009; Erickson \& West, 2003; Ford et al., 2005; Loeb \& O'Keefe, 2006; Norberg \& Rayner, 1987; Blakey et al., 2019; Owen et al., 2004; Patriquin \& Barclay, 2003; Sleep \& Brigham, 2003; Fenton, 1990; Fenton \& Rautenbach, 1986; Crome \& Richards, 1988; Brooks, Loeb \& Gerard, 2017; Fukui et al., 2011). Open-, edge-, and clutter-adapted bats are sometimes referred to as gap specialists, gap incorporators, and closed-canopy specialists (Crome \& Richards, 1988) or open, edge, and narrow space bats (Denzinger \& Schnitzler, 2013).

\section{Importance of Forest Gaps}

As seen in Table 2, there are representatives of all three morphogroups present in the Siuslaw NF and these species display a wide range of foraging methods. While the interiors of forest stands certainly constitute important roosting habitat for all morphogroups and other activities of clutter-adapted bats (see Importance for Forest Interiors section below), forest gaps and the edge habitat that gaps create are highly important to edge- and open-adapted bats for foraging and commuting (Grindal \& Brigham, 1998; Patriquin \& Barclay, 2003; Owen et al., 2004; Krusic et al., 1996; Ellis et al., 2002; Erickson, 1993; Erickson \& West, 1995; Menzel et al., 2002; Froidevaux et al., 2016; Brooks et al., 2017). Despite clutter-adapted species being less dependent upon forest gaps than the other two morphogroups, studies have shown that clutter-adapted bats can also benefit from forest openings (Clark et al., 1993; Lauzon, 2019; Walsh \& Harris, 1996; Grindal \& Brigham, 1999; Hogberg, Patriquin \& Barclay, 2002; Law \& Chidel, 2002; Fukui et al., 2011; Jung, Thompson \& Titman., 1999; Menzel et al., 2005; Brooks et al., 2017; Brooks, 2009; Wunder \& Carey, 1996; Ellis et al., 2002; Sparks et al., 2005; O’Keefe, 2009).

A particularly good demonstration of the value of forest gaps for bats are a series of studies conducted in southeastern British Columbia (Grindal \& Brigham, 1998). Grindal and Brigham's research in 1998 revealed that overall bat activity in a forested region increased after the creation of small clear-cut patches. Two consecutive studies in the same region found that there was significantly greater overall foraging and commuting activity within relatively recent clear-cut patches and along their edges 
as compared to intact forest, although low levels of activity were recorded in forest interiors (Grindal \& Brigham, 1999; Lauzon, 2019). Lauzon (2019) specifically discovered that among open-adapted species, foraging and commuting activity was significantly greater within gaps and along edges. Among clutter-adapted species, foraging activity was greatest among edges but there was not a significant difference in commuting activity among the three habitats (Lauzon, 2019).

A valuable study in the western hemlock-Douglas fir stands of Washington, closer to the coastal forests of Oregon, found that overall bat activity was higher in recent clear-cuts than in young thinned, young unthinned, and mature forest stands (Erickson \& West, 1995). Open-adapted bats were recorded most often in clear-cuts and clutter-adapted bats were also recorded more often in clear-cuts but it was not uncommon for them to use mature stands as well (Erickson \& West, 1995). Many additional studies have been conducted throughout the Pacific Northwest region and across the United States which corroborate the above findings and are referenced throughout this document.

The lack of structural complexity is presumably the most important driver of bats' affinity for forest gap and edge habitat (Loeb \& O'Keefe, 2011). As described above, forest gaps devoid of obstacles function as energy efficient foraging grounds, particularly for the fast and slow aerial hawkers in the open- and edge-adapted morphogroups (Kalko \& Schnitzler, 1993; Barclay \& Brigham, 1994; Brigham et al., 1997). Additionally, the lack of clutter reduces the amount of interfering bounce-back from echolocation calls allowing bats to be more efficient in locating prey (Kalko \& Schnitzler, 1993; Barclay \& Brigham, 1994; Brigham et al., 1997). Uncluttered forest gaps can be used as energy saving commuting pathways by all morphogroups, not just as foraging grounds (Wunder \& Carey, 1996). While this explanation is brief, it is an attempt to avoid rehashing information provided in Chapter 1 and is not meant to downplay the strong influence of structural complexity on bat activity and energy conservation.

Prey availability also is a likely factor influencing bat habitat selection and there is some evidence that forest gaps offer elevated prey availability. A study conducted in a variety of locations in coastal temperate forests of the Pacific Northwest found that insect abundance was greater in forest gaps in comparison to forest interiors (Lunde \& Harestad, 1986). However, this trend is not universal among studies in the region. Results of Grindal and Brigham's (1999) study showed that insect biomass and species richness was significantly lower in clear-cut patches compared to interior forest. It is pertinent to note that this study was conducted right after the clear-cuts were created and insect communities may have had yet to recover from the disturbance. Lauzon's (2019) research conducted 20 years later at the same site, found no significant difference in insect biomass or insect species richness between young regenerating cutblocks and intact forest interiors.

To further complicate the issue, the strength of influence that prey availability has over habitat selection is unknown (Morris, Miller \& Kalcounis-Rueppell, 2010). Several studies in the Pacific Northwest region have shown that bat activity is positively correlated with insect availability (Kalcounis \& Brigham, 1995; Tibbels \& Kurta, 2003; Brooks et al., 2017). However, other studies have found that insect availability had no impact on bat activity (Grindal \& Brigham, 1999; Obrist et al., 2011; Lunde \& Harestad, 1986). A study in Pennsylvania even found a negative relationship between bat activity and insect biomass (Wolbert, Zellner \& Whidden, 2014).

Conclusions drawn from previous research indicate that habitat structure has a greater influence on bat activity than prey availability (Brigham et al., 1997, Grindal \& Brigham, 1999; Ober \& Hayes, 2008; Loeb \& O'Keefe, 2011). For example, a study conducted in North Carolina found that while feeding buzzes of aerial hawkers were positively correlated with greater abundances of Lepidoptera sp. at gap edges, structural stand characteristics were more important predictors of foraging activity (Morris, Miller \& Kalcounis-Rueppell, 2010). Regardless, it is assumed that bats adhere to the optimal foraging theory 
and seek to maximize their net energy intake (Stephen \& Krebs, 1986). Thus, it is likely that prey availability plays a role in bat habitat selection.

Not only are forest gaps important for foraging and commuting activity, canopy gaps can also influence roosting behavior. As discussed at the beginning of this chapter, temperature is an important factor in roost selection, especially for reproductive females, as warmer roosts reduce energetic demands to maintain appropriate body temperatures (Kunz, 1928; Kurta, 1986). Roosts with high temperatures are integral in allowing reproductive females to avoid going into torpor and promote high fetal and juvenile growth rates as well as timely parturition and higher chances of juvenile survival (Boyles et al., 2016; Racey \& Swift, 1981; Hoying \& Kunz, 1998; Racey, 1982; Racey, 1973; Grindal et al., 1992).

Studies have shown that some bat species roost in snags near or within canopy gaps (Kalcounis-Rüppel, Psyllakis, \& Brigham, 2005; Loeb \& O'Keefe, 2011; Campbell, Hallett \& O'Connell, 1996; Vonhof \& Barclay, 1996; Brigham et al., 1997; Waldien, Hayes, \& Arnett, 2000; Constantine, 1966; Arnett \& Hayes, 2009). A meta-analysis conducted by Kalcounis-Rüppel, Psyllakis, and Brigham (2005) found that many temperate insectivorous forest-dwelling species choose to roost in areas with open canopy. Openings allow solar radiation to penetrate the forest canopy and raise the interior temperatures of roosts (Betts, 1998a; Waldien, Hayes, \& Arnett, 2000; Kalcounis-Rüppel, Psyllakis, \& Brigham, 2005; Loeb \& O'Keefe, 2011). Although not well studied, another explanation for open- and edge-adapted bats' use of roosts near or on the edges of forest gaps, is to decrease the distance and amount of energy needed to commute to foraging grounds (Loeb \& O'Keefe, 2015). However, some species avoid roosting in snags near large forest gaps such as traditional clear-cuts as these features may attract predators (Arnett \& Hayes, 2009).

\section{Types of Forest Gaps}

While it is clear that forest gaps provide beneficial habitat for foraging, commuting, and roosting activity, what constitutes a functional forest gap for bats is not well defined. Previous research shows that bats can utilize many different types of gaps regardless of how the gap was created and that gap types can differ in many parameters such as size, shape, and regenerating plant structure. In this document a forest gap is defined as an opening of any size and shape sufficiently devoid of vegetation that allows for unobstructed fast, straight line flight. By this definition, several types of forest gaps should be considered including man-made clear-cut patches, open space above roads, burn areas from both natural and anthropogenic fire, uncluttered herbaceous meadows, openings created by wind-throw and disease, and open space above water bodies. This section briefly describes each of these gap types and how bat activity may differ among them.

First, the role of space above tree canopies must be addressed. While the open area above tree canopies is structurally simple and bats are known to utilize the space (Menzel et al., 2005; Kalcounis et al., 1999), it is not considered a forest gap nor does it eliminate the need for forest gaps as foraging grounds. Forest gaps likely offer better foraging opportunities; a study in a temperate forest of Massachusetts revealed that insect abundance was eight times greater at ground level than above tree canopies (Preisser, Smith \& Lowman, 1998). Although not well studied, there are differences in the vertical distribution of bats between deciduous and coniferous dominant forests. For example, a study in Saskatchewan found that there was a greater proportion of bat activity occurring above the canopy of aspen dominated stands compared to spruce or jack pine dominated stands (Kalcounis et al., 1999). 
Grindal and Brigham (1999) proposed that the tops of canopies may act as an alternative edge habitat. However, the tops of conifers do not provide a distinct edge as deciduous trees might. Thus, in coastal forests of the Pacific Northwest that are generally dominated by conifers, open space above tree canopies likely does not provide high quality foraging habitat in comparison to true forest gaps.

\section{Timber Harvest Gaps}

Man-made gaps resulting from timber harvest are one of the most well-researched forest gap types in terms of bat activity. Many studies have revealed that elevated levels of foraging and overall bat activity occur in clear-cut areas and their edges compared to thinned and intact forest stands (Ellis et al., 2002; Erickson \& West, 1995; Grindal \& Brigham, 1998, 1999; Krusic et al., 1996; Ford et al., 2005; Menzel et al., 2002; Patriquin \& Barclay, 2003; Brooks, 2009; Lauzon, 2019; Jung et al., 1999) (Table 3). In a 2-year study within western hemlock dominated forests west of the Cascades in Washington, $57 \%$ of all bat detections occurred in 2-3 year old clear-cut patches while only $30 \%, 14 \%$, and $0 \%$ were recorded in mature, pre-commercially thinned, and young unthinned stands respectively (Erickson \& West, 1995). Similarly, in southern British Columbia, Grindal and Brigham (1998) recorded approximately 14 bat passes per hour in recent clear-cut blocks but less than 2 bat passes per hour in intact mature western red cedar and western hemlock stands. It is important to note that the results of many of these studies show elevated activity levels of open- and edge- adapted species in this gap type but not always of clutter-adapted species (Lacki, Amelon \& Baker, 2007; Patriquin \& Barclay, 2003).

Table 3: Comparison of bat activity levels between clear-cuts and other habitat types. Habitat type with highest level of bat activity in bold.

\begin{tabular}{|c|c|c|c|c|}
\hline \multicolumn{5}{|c|}{ Western Washington, USA - Western hemlock forest (Erickson \& West, 1995) } \\
\hline Habitat Type & $\begin{array}{c}\text { Clear-cut } \\
\text { (unknown size) }\end{array}$ & $\begin{array}{l}\text { Pre-commercially } \\
\text { thinned stand }\end{array}$ & $\begin{array}{l}\text { Young, unthinned } \\
\text { stand }\end{array}$ & $\begin{array}{l}\text { Mature } \\
\text { stand }\end{array}$ \\
\hline Age (years) & $2-3$ & $12-20$ & $30-40-$ & $50-70$ \\
\hline \# total passes/night & $\sim 7.5$ & $\sim 2$ & 0 & $\sim 4$ \\
\hline \multicolumn{5}{|c|}{ New Hampshire and Maine, USA - Red spruce-balsam fir forest (Krusic et al., 1996) } \\
\hline Habitat Type & $\begin{array}{l}\text { Clear-cut } \\
\text { (0.1-0.8 ha) }\end{array}$ & Sapling-pole stand & Mature stand & $\begin{array}{l}\text { Overmature } \\
\text { stand }\end{array}$ \\
\hline Age (years) & $<9$ & $10-39$ & $40-89$ & $>89$ \\
\hline \# feeding buzzes/night & $\sim 0.08$ & $<0.005$ & $<0.005$ & $<0.005$ \\
\hline \# commuting passes/night & $\sim 16$ & $<4$ & $<3$ & $<4$ \\
\hline \multicolumn{5}{|c|}{ British Columbia, Canada - Western red cedar-western hemlock forest (Grindal \& Brigham, 1998) } \\
\hline Habitat Type & $\begin{array}{l}\text { Clear-cut } \\
\text { (0.5-1.5 ha) }\end{array}$ & & & $\begin{array}{l}\text { Mature } \\
\text { stand }\end{array}$ \\
\hline Age (years) & $<1$ & & & $>200$ \\
\hline
\end{tabular}




\begin{tabular}{|c|c|c|c|c|}
\hline \# total passes/hour & $\sim 14$ & & & $<2$ \\
\hline \multicolumn{5}{|c|}{ British Columbia, Canada - Western red cedar-western hemlock forest (Grindal \& Brigham, 1999) } \\
\hline Habitat Type & $\begin{array}{l}\text { Clear-cut interior } \\
\text { (12-116 ha) }\end{array}$ & $\begin{array}{l}\text { Clear-cut edge } \\
\text { (12-116 ha) }\end{array}$ & & $\begin{array}{l}\text { Mature } \\
\text { stand }\end{array}$ \\
\hline Age (years) & $<1$ & $<1$ & & $>200$ \\
\hline \# feeding buzzes/hour & $<0.5$ & $\sim 1.5$ & & $<2$ \\
\hline \multicolumn{5}{|c|}{ South Carolina, USA - Mixed hardwood forest (Menzel et al., 2002) } \\
\hline Habitat Type & $\begin{array}{c}\text { Clear-cut } \\
(0.02-0.05 \text { ha })\end{array}$ & Bottomland stand & $\begin{array}{l}\text { Upland pine/mixed } \\
\text { hardwood stand }\end{array}$ & \\
\hline Age (years) & $<5$ & $>70$ & $>70$ & \\
\hline \# total passes/night & 7.25 & 0.93 & 1.7 & \\
\hline \# feeding buzzes/night & 2 & 0.05 & 0.05 & \\
\hline \multicolumn{5}{|c|}{ Massachusetts, USA - Mixed pine forest (Brooks, 2009) } \\
\hline Habitat Type & $\begin{array}{c}\text { Clear-cut (unknown } \\
\text { size) }\end{array}$ & $\begin{array}{l}\text { Closed canopy } \\
\text { stand }\end{array}$ & Partial cut stand & \\
\hline Age (years) & unknown & unknown & unknown & \\
\hline \# total passes/20 min. & 6.2 & 1.3 & 3.1 & \\
\hline
\end{tabular}

Though regulation by the Northwest Forest Plan may mandate that structural components such as standing snags be left in logged areas, most clear-cuts are sufficiently structurally simple to constitute as forest gaps. In addition to the open clear-cut space itself, small logging roads created to facilitate tree harvest function as elongated gaps and can be used by bats (see the below Gaps from Roads section for more detail). In the previously mentioned study by Grindal and Brigham (1998), bat activity was recorded at locations pre- and post- road creation; prior to road creation, less than 1 bat pass was recorded per hour but, after trees were cleared for the roadway, around 13 bats were recorded per hour.

Bat-related studies involving clear-cuts in North America are generally initiated at least 1.5 years after the actual logging activity takes place (Law, Park, \& Lacki, 2015) and the immediate impacts of clear-cuts on open- and edge-adapted bat activity are unclear. Logging certainly has the potential to cause negative impacts for all morphogroups if suitable roosts are destroyed in the logging process (Loeb \& O'Keefe, 2006). However, while it is expected for bat activity to be depressed directly after a timber harvest disturbance, activity levels of even clutter-adapted species are likely to recover if adequate roosting habitat is maintained on the landscape (Law, Park \& Lacki, 2015). One study in Alberta, Canada examined the impacts of logging activity in winter months on the activity of bats in the following early summer (Patriquin \& Barclay, 2003). Foraging activity of unidentified Myotis species, little brown bats, and silver-haired bats was greatest in clear-cut areas though no feeding buzzes of the northern long-eared bat were detected in clear-cuts (Patriquin \& Barclay, 2003). These results suggest that, at a 
minimum of 6 months after logging activity, clear-cuts can provide high quality foraging opportunities for many bat species, including some clutter-adapted bats.

Of course not all logging activity results in clear-cuts; selective harvesting often results in only the decrease of tree density, not the elimination of trees. Many of the previously mentioned studies compare acoustic bat activity data collected from the following stand types: clear-cut patch, thinned/early successional stand, and intact/mature/late-successional forest stand. Results show that thinned stands do not function in the same manner as forest gaps. Overall bat activity in thinned stands is often lower than in clear-cut patches (Erickson \& West, 1995; Menzel et al., 2002: Erickson 1993). In the previously mentioned study by Patriquin and Barclay (2003) in Alberta, Canada, thinning treatments proved to be of little benefit for the activity of bats. However, results do vary among studies and levels of commuting activity can be high within thinned stands in some circumstances (Carr, Weatherall, \& Jones, 2020; Humes, Hayes \& Collopy, 1999). Thinned stands resulting from selective logging treatments are not considered forest gaps.

Characteristics of gaps created by logging vary considerably depending upon the motivation behind the logging activity. For example, gaps created for the purposes of timber sale are generally much larger in size than gaps created for the use of wildlife. Small clear-cuts can be created in a way that mimics natural disturbances such as windthrow or disease while large clear-cuts are less reminiscent of gaps that come about by natural processes. Gap size can have significant influence upon which bat species will utilize the area for foraging (Grindal \& Brigham, 1998; Menzel et al., 2002; Brooks, Loeb, \& Gerard, 2017; Ford et al., 2005; Fukui et al., 2011). Gap size is likely the most important parameter impacting the utility of gaps created by logging. Some clear-cut areas are immediately re-planted with a single species of tree while others allow natural vegetation to regenerate; this too has implications for how long the clear-cut will function as foraging grounds for bats. Both previously mentioned parameters are discussed in detail in Chapter 3 below. Due to the widely varied nature of characteristics associated with this gap type, it is difficult to make generalized statements about man-made clear-cuts. However many studies conducted at clear-cut sites are referenced throughout this document.

While large clear-cuts were created within the Siuslaw NF in earlier years as described in Chapter 1 , this type of logging activity is no longer permitted in the forest. As the Siuslaw NF has been designated as a Late-Successional Reserve, timber production is not a priority of the forest and tree harvest can only occur in stands $<80$ years old (USDA Forest Service \& Bureau of Land Management, 1994a). However, man-made clear-cuts are still represented on the landscape. The US Forest Service creates some small clearings, often within monotypic plantations of Douglas fir, for the purpose of increasing habitat diversity for fauna and flora and to create characteristics more typical of late-successional stands. These small openings are generally circular in shape and the centermost tree is left standing in the clearing.

\section{Meadows, Grasslands, and Herbaceous Gaps}

Natural forest gaps such as meadows, grasslands, and herbaceous areas can also function as important foraging and commuting grounds for bats. A landscape analysis of western forests of Oregon and Washington revealed that open areas including meadows and grasslands were positively correlated with bat activity and that edge habitat associated with these gaps were particularly important (Erickson \& West, 2003). A study in the Appalachian Mountains found that open herbaceous fields and abandoned beaver ponds that had progressed into meadows constituted prime foraging habitat for species of all morphogroups (Brooks, 2009). A study based in North Dakota found that pregnant and lactating female little brown bats preferentially chose to forage over grasslands and herbaceous areas, particularly at the edges between these open areas and forested habitat (Nelson \& Gillam, 2017). However, these natural 
gaps have the potential to be structurally complex if trees have encroached into the clearing. The question of when a gap becomes sufficiently cluttered so that it no longer functions as a gap is difficult to answer although it is addressed later in this chapter.

While high elevation meadows are an important ecosystem within the Coast Range, they are rare within the Siuslaw NF. Historically early successional habitat including grass, forb, shrub, sapling, and pole stages constituted 12-29\% of the Oregon Coast Range (Wimberley et al., 2000). Though today Mary's Peak Meadow and Pioneer Butte Meadow constitute the largest meadows within the Siuslaw NF. Prior to meadow restoration projects in 2015 led by the US Forest Service, only $2 \%$ of these historic meadows were made up of early seral habitat (USDA Forest Service, 2010). Invasion of sub-alpine meadows has been reported across the Pacific Northwest and is likely due to a combination of factors. Tree encroachment has been favored by climatic changes that began in the late nineteenth century and perhaps ended in the 1940s (Franklin et al., 1971). Additionally, a shift from indigenous management of intentional fires that promoted open meadows to modern day management of fire suppression further encourages tree invasion (Boyd, 1999). Thus, this gap type is not well represented within the Siuslaw NF though Mary's Peak and Pioneer Butte Meadow are exceptional examples.

\section{Gaps from Fire}

Fire, whether being from a natural or anthropogenic source, can be a prominent catalyst of gap creation on the landscape. Several studies have found that burned forest stands with reduced structural complexity and more open canopies support higher levels of overall bat activity in comparison to intact stands (Blanco \& Garrie, 2020; Boyles \& Aubrey, 2006; Lacki et al., 2009; Perry, Thill \& Leslie, 2007; Buchalski et al., 2013; Malison \& Baxter, 2010). A recent study in the northern Sierra Nevadas examined bat occupancy in relation to fire regime and found that open-adapted bat activity was positively associated with open areas that experienced frequent and high intensity fires (Blakey et al., 2019). Clutter-adapted species were negatively associated with these areas and the impact on edge-adapted species was highly variable (Blakey et al., 2019). Malison and Baxter (2010) found that bat activity was significantly higher in high severity burn areas than in unburned areas of Idaho. However, there are widely varied results among similar studies with some finding no impact of fire on bat activity (Law et al., 2018) and others revealing that fire had a negative impact (Jemison et al., 2012).

Aside from decreasing clutter, fire is thought to increase the availability of quality of roosting habitat by accelerating snag creation (Buchalski et al., 2013). As forest canopies are more open after a fire disturbance, these snags also receive greater amounts of solar radiation making them of high value to reproductive females (Lacki et al., 2009). After removing initial clutter, early colonizing plants growing in postfire areas can support insect activity presenting optimal foraging opportunities for bats (Lacki et al., 2009; Swengel, 2001). Fire has also been found to increase the flux of aquatic organisms to land benefiting bats foraging in riparian areas (Malison \& Baxter, 2010). However, it is also possible that a devastating fire will remove snags from the landscape, negatively impacting bats (Boyles \& Aubrey, 2006). Differing burn intensities can create gaps of differing sizes; low-intensity burns generally create only small canopy gaps, if a gap is created at all, while high-intensity burns have the potential to create large openings at the landscape scale.

As discussed in Chapter 1 above, fire is not a frequent disturbance in the Siuslaw NF at this time due to high levels of moisture along the coast and fire suppression efforts by the US Forest Service. However, fires do occasionally occur in warm, dry months and can create canopy gaps in the Siuslaw NF. Much of the existing literature regarding the impacts of fire on bats comes from more arid regions and not from the mesic coastal forests of Oregon where fire is less common. Further research concerning the 
effect of fire on bats within the Coast Range is needed, though it is expected that fire in this region creates beneficial roosting and foraging habitat as has been described in other regions.

\section{Gaps from Windthrow and Disease}

Canopy gaps can be created by other natural disturbances such as windthrow and disease of trees though few studies have been conducted to characterize how bats respond to these naturally created gaps. However, limited existing research shows that small gaps created by these processes can present beneficial foraging and commuting opportunities for foraging for a wide range of bat species (Hayes \& Loeb, 2007; Loeb \& O'Keefe, 2011; Fukui et al., 2011). As with previously described gap types, the size of canopy gaps associated with these natural disturbances can vary dramatically: gaps can be as small as just meters wide after the death of a single tree or several hectares in size from a strong windstorm. The gap size is likely the most influential characteristic of this gap type. Fukui et al. (2011) recorded bat activity in forest stands post hurricane disturbance and found that bats were readily using the windthrow canopy gaps. Very small canopy gaps excluded activity of open- and edge-adapted species but activity of clutter-adapted bats was elevated in these openings (Fukui et al., 2011). Interestingly, overall species richness decreased with increasing gap size and even open- and edge-adapted species utilized relatively small and medium-sized windthrow gaps (Fukui et al., 2011). It is likely that very small gaps created by disease that affects only one tree do not provide enough space for open- and edge-adapted species to efficiently forage. Please see the section Gap Size and Shape below in Chapter 4 for more details.

As windstorms with the force to create windthrow gaps occur almost yearly in the Siuslaw NF and windstorms with hurricane force winds occur every 25 years (Harmon \& Pabst, 2019), this gap type is well represented on the landscape. This is likely the most dynamic process by which forest gaps are naturally created in the mesic coastal forests of Oregon. Additionally fungal diseases such as laminated root rot may cause the deaths of single trees or small groups of trees creating small canopy gaps, which can be utilized by clutter-adapted species.

\section{Water-Associated Gaps}

Openings above water bodies are likely the most studied gap type. These water-associated gaps have long been considered to be highly important for foraging and commuting activity (Grindal, Morissette \& Brigham, 1999; Brooks, 2009; Thomas, 1988; Menzel et al., 2005; Owen et al., 2004; Anthony \& Kunz, 1977; Racey \& Swift, 1985; Jones \& Rayner, 1988; Brigham, 1991; Saunders \& Barclay, 1992; Barclay \& Brigham, 1994; Rautenbach, Whiting \& Fenton. 1996; Walsh \& Harris, 1996; Vaughan et al., 1997; Wilkinson \& Barclay, 1997). A study within the southern interior of British Columbia found that foraging activity was more than 40 times greater and commuting activity was 10.8 times greater at lakes and riparian habitat than activity at upland forest (Grindal, Morissette, \& Brigham, 1999). Foraging rates of Myotis species along the Oregon Coast Range and the western Cascades of Washington were found to be more than 10 times greater in gaps above water bodies than in forest stands (Thomas, 1988). Many clutter-adapted species, notably the Yuma myotis and little brown bat, utilize this gap type for foraging (Herd \& Fenton, 1983; Lunde \& Harestad, 1986; Brigham, Aldridge \& Mackey, 1992). However, open-adapted bats such as the silver-haired bat also are known to frequently forage in this gap type (Campbell, Hallett \& O’Connell, 1996).

In part, the elevated utility of these areas as foraging grounds can be attributed to the high abundance of insects that can reliably be found near aquatic environments (Racey \& Swift, 1985; 
Brigham \& Fenton, 1991; Thomas, 1988; Brigham, Aldridge \& Mackey, 1992). Because of this, it has been hypothesized that this gap type may be especially important to reproductive females that have greater food requirements than nonreproductive females and males (Barclay, 1989; Grindal, Morissette, \& Brigham, 1999). Results from a study in southern British Columbia where significantly more females were captured in riparian areas compared to upland sites support this hypothesis (Grindal, Morissette, \& Brigham, 1999).

When foraging over water bodies, bats tend to avoid areas with clutter such as vegetation and rocks (Mackey \& Barclay, 1989). Whether gaps above water bodies truly function as a forest gap that can be used by edge- and open-adapted bats for foraging largely depends upon the size and shape of the waterbody. For example, space above ponds, lakes, or bays offer large clutter-free areas allowing for the aerobatic fast flight of open-adapted bats (Menzel et al., 2002; Brooks, 2009; Kalko \& Schnitzler, 1993; Barclay \& Brigham, 1994; Brigham et al., 1997). On the other hand, gaps above small streams may retain an overhead canopy and dense riparian vegetation making the habitat suitable for foraging methods like gleaning and hovering but difficult for slow and fast aerial hawking (Brooks, 2009). Thomas' (1988) study found that small, clutter-adapted Myotis species had higher foraging rates above small streams and ponds but this trend was not observed among the larger bodied edge- and open-adapted species.

Gaps associated with water bodies can also function as energy saving commuting pathways. A study in the White Mountains revealed that foraging activity and especially commuting activity was positively correlated with water bodies and forest trails but negatively correlated with forested patches (Krusic et al., 1996). Feeding buzzes were recorded primarily over still water compared to moving water, trails, and forest sites (Krusic et al., 1996). Even without standing or flowing water, dry beds of intermittent streams can still provide optimal commuting habitat for bats. Research in California revealed that dry streams beds which had only running water during brief seasonal rain events had higher bat activity throughout the summer even when dry than forested upland sites but that larger streams with continuous water flow had the highest levels of bat activity (Seidman \& Zabel, 2001).

While roosting habitat is not available within water-associated gaps, riparian areas associated with this gap type often contain high densities of snags and older trees (Cross, 1988). A study in western Oregon found that long-legged myotis commonly roost in riparian areas (Arnett \& Hayes, 2009). Additionally, the high proportion of deciduous trees often found in riparian zones constitutes important roosting habitat for certain species like the hoary bat (Cross, 1988). However, research has demonstrated that upland roosting habitat is likely of greater importance than that of riparian zones (Campbell, Hallett \& O'Connell, 1996; Waldien, Hayes \& Arnett, 2000; Arnett \& Hayes, 2009). Higher elevation areas away from water courses experience greater incoming solar radiation making roosts on ridges warmer than roosts in riparian areas; bats must make a tradeoff between warm roosts and proximity to sometimes ideal foraging grounds and drinking water (Campbell, Hallett \& O'Connell, 1996; Baker \& Lacki, 2006).

While gaps and riparian areas associated with water bodies clearly provide beneficial and multifaceted habitat for bats, Myotis species are often more closely associated with water than other species. For example, results from a study in southwestern Ontario suggest that while Myotis species were positively associated with water, big brown bats and hoary bats were neither positively nor negatively associated despite the fact that large lakes were sampled along with smaller water bodies (Furlonger, Deward \& Fenton, 1987). As previously mentioned, Myotis species including the Yuma myotis and little brown bats are also commonly detected around water bodies (Thomas, 1988; Herd \& Fenton, 1983; Lunde \& Harestad, 1986; Brigham, Aldridge, \& Mackey, 1992).

In addition to creating habitat for foraging, commuting, and roosting, this is the only gap type that can serve as a source of drinking water. However, some water bodies may not be suitable for 
drinking as bats drink from still water bodies, not fast-moving currents (Krusic et al., 1996; Seidman \& Zabel, 2001). The majority of insectivorous bats' water needs can be sustained by their insect prey but, depending upon the species, up to one quarter of their water requirements come from drinking water (Zabel \& Anthony, 2003; Kurta et al., 1989; Kurta, Kunz \& Nagt, 1990; McLean \& Speakman, 1999). In fact, these calm water bodies present more ideal habitat for foraging as well. Some studies have found that the sound from turbulent water can negatively impact bats' ability to find prey by echolocation (von Frenckell \& Barclay, 1987; Mackey \& Barclay, 1989). However, bats do use areas with flowing water for commuting purposes (Krusic et al., 1996).

Due to the high density of streams and high availability of lakes and ponds, water-associated gaps are likely the most abundant gap type available in the Siuslaw NF. The forest contains some 1,200 miles of anadromous streams and 30 natural lakes (USDA, n.d.a). However, many of the streams in the forest are narrow and may not function as foraging grounds for open- and edge-adapted species. The high availability of water presumably helps to support an abundant and diverse community of insect prey.

\section{Roads and Trails}

While most bat species tend to avoid wide roads with high traffic volumes (Altringham \& Kerth, 2016; Fensome \& Mathews, 2016) (see Chapter 3), small, infrequently traveled forest roads and foot paths can be used by bats for foraging and commuting (Fenton \& Bell, 1979; Brigham, Aldridge \& Mackey, 1992; Grindal \& Brigham, 1998; Krusic et al., 1996; Menzel et al., 2002; Brooks, 2009; Wai-Ping \& Fenton, 1989). Minor rural roads in forested environments offer structurally simple openings that are relatively undisturbed by vehicular traffic, particularly at night, and provide nearby vegetation for cover. In the Pacific Northwest, roadways are known to be used as foraging grounds and commuting pathways specifically by California myotis, Yuma myotis, and the long-legged bat (Fenton \& Bell, 1979; Brigham, Aldridge \& Mackey, 1992; Menzel et al., 2002; Wai-Ping \& Fenton, 1989). These findings do not rule out the utility of this gap type for other Pacific Northwest species but rather highlights the need for additional research to better characterize species-specific responses to forest roads and trails.

In southern British Columbia, Grindal and Brigham (1998) found that overall bat activity increased after the creation of small logging roads. Research in the Appalachian Mountains revealed high activity of clutter-, edge-, and open-adapted species at narrow forest roads; these roads were hypothesized to primarily be used as commuting corridors between roosts and foraging grounds (Brooks, 2009). Acoustic recordings in the White Mountains showed that foraging activity and especially commuting activity were positively correlated with the presence of forest trails (Krusic et al., 1996). A study in South Carolina found that total bat passes and total number of feeding buzzes were greater at temporary logging roads than in intact forest (Menzel et al., 2002). Research in South Carolina revealed that the occurrence of big brown bats, seminole bats (Lasiurus seminolus), and tricolored bat (Perimyotis subflavus) in forest buffers was greater than five times more likely when an adjacent road was present (Hein, Castleberry \& Miller, 2009). Studies outside of North America have yielded similar results (Adams, Law \& French, 2009; Lesiński, Olszewski, \& Popczyk, 2011; Law \& Chidel, 2002).

Along with providing structurally simple habitat that functions as energy-conserving commuting pathways, small forest roads may affect insect prey availability making the openings particularly fertile 
foraging grounds. Results of Melis et al. (2010) suggest that insects may also use roads as movement corridors, just as bats do; beetle species richness was found to be greater near roads and there was no evidence that beetles avoided low-traffic roadways. The impact of roads on insects is often traffic density dependent or road width dependent with low-traffic, narrow roads often having positive effects on insect availability (Muñoz, Torres, \& Megías, 2014).

While it is clear that bats do use minor forest roads for commuting and foraging, most research investigating the effects of roads on bat activity concentrates on the negative impacts of larger, well-traveled roads (Kites \& Merenlender, 2014; Berthinussen \& Altringham, 2012; Berthinussen, 2013; Medinas et al., 2019; Claireau et al., 2019). The noise produced by traffic can impact foraging ability (Schaub, Ostwald \& Siemers 2008; Siemers \& Schaub 2011), cause habitat fragmentation (Fensom \& Mathews, 2016), and cause direct mortality by collision with vehicles (Lesiński,, Popczyk, \& Olszewski, 2011; Berthinussen \& Altringham, 2012; Fensome \& Mathews, 2016). Negative impacts of roadways are further discussed in Chapter 3. The utility of this particular gap type is likely species-dependent and further research is needed to identify thresholds at which this gap type becomes avoided by bats. Based upon results of previous connectivity studies, it is likely that thresholds are driven by traffic volumes and road width (Altringham \& Kerth, 2016; Fensom \& Mathews, 2016).

This gap type is well-represented in the Siuslaw NF. There are many small roadways throughout the forest used for access by the US Forest Service and sometimes for logging vehicles. Many of these roadways are gated so traffic volumes are low even during the day and roads open to the public likely are not well-traveled after dark. There are hiking trails open to the public though many of these trails are concentrated along the coast. Based upon the results of previous studies, it is likely that these gaps are utilized by local bats for foraging and commuting purposes.

\section{Role of Edge Habitat Created by Gaps}

As briefly discussed above in Chapter 2, the interface between the interiors of gaps and the edges of forests serves as important foraging and commuting habitat for many bat species regardless of morphogroup designation (Clark, Leslie \& Carter, 1993; Walsh \& Harris, 1996; Grindal \& Brigham, 1999; Hogberg, Patriquin \& Barclay, 2002; Hein, Castleberry \& Miller, 2009; Morris, Miller, \& Kalcounis-Rueppell, 2010; Jantzen \& Fenton, 2013; Verboom \& Huitema, 1997; Law \& Chidel, 2002; Patriquin \& Barclay, 2003; Fenton, 1990; Furlonger, Dewar \& Fenton, 1987; Krusic et al., 1996; Menzel et al., 2002; Brooks et al., 2017; Swystun, Psyllakis, \& Brigham, 2001; Nelson \& Gillam, 2017; Murray \& Kurta, 2004; Henderson \& Broders, 2008). Some studies have even revealed greater foraging activity of bats at gap edges than in the middle of clearcut gaps or in surrounding forest (Crampton \& Barclay, 1996; Grindal, 1996). This complements observations from several studies that some species of bats avoid flying through large open spaces and prefer to fly along linear features such as tree and shrub lines (Limpens et al., 1989; Limpens \& Kapteyn, 1991; de Jong, 1994; Verboom \& Huitema, 1997; Verboom, 1998).

It is likely that the most influential driver of bats' affinity for edge habitat is lack of clutter. While there are certainly objects to avoid if a bat flies close to the treeline, structural complexity is greatly reduced at gap edges making energy-efficient foraging possible for edge- and open-adapted bats. A 
North Carolina study concluded that forest edges function in a similar way to gaps themselves (Morris, Miller, \& Kalcounis-Rueppell, 2010). Gap edges can further reduce energy expenditure by shielding bats from high winds that dampen bat activity (Norberg \& Rayner, 1987; Norberg, 1990; Verboom \& Spoelestra, 1999; Racey and Swift 1985; Verboom 1998; Walsh \& Harris, 1996).

An assumed driver for this observed behavior is insect availability (Verboom \& Spoelestra, 1999; Verboom \& Huitema, 1997; Whitaker, Carroll \& Montevecchi, 2000; Grindal, 1996; Morris, Miller, \& Kalcounis-Rueppell, 2010; Grindal \& Brigham, 1999; Swystun, Psyllakis \& Brigham, 2001; de Jong, 1994). Some studies have found that insects congregate at leeward gap edges making these edges particularly dense in prey (Lewis, 1970; Whitaker, Carroll \& Montevecchi, 2000). However, there are disparities among results of similar studies that have quantified insect abundance between forest gaps, gap edges, and forest interiors (de Jong, 1994; Furlonger, Deward \& Fenton, 1987; Cross, 1988; Thomas, 1988; Barclay, 1991).

Another possible explanation for bats' affinity for gap edges is perceived protection of forest cover from potential predators (Verboom \& Spoelestra, 1999; Verboom 1998; Lima \& O'Keefe, 2013 : Walsh \& Harris, 1996; Duverge et al., 2000). Bats in the Pacific Northwest region have many predators including domestic cats and other small carnivores, raptors, rodents, bullfrogs, snakes, and even fish, although bats are not often taken by any of these predators (Christy \& West, 1993). However, research suggests that bats are particularly vulnerable to owls when moving through open areas (Speakman, 1991a, 1991b) and nearby forest cover may provide protection. Owl species in Oregon include the barn owl (Tyto alba), tawny owl (Strix aluco), long-eared owl (Asio otus), great horned owl (Bubo virginianus), short-eared owl (Asio flammeus), and Western screech owl (Megascops kennicottii) all known to take bats (Speakman, 1991a, 1991b).

Further hypotheses explaining this behavior include that linear features like gap edges may be important to bats for maintaining orientation (Limpens \& Kapteyn, 1991; Verboom et al., 1999), can be used as navigational markers (Verboom et al., 1999; Verboom, 1998; Limpens et al., 1989; Limpens \& Kapteyn, 1991), and may provide flight conduites (Kalcounis-Rueppell et al., 2013; Law \& Chidel, 2002). While the exact driver or combination of drivers for this behavior is unknown, research has shown that overall bat activity and certainly the activity of select species can be greatest at gap edges (Hein, Castleberry \& Miller, 2009; Morris, Miller, Kalcounis-Rueppell, 2010; Jantzen \& Fenton; 2013; Verboom \& Huitema, 1997; Law \& Chidel, 2002; Patriquin \& Barclay, 2003; Fenton, 1990).

The structure and quantity of edge habitat can vary depending upon gap type which may influence patterns of activity. Some gap types like clear-cuts and roads generally have fairly well-defined treelines around the perimeter of the opening while gaps created by other natural processes may be less clean-cut. Most research has focused on activity of bats at the edges of clear-cuts but not other gap types. While there has not been any research specifically addressing this topic in the region, it is possible that less well-defined edges may not provide these same benefits and could function differently than hard edges. Different types of gaps also have differing amounts of edge habitat available to bats. For example, streams and roads have a much higher availability of edge habitat than gap types with a rounder shape. Implications of gap shape are discussed below in Chapter 3. 


\section{Role of Forest Interiors}

While this document is largely concerned with the importance of forest gaps, it would be misleading to not acknowledge the vital roles that forest interiors fulfill for Pacific Northwest bats. While bats may be divided into different morphogroups, all of the bat species discussed are forest-dwelling species, emphasizing the importance of forested habitat. Due to the lack of available caves in the coastal forests of Oregon, bats primarily use snags with suitable crevices and cavities within forest stands as roosting habitat (Zabel \& Anthony, 2003). Availability and quality of tree roosts are known to be limiting factors of Oregon bat populations (Arnett \& Hayes, 2003; Lewis, 1995; Arnett \& Hayes, 2009; Hayes \& Loeb, 2007; Hayes, 2003, Kunz, 1982). In addition to the value of forest interiors as roosting habitat, clutter-adapted bats exhibit high levels of foraging and commuting activity within forest stands (Thomas \& West, 1991; Krusic et al., 1996; Humes, Hayes \& Collopy, 1999).

However, forest stands of all ages and successional stages are not used equally by bats; just as forest structure influences bats' use of gaps, forest structure influences bats' use of forest interiors. Many studies have shown that bat activity is greater in mature and old-growth stands compared to younger stands with higher tree densities (Perkins \& Cross, 1988; Thomas, 1988; Jung, Thompson \& Titman, 1999; Luszcz \& Barclay, 2016; Arnett \& Hayes, 2009; Thomas \& West, 1991; Krusic et al., 1996; Crampton \& Barclay, 1998; Humes, Hayes, \& Collopy, 1999; Menzel et al., 2005; Loeb and O'Keefe, 2006: Carey, 1989; Erickson, 1993; Parker et al., 1996; Brigham et al., 1997; Betts, 1998b). Several of these studies were conducted in the Pacific Northwest region and provide insight as to how overall bat activity differs among seral stages.

A study conducted in the Oregon Coast Range and western Cascades found that bat activity was significantly higher in old-growth stands $>200$ years old than in stands $<75$ years old and stands between 100 to 165 years old (Thomas, 1988). Within the Coast Range specifically, activity was 2.54-9.75 times greater in old-growth stands than in younger stands (Thomas, 1988). In the Cascades of Washington, Erickson (1993) found that bat activity was greatest within stands 4-7 years old post-clear-cut but that activity was greater in stands $>51$ years old compared to stands $10-13$ years old. A study within Douglas fir-western hemlock stands of Washington found that clear-cut patches aged 2-3 years old supported highest levels of bat activity, young thinned stands 10-13 years old with unconnected canopies and stands 51-62 years old supported moderate activity, and unthinned stands 30-40 years old supported almost no activity (Erickson \& West, 1995). Timing of activity in mature stands suggested that these areas were being used primarily as roosting habitat (Erickson \& West, 1995). In the White Mountains of New Hampshire and Maine, Krusic et al. (1996) recorded highest overall activity in regenerating stands 0-9 years old, moderate activity in conifer stands $>89$ years old, and low activity in sapling-pole conifer stands 10-39 year old and mature conifer stands 40-89 year old conifer.

Other studies have revealed differences in forest age preferences among species and morphogroups. A study in Ontario found that activity of Myotis spp., hoary bats, and silver-haired bats was higher in white pine stands $\geq 120$ years old than in mature stands $90-120$ years old and other younger stands (Jung, Thompson \& Titman, 1999). Research in southwestern British Columbia revealed that activity of open-adapted bats in young stands 1-60 years old was double that of activity in mature stands 61-120 years old and older stands $>121$ years old. However, Myotis spp. activity was most frequent in old stands, second most frequent in mature stands and least frequent in young stands (Luszcz \& Barclay, 2016). As previously discussed, the generalized morphogroups based upon wing morphology and echolocation call structure are generally reliable predictors of species-specific responses to structural complexity (Brooks et al, 2017; Morris, Miller \& Kalcounis-Rueppell, 2010; Humes, 1996; LaVal 
et al., 1977; Aldridge \& Rautenbach, 1987; Bender et al., 2015; Brooks, 2009; Erickson \& West, 2003; Ford et al., 2005; Loeb \& O'Keefe, 2006; Norberg \& Rayner, 1987; Blakey et al., 2019; Owen et al., 2004; Patriquin \& Barclay, 2003; Sleep \& Brigham, 2003; Fenton, 1990; Fenton \& Rautenbach, 1986; Crome \& Richards, 1988; Brooks et al., 2017; Fukui et al., 2011) and can be used to predict species-specific use of stands at different seral stages.

While the timing of overall bat activity from Erickson and West's (1995) study suggests that bats use mature stands for roosting, additional research has focused on documenting roosting activity itself. A study in the western Cascades of Oregon found that big brown bats most commonly choose roosts in stands 81-200 years old while long-legged myotis most commonly chose to roost in stands $41-80$ years old or stands $>200$ years old (Arnett \& Hayes, 2009). Both species rarely ever roosted in stands $<40$ years old though long-eared myotis did not show a strong preference for any particular stand age (Arnett \& Hayes, 2009). A notable survey conducted by Perkins and Cross (1988) in southwestern Oregon found the vast majority of silver-haired bats roosted in mature and old-growth stands $\geq 101$ years old rather than in stands $<100$ years old, whereas hoary bats were exclusively found in older stands.

The specific age ranges that researchers chose to compare causes some disparity among results of the above studies. Regardless, an underlying pattern of higher levels of overall bat activity and roosting occurring in late-successional and old-growth stands compared to mid-successional stands is clear. As previously mentioned, one factor likely driving this pattern of stand use among differing successional stages are structural differences (Erickson \& West, 1995; Erickson, 1993). Stands of intermediate successional stage have high densities of trees that presumably exclude edge- and open-adapted bats from utilizing the stands as foraging habitat. Results from Jung et at. (1999) suggest that the less cluttered understories of old-growth stands create more room for flight and that their canopies may decrease risk of predation. Additionally, climax stands tend to have lower densities of trees (Jung et al., 2012) but high habitat complexity, increasing the diversity of available habitat (Zabel \& Anthony, 2003).

Likely the most important factor influencing bats' preference for late-successional stands is the availability of high quality, large diameter snags (Erickson \& West, 1995; Erickson, 1993; Zabel \& Anthony, 2003; Thomas, 1988; Crampton \& Barclay, 1998; Humes, Hayes \& Collopy, 1999; Law, Park, \& Lacki, 2015). Results of an Oregon-based study found that bats are tightly associated with both dead and live trees $>50 \mathrm{~cm}$ DBH (Erickson \& West, 2003) and results of Washington studies are very similar (Christy \& West, 1993; Campbell, 1993). Tall snags that are also wide in diameter offer thermal stability (Otto, Becker \& Encarnação, 2016; Hayes, 2003; Barclay \& Kurta, 2007) important to reproductive females (Barclay, 1991; Boyles et al., 2016). Additionally, taller older trees are more likely to have been affected by wind and lightning which can cause cracks and crevices suitable for roosting (Perkins \& Cross, 1988). A Washington study conducted in Douglas fir-western hemlock stands found that bats avoided roosting in young stands despite having a relatively high density of snags; this was likely due to the snags' small diameters (Erickson \& West, 2003). Other qualities of trees found in older forest stands can be beneficial as well. For example, as some tree species age, notably the Douglas fir, bark crevices and fissures become deeper and can be used as roosts (Perkins \& Cross, 1988).

However, as with all patterns of bat activity, there are exceptions to the general rule of roosting preferences. For example, a study in the central Cascades of Oregon found that long-legged myotis females did not exhibit roost selection preferences among successional stages (Ormsbee \& McComb, 1998). Some bat species are not solely reliant upon snags for roosts; long-eared myotis are known to use logs, rocks, and stumps as roosts in addition to snags (Arnett \& Hayes, 2009) and hoary bats will roost within foliage of conifers (Kunz, 1982). Regardless, in terms of general roosting habits and overall bat 
activity, bats' preference for late-successional and old-growth stands over mid-succession stands has been well documented in the Pacific Northwest region.

\section{Transition from Gap to Forested Habitat}

Thus far the three main habitats that bats encounter in forests of the Pacific Northwest region have been discussed: canopy gaps, gap edges, and interior forest. However, the condition and structure of these habitats is not stagnant and changes drastically over time. Even after a stand-leveling disturbance, newly created gaps do not remain devoid of vegetation for long; generally by the sapling-pole stage, canopy gaps become rare (Donato et al., 2012) or, if gaps still exist by this time, gap edges are less distinct (Lauzon, 2019). Pinpointing an exact age or successional stage at which gaps no longer function as open habitat for bats is difficult and likely depends on a number of factors including forest type, soil type, rainfall, temperature, and many others. To date, few longitudinal studies have been conducted following the activity of bats in gaps over time. The most complete information currently available regarding this process is discussed below.

As previously discussed, young forest gaps relatively devoid of vegetation function as high quality foraging and commuting habitat. Older forest gaps are likely to contain herbaceous plants, shrubs, and saplings. Although few studies have quantified the impacts of non-tree vegetation on bat activity within forest gaps, the results of several studies suggest that bat activity is either promoted or not impacted by understory vegetation in canopy gaps. The activity of hoary bats, eastern red bats, and Myotis spp. was positively associated with the presence of woody vegetation in southeastern Ontario (Furlonger, Deward \& Fenton, 1987). Similarly, a study of aging clear-cut patches in England found that activity of clutter-adapted species increased with ground vegetation cover and that activity of edge- and open-adapted species increased with mean vegetation height (Froidevaux et al., 2016). However, research conducted in western Oregon and Washington revealed that the density of understory trees $<5$ cm DBH was not an important predictor of bat activity (Erickson \& West, 2003). Despite the lack of focused research on this topic, it can be assumed that foraging activity of all three morphogroups is not impeded by low growing vegetation. Bats may even be drawn to areas with understory cover due to greater insect availability. A study that focused on riparian zones within the Oregon Coast Range found that insect abundance was positively associated with increasing shrub cover (Ober \& Hayes, 2008).

Though further research is needed to understand the specific impacts of sapling and non-tree vegetative growth on bat activity within forest gaps some assumptions can be drawn from existing literature. First, gleaning bats generally forage at lower heights than aerial hawkers (Menzel et al., 2005; Müller et al., 2013), thus it is likely that non-tree growth impacts clutter-adapted species more than open-adapted species. Second, the culmination of the above research implies that the foraging activity of all three morphogroups is not negatively impacted by the presence of non-tree growth in open canopy habitats. Open- and edge-adapted bats generally forage at heights above even tall-growing shrubs (Menzel et al., 2005; Müller et al., 2013) and the presence of shrubs may increase insect availability particularly for low-flying clutter-adapted species. As discussed above in Chapter 1 , lack of structural complexity is presumably the most important driver of bats' affinity for forest gaps and edge 
habitat (Loeb \& O'Keefe, 2011). However, non-tree vegetation does not appear to inhibit the activity of open- and edge-adapted bats therefore the structure of trees is likely the controlling factor.

Many studies have compared bat activity in stands of different successional stages (e.g. earlysuccessional, mid-successional, late-successional, and old-growth) or stands that have been structurally altered (e.g. clear-cut, various thinning practices, and intact forest stands). These studies compare snapshots of stands at a particular point in time but do not necessarily capture nuanced long-term changes in bat activity as forest stands change in structure with age. While not a continuous study over time, research by Lauzon (2019) reexamined bat activity in the same southeastern British Columbia forest stands 20 years after Grindal and Brigham's studies in 1998 and 1999. The original study found that foraging and commuting activity was highest at the edges of recent clear-cut patches and higher within clear-cut patches than in intact forest stands aged 81-250 years old (Grindal \& Brigham, 1999). Interestingly, the follow up study by Lauzon (2019) reported similar findings despite the fact that tree canopies in the previously clear-cut patches were between 5-20 m tall in 2019.

Significantly greater foraging activity of both clutter- and open-adapted bats was recorded within regenerating patches (>20 years old) and their edges than within intact forest stands (Lauzon, 2019). Commuting activity of open-adapted bats was significantly greater in regenerating patches and edges than in intact forest stands but commuting activity of clutter-adapted bats did not differ among habitat types (Lauzon, 2019). These results were surprising, considering the high density of relatively tall trees in the regenerating patches and imply that both clutter- and open-adapted bats may preferentially forage at forest edges even if the edge is created by differences in canopy height, not by a gap in the canopy. In addition, open-adapted bats may use these types of edges as commuting corridors; Lauzon (2019) suggested that this edge type may still serve some of the same functions (e.g. protection from wind, higher prey availability, and navigational landmarks) as edges created by canopy gaps.

Consideration of the all above findings does not offer a distinct cut-off at which aging gaps no longer function as uncluttered foraging habitat for open- and edge-adapted species. However, it does demonstrate that regenerating non-tree vegetation and even some tree growth in older forest gaps does not always inhibit foraging activity. These findings highlight the need for long-term studies to better characterize the functionality of aging gaps for open- and edge-adapted species. As with many facets of bat ecology, it is likely that individual species exhibit differing responses to gap age. Studies of this nature in Pacific Northwest region would provide much needed insight into the functional transition between structurally simple and cluttered habitat.

\section{CHAPTER 3: Artificial Gap Creation and Parameters Influencing Bat Activity}

While forest managers may have limited influence over the spatial context and features of gaps created by natural processes such as fire and windthrow, they do have the ability to create artificial forest gaps by means of logging. As discussed in earlier chapters, artificial gaps have the potential to be 
readily used as foraging grounds and commuting pathways by bats. However, the dynamics of bats and gaps are complex and previous research demonstrates that several gap parameters should be taken into consideration when planning artificial gap creation. Through extensive literature review, a short list of highly influential parameters were identified and are discussed below. Physical characteristics including gap size, gap shape (e.g. availability of edge habitat), elevation, and the structure of regenerating plants as well as the spatial context of the gap such as proximity and connectivity of the gap to other resources are included.

The remaining text of Chapter 4 first explains the methods by which the literature review was conducted to derive pertinent information regarding bat-gap dynamics in the region. Second, each gap parameter is discussed in depth, highlighting the results of relevant research that informed specific parameter recommendations. The direct impact of each parameter on bat activity is explored as well as impacts on additional factors such as insect availability which may alter bat activity indirectly (Kalcounis \& Brigham, 1995; Tibbels \& Kurta, 2003). Each parameter is discussed in a general manner applicable to most Pacific Northwest forests and then specifically in regards to the Siuslaw NF. Third, additional gap parameters related to managerial concerns specific to the Siuslaw NF are listed. Fourth, an example parameter table (Table 3) provides an overview of gap parameters and recommendations that are used in the case study of the Siuslaw NF. Lastly, potentially influential parameters in need of future research are addressed.

Please note that the parameters discussed in the below text and in Table 3 are not a complete list of all gap parameters that may be influential to bats but do provide a shortened, focused list. As habitat structure is thought to be the most influential factor in determining bat habitat preferences (Brigham et al., 1997, Grindal \& Brigham, 1999; Ober \& Hayes, 2008; Loeb \& O'Keefe, 2011), parameters related to structure were prioritized. Additionally, as the Siuslaw NF is used as a case study in this document, parameters pertinent to concerns of Siuslaw NF wildlife and forest managers as well as local policy were also prioritized. While many of the parameters prioritized in this document are applicable to other forests in the region, if this approach were to be applied to a different forest, this list of parameters and recommendations should be reevaluated according to the specific characteristics and managerial concerns of that forest.

\section{Literature Review Methods}

As this document entails only a qualitative analysis of the existing literature available on the dynamics of bats and forest gaps, no hard restrictions were set on what literature was included in this review. However, the subsequent general guidelines were followed. Research from the last 20 years was prioritized over older research, though influential papers from the 1980s and 1990s were included when appropriate. Almost all cited literature originated from the Pacific Northwest region. Where there are gaps in knowledge in the Pacific Northwest, research from elsewhere in North America and occasionally from other continents is included. These studies from outside of the Pacific Northwest are clearly labeled to inform the reader where the data originated. Among the literature cited throughout this report, the experimental methods employed by each author varied drastically. These discrepancies in experimental methods must be considered when making direct comparisons of results between studies. 


\section{Important Gap Parameters}

\section{Gap Size and Shape}

By the definition of forest gap used in this document, forest gaps can vary from just several meters wide to encompassing several hectares. Results vary among studies examining the influence of gap size on bat activity and some results indicate that gap size has no effect at all. However, it is important to note there are large discrepancies in gap sizes investigated among studies. The results of a study in British Columbia showed no significant difference in overall bat activity among 0.5-1.5 ha gaps, though bat activity did decrease with increasing gap size (Grindal \& Brigham, 1998). Similarly, research in North Carolina found no significant difference in overall bat activity or bat species richness among gaps from 0.2-18.5 ha in size; species from all three morphogroups were detected (Brooks, Loeb, \& Gerard, 2017). While these two studies indicate that gap size has no significant effect on overall bat activity, it is pertinent to note that all gaps studied were $>0.2$ ha although bats are known to utilize smaller openings and, Brooks, Loeb, and Gerard (2017), tested broad groupings of gap sizes.

Results from studies that recorded bat activity in gaps smaller than 0.1 ha suggest that the assemblage of bats present in gaps is highly influenced by gap size (Menzel et al., 2002; Ford et al., 2005; Fukui et al., 2011) (Table 4). Clutter-adapted bats may avoid utilizing gaps that are greater than 0.1 ha in size (Ford et al., 2002; Fukui et al., 2011) (Table 4) though have been recorded in larger gaps in some cases (Brooks, Loeb \& Gerard, 2017). It is possible that acoustic monitors fail to pick up the low-intensity calls of many clutter-adapted and some edge-adapted species (Ford et al., 2005) making it appear as though these species are not present in larger gaps. On the other hand, open-adapted species are excluded from small gaps and most commonly use gaps greater than 0.075 ha (Ford et al., 2005; Brooks, Loeb \& Gerard, 2017), though some species, including the hoary bat and silver-haired bat, appear to be less constrained by gap size (Table 4). However, it is possible that acoustic monitors used in these studies detected hoary bats and silver-haired bats that were flying over the gap rather than using the gap itself. Edge-adapted bats seem to have the greatest plasticity with some species utilizing gaps from 0.003 ha to larger than 1 ha (Menzel et al., 2002; Ford et al., 2005; Fukui et al., 2011; Brooks, Loeb \& Gerard, 2017) (Table 4).

Table 4: Generalized probability of presence of select bat species according to gap size. Green represents high probability, yellow represents moderate to low probability, and pink represents species absence.

\begin{tabular}{|c|c|c|c|c|c|c|c|c|}
\hline \multirow{2}{*}{ South Carolina, USA - Mixed hardwood and pine forest (Menzel et al., 2002) } \\
\hline & \multicolumn{5}{|c|}{ Open-adapted } & \multicolumn{2}{|c|}{ Edge-adapted } & \multicolumn{2}{|c|}{ Clutter-adapted } \\
\hline & Efu & Lci & Lno & Tbr & Psu & & & \\
\hline 0.03 & & & & & & & & \\
\hline 0.5 & & & & & & & & \\
\hline West Virginia, USA - Mixed hardwood and pine forest (Ford et al., 2005) & Clutter-adapted \\
\hline $\begin{array}{c}\text { Gap Size } \\
\text { (ha)* }\end{array}$ & \multicolumn{7}{|c|}{ Open-adapted } & \multicolumn{3}{|c|}{ Edge-adapted } \\
\hline
\end{tabular}




\begin{tabular}{|c|c|c|c|c|c|c|c|c|}
\hline & Efu & Lci & Lno & Psu & Mlu & & Mse & Mso \\
\hline \multicolumn{9}{|l|}{$<0.035$} \\
\hline \multicolumn{9}{|l|}{$0.035-0.075$} \\
\hline \multicolumn{9}{|l|}{$0.075-0.09$} \\
\hline \multicolumn{9}{|c|}{ Hokkaido, Japan - Mixed hardwood forest and coniferous plantations (Fukui et al., 2011) } \\
\hline \multirow{2}{*}{ Gap Size (ha) } & \multicolumn{3}{|c|}{ Open-adapted } & \multicolumn{3}{|c|}{ Edge-adapted } & \multicolumn{2}{|c|}{ Clutter-adapted } \\
\hline & Nav & Vsi & & Mma & Mik & $\mathrm{Rfe}$ & Mhi & Mus \\
\hline \multicolumn{9}{|l|}{$<0.03$} \\
\hline \multicolumn{9}{|l|}{$0.03-0.06$} \\
\hline \multicolumn{9}{|l|}{$0.06-0.3$} \\
\hline \multicolumn{9}{|c|}{ Table Key: } \\
\hline Bat Species: & \multicolumn{8}{|c|}{$\begin{array}{l}\text { Eptesicus fuscus (Efu), Lasiurus cinereus (Lci), Lasiurus noctivagans (Lno), Murina hilgendorfi } \\
\text { (Mhi), Murina ussuriensis (Mus), Myotis ikonnikovi (Mik), Myotis lucifugus (Mlu), Myotis } \\
\text { macrodactylus (Mma), Myotis septentrionalis (Mse), Myotis sodalis (Mso), Nyctalus aviator } \\
\text { (Nav), Tadarida brasiliensis (Tbr), Perimyotis subflavus (Psu), Rhinolophus ferrumequinum } \\
\text { (Rfe), Vespertilio sinensis (Vsi). Species with bolded abbreviations are found in Siuslaw NF. }\end{array}$} \\
\hline $\begin{array}{l}\text { Probability of } \\
\text { Presence: }\end{array}$ & & \multicolumn{2}{|c|}{ High probability } & \multicolumn{2}{|c|}{$\begin{array}{l}\text { Medium to low } \\
\text { probability }\end{array}$} & & \multicolumn{2}{|c|}{ Not present } \\
\hline
\end{tabular}

Though responses to gap size are species dependent, there is no evidence that extremely large gaps provide added benefit to any of the three morphogroups, even open-adapted species. For the central hardwoods region of the United States, Loeb and O'Keefe (2011) suggest that forest gaps created for the benefit of bats should be $<10$ ha in size. The previously mentioned study conducted by Menzel et al. (2002) found no significant difference in bat activity between the centers and edges of gaps sized 0.02-0.5 ha among representative species of all three morphogroups. This demonstrates that gaps $<0.5$ ha in size likely do not exceed a maximum size threshold for open-, edge-, and perhaps some clutter-adapted bats.

There is additional evidence that indicates that bat activity is promoted in small gaps as opposed to large gaps. Avoidance of the interiors of large gaps has been observed in many studies even among open-adapted species (Limpens et al., 1989; Limpens \& Kapteyn, 1991; de Jong, 1994; Verboom \& Huitema, 1997; Verboom, 1998; Murray \& Kurta, 2004; Henderson \& Broders, 2008) and is perhaps due to perceived pressures of predation. Fukui et al. (2011) concluded that more intense disturbances such as the creation of large clear-cut patches may reduce bat diversity while less intense disturbances that result in smaller gaps may promote greater species richness. While habitat structure is likely the driving force behind gap size preferences of bats (Brigham et al., 1997, Grindal \& Brigham, 1999; Ober \& Hayes, 2008; Loeb \& O'Keefe, 2011), it is possible that insect availability also plays a role. However, this theory is 
in need of further research; insect availability was not impacted by gap size in studies by Brooks, Loeb, and Gerard (2017) or Grindal and Brigham (1988).

Thus, based upon the cumulative results of the above research, it is recommended that artificial forest gaps be between $0.075-0.5$ ha in size. However, this recommendation comes with the caveat that the vast majority of studies informing this recommendation originated from outside of the Pacific Northwest region. As noted in the following paragraph, further study in the Pacific Northwest region is needed to better refine this recommendation. Relatively small gaps constitute important foraging and commuting habitat and are likely to benefit species of all three morphogroups (Loeb \& O'Keefe, 2011; Menzel et al., 2002). According to existing literature, gaps within this range are beyond the minimum size threshold to accommodate the needs of open- and edge-adapted species but are small enough that clutter-adapted species may also utilize the gaps for foraging (Table 4). In addition, limiting the size of artificial gaps to a small scale may present less of a challenge for forest managers when justifying the creation of gaps. For example, within the Siuslaw NF, a Late-Successional Reserve where logging is highly limited, there are more opportunities to create small gaps across the landscape as opposed to large ones.

However, there are discrepancies among existing studies as to the minimum gap size threshold for open-adapted bats. Despite both studies by Menzel et al. (2002) and Ford et al. (2005) being conducted within the Central hardwood region of the eastern United States, some open-adapted species used much smaller gaps in South Carolina than in West Virginia (Table 5). These discrepancies as well as the possibility that existing studies do not accurately capture gap use among species with low intensity calls (Ford et al., 2005) demonstrate the need for intensive future research to better characterize gap size preferences among morphogroups. As studies exploring gap size preferences have largely been conducted within the eastern United States, it is imperative that research be conducted in the Pacific Northwest region to understand the particular needs of local bat communities. As updated information becomes available regarding this gap parameter, the gap size recommendation provided by this document should be updated accordingly.

Not only does gap size have the potential to influence bat activity, the shape of the artificially created gap should also be evaluated. A study in the Appalachian Mountains found that overall bat activity was greatest in gaps with elongated shape (Brooks et al., 2017). As previously discussed in Chapter 2, edge habitat along the perimeter of gaps can provide important foraging and commuting grounds in addition to the interior of the gap opening. Several studies have found that more foraging activity occurs along the edges of clearcuts compared to the interior of the opening or in the surrounding forest (Crampton and Barclay, 1996; Grindal, 1996). It is highly likely that a greater availability of edge habitat in gaps with elongated or irregular shape are more conducive to elevated levels of bat activity than in forest gaps with a rounder shape (Menzel et al., 2002; Brooks et al., 2017). Thus, it is recommended that artificial forest gaps created in the Siuslaw NF have an elongated or irregular shape which maximizes the length of available edge habitat.

\section{Forest Type}

Results vary as to whether bats exhibit a preference for certain forest types for foraging and other activities. Patriquin and Barclay's (2003) study in Alberta revealed that there was no significant difference in overall bat activity among conifer-dominant forest composed primarily of white spruce 
(Picea glauca), deciduous-dominant forest made up of mostly trembling aspen (Populus tremuloides), and mixed forests composed of both tree species. However, Myotis spp. activity was significantly greater in conifer-dominant forest (Patriquin \& Barclay, 2003). Similarly, another study in Alberta found no difference in overall bat activity among conifer-dominated stands predominantly made up of white spruce and black spruce (Picea mariana), deciduous-dominated stands predominately made up of balsam poplar (Populus balsamifera) and trembling aspen, or mixed stands (Hogberg, Patriquin \& Barclay, 2002). In contrast, a study in southwestern British Columbia found that open-adapted bat activity was almost two times greater in Engelmann spruce (Picea engelmannii) stands than in black cottonwood (Populus balsamifera) stands (Luszcz \& Barclay, 2016). In the same study Myotis spp. activity was almost one and a half times greater in black cottonwood and coastal western hemlock stands than in interior Douglas fir stands or Engelmann spruce stands (Luszcz \& Barclay, 2016). A study in Saskatchewan revealed that mean overall bat activity and foraging activity was greater in mixed aspen (Populus spp.) and white spruce (Picea glauca) forest types than in aspen or jack pine (Pinus banksiana) forests types (Kalcounis et al., 1999).

While no strong patterns of forest type preferences emerge from the four previously mentioned studies, there is some evidence that bats may select for certain forest types in certain areas. One possible factor driving these preferences is that different forest types provide different resources for insects which leads to differences in insect abundance and diversity (Kalcounis et al., 1999). Funk and Croteau (1994) suggested that, due to defensive strategies of conifers such as resin production, coniferous forests may have lower insect availability. Another factor that may cause preferences among forest types is tree species composition. The species of trees present in a certain forest type and the prevalence of each species can impact roost quality and availability as different species are more prone to natural hollowing processes. Bats use both naturally created hollows and crevices as well as hollows created by primary excavators (Aubry \& Raley, 2002). Several of these habitat modifying species found in Oregon prefer to excavate Douglas fir trees (Bevis \& Martin, 2002), although others like the pileated woodpecker (Dryocopus pileatus) are less discriminatory (Aubry \& Raley, 2002).

As there are not any clear preferences of bats for certain forest types, this document does not provide a specific recommendation for artificial gap creation regarding forest type for the Pacific Northwest region. However, the above studies demonstrate that forest type preferences of bats have been documented for specific forests and this parameter could be important at a scale smaller than the regional scale. There are many localities within the Pacific Northwest region which have not been exclusively studied to characterize forest type preferences of bats and future research is needed. An example of how this parameter could be explored for a specific forest is provided below in relation to the Siuslaw NF. If this approach were to be applied to a forest other than the Siuslaw NF, this parameter should be given special consideration by forest managers.

To date, no studies exclusively testing forest type preferences of bats for foraging have been conducted in Oregon. However, Oregon studies in or near the Coast Range have examined roosting preferences. A study of forest stands across Oregon found that hoary bats exclusively roosted within Douglas fir and western hemlock while silver-haired bats, in addition to Douglas fir and western hemlock, roosted in ponderosa pine, sugar pine, and true fir (Perkins \& Cross, 1988). A study on the western side 
of the Oregon Cascades found that big brown bats, long-legged myotis, and short-eared myotis almost always chose to roost in Douglas fir snags and the chances of a snag being chosen as a roost increased with increasing DBH (Arnett \& Hayes, 2009). All three species were also observed using western hemlock snags and big brown bats and long-legged myotis used western redcedars (Arnett \& Hayes, 2009). Each tree species was used in a similar proportion to their availability on the landscape. A study in northern California found that fringed myotis individuals roosted primarily in Douglas fir trees and occasionally in ponderosa pine (Weller \& Zabel, 2001). A study of long-eared myotis roosting habitat revealed that the species most commonly used Douglas fir and western hemlock snags for roosting but also utilized stumps of the same tree species as well as snags (Waldien, Hayes, \& Arnett, 2000).

While there is no clear evidence that Oregon bat species specifically select for or against any forest type while foraging, research has shown that bat species often roost in Douglas fir, western hemlock and western red cedar. Douglas fir and western hemlock are either dominant or very common in all forest types found within the Siuslaw NF and western redcedar can be found within the coastal Sitka spruce zone (Hemstrom \& Logan, 1986; USDA Forest Service, 1990). A more detailed account of forest types within the Siuslaw NF can be found above in Chapter 1. Thus, it is unlikely that forest type is a largely important consideration when planning artificial gap creation in the Siuslaw NF. However, as more research becomes available from the Pacific Northwest region and especially from the coastal forests of Oregon, this assessment should be revisited. Additionally, if this approach to artificial gap creation is being applied to other forests or regions, forest type may require additional consideration.

\section{Proximity to Roosting Habitat}

While the spatial context of forest gaps used by bats for foraging has been examined in Mediterranian environments (Rainho \& Palmeirim, 2011), it has not been explicitly studied in the Pacific Northwest despite its importance to management. For any resource, including forest gaps, to be utilized, it must be a reasonable distance from habitat that meets other needs of bats (Zabel \& Anthony, 2003, Tuttle, 1976). Assuming that bats adhere to the optimal foraging theory, bats will maximize net energetic intake by minimizing time and energetic output toward commuting between habitats (Pyke, 1984). If the energetic costs are high to fly from roosting habitat to reach a gap for foraging, that gap will likely not be utilized by bats (Tuttle, 1976, Rainho \& Palmeirim, 2011). A study in Ontario revealed that bats will regularly hunt in subpar foraging habitats that are in close proximity to roosts rather than commute to better quality foraging grounds further away (Geggie \& Fenton, 1985). Additional studies have confirmed that bats more frequently utilize foraging grounds that are closer to roosting sites (Furlonger, Deward, \& Fenton, 1987; Erickson \& West, 2003). Unfortunately determining the distance bats will travel to reach foraging grounds is not a straightforward pursuit. Many factors including species, age, sex, and reproductive status influence this particular facet of bat ecology.

Of open-adapted bat species, the movements of big brown bats have been particularly well studied. Early research of big brown bats indicated that, on average, individuals move 1-2 km away from day roosts during nightly foraging excursions (Kurta \& Baker, 1990). A study in Ottawa found that big brown bats traveled an average of $924 \mathrm{~m}$ from day roosts to reach foraging grounds with some individuals traveling only $200 \mathrm{~m}$ and one individual sometimes traveling $4.1 \mathrm{~km}$ (Brigham \& Fenton, 1986). A radio telemetry study in Colorado revealed that female big brown bats using a maternity roost in an urban area would travel 9.2-18.8 km to reach fields, forest stands, and water bodies for foraging 
(Everette et al., 2001). Researchers in Michigan estimated the average home range of female big brown bats to be 2.7 ha and that of a single male big brown bat to be 6.3 ha (Swingen et al., 2018). According to these home range sizes, bats generally foraged $<1 \mathrm{~km}$ from their day roosts (Swingen et al., 2018). Like the big brown bat, the hoary bat is an open-adapted species but is better suited to long-distance travel as is evidenced by their long seasonal migrations which can be greater than 1,000 km round-trip (Weller et al., 2016). Results from a New Hampshire study that tracked a single juvenile male hoary bat suggested that the individual foraged in an area spanning 156 ha (Veilleux et al., 2009), much larger than that of the big brown bat.

Some other bats also typically travel similarly short distances between roosts and foraging grounds. Given the 7.2 ha home range size of northern long-eared bats and even smaller ranges for little brown bats, bats in Michigan were predicted to generally forage within $1 \mathrm{~km}$ of their roosts (Swingen et al., 2018). A study in the northern coastal forests of California revealed that Townsend's big-eared females traveled an average of $3.2+/-0.5 \mathrm{~km}$ and males traveled $1.3+/-0.2 \mathrm{~km}$ (Fellers \& Pierson, 2002). However, this estimate may be low as other studies of Townsend's big-eared bats have revealed maximum distance traveled from roosts to foraging grounds to be relatively long (5-13 km) (Adam et al., 1994; Brown, Berry \& Brown, 1994; Clark, Leslie \& Carter, 1993; Fellers \& Pierson, 2002) suggesting that it is possible for clutter-adapted species to move fairly large distances nightly.

As demonstrated by the wide range of distances traveled between day roosts and foraging habitat revealed by the studies above, it is difficult to generalize distances traveled among different species, all of which have unique life histories, and among sexes and ages. To further complicate the issue, bats are not stationary creatures and some species frequently move between multiple day roosts (Ormsbee \& McComb 1998; Brigham 1991; Weller \& Zabel, 2001; Vonhof \& Barclay 1996; Crampton \& Barclay, 1996, 1998; Kalcounis \& Hecker, 1996; Mattson et al., 1996; Brigham et al., 1997; Waldien, Hayes \& Arnett, 2000; Lewis, 1996; Betts 1998b). Bats have been documented frequently selecting new day roosts up to several hundred meters away from the roost used the previous day (Brigham et al., 1997; Betts 1998b; Crampton \& Barclay, 1996; Mattson et al., 1996), and may travel up to several kilometers between roosts (Ormsbee \& McComb, 1998). For example, a Michigan study by Swingen et al. (2018) found that female northern long-eared bats used the same roost for an average of 1.3 days while female big brown bats stayed an average of 1.4 days; roosts were reused after 1 or 2 days of abandonment. Distances traveled between roosts used on consecutive nights averaged $280 \mathrm{~m}$ with $82 \%$ of these roosts being $<500 \mathrm{~m}$ apart from one another (Swingen et al., 2018). A study of fringed myotis in northern California revealed that individuals used a single roost for an average of 1.7 days and traveled an average of $254 \mathrm{~m}$ in between roosts (Weller \& Zabel, 2001). One probable explanation for this behavior of frequently changing roosts is the reduction of ectoparasite loads (Lewis, 1996).

However, as with most facets of bat ecology, roosting patterns vary among different species and are influenced by habitat structure (Lewis, 1995; Roadhouse \& Hyde, 2014). Even though some species regularly switch between roost trees, they may choose to roost within snags in the same general location. For example, western long-eared bats in Alberta exhibited low fidelity to individual roost trees but generally roosted within a home range $<2$ ha in size (Nixon, Gruver \& Barclay, 2009). Lactating females often exhibit greater fidelity to certain roost sites using particular roosts for longer periods of time than nonreproductive females and males (Zabel \& Anthony, 2003; Mattson, Buskirk \& Stanton, 1996; Kalcounis \& Hecker, 1996), although this is not always the case (Swingen et al., 2018). Further research is needed to understand long-term roosting patterns of bat species in the Pacific Northwest and the processes which drive them. 
While some bats do not exhibit fidelity to roost trees, bats are known to return to their foraging grounds (Wai-Ping \& Fenton, 1989; Audet, 1990; Fellers \& Pierson, 2002; Rodhouse \& Hyde, 2014). Spotted bats equipped with radio transmitters in British Columbia commonly used the same commuting corridors and foraging grounds night after night (Wai-Ping \& Fenton, 1989). In the coastal forests of California, Townsend's big-eared bats have also shown fidelity to foraging grounds (Fellers \& Pierson, 2002). In a desert canyon setting, the western small-footed myotis regularly used the same foraging site at a river confluence nightly (Rodhouse \& Hyde, 2014). Positioning artificial gaps near prime roosting habitat would not only ensure that bats would be able to access the gap but would also encourage continual use of the resource.

It is likely that reproductive females are more constrained in the distances they can travel from their maternity roosts to reach foraging grounds than males and nonreproductive females (Campbell, Hallett \& O'Connell, 1996; Tuttle, 1976; Barclay, 1989). Research on the endangered gray bat (Myotis grisescens) showed that when lactating bats had to travel longer distances from maternity roosts to foraging grounds, growth rates of juveniles decreased and juvenile mortality rates increased (Tuttle, 1976). Lactating females are known to return to their maternity roost to nurse their young throughout the night in between foraging sessions (Henry et al., 2002). This implies that, in order for lactating females to minimize energy expenditure when commuting, females must use foraging grounds and roosts in close proximity to one another. This has been observed in western small-footed myotis females that utilize roosts closer to foraging sites while nursing but use roosts further away after pups are weaned (Rodhouse \& Hyde, 2014).

A radio telemetry study conducted in Ontario revealed that pregnant little brown bats regularly flew $<1 \mathrm{~km}$ away from day roosts to forage and used night roosts in between bouts of foraging activity only returning to their day roosts before morning (Henry et al., 2002). After giving birth, bats rarely traveled $>600 \mathrm{~m}$ from maternity roosts to forage, did not use night roosts, and instead returned to the maternity roost 1-2 times a night to nurse (Henry et al., 2002). Home ranges of female little brown bats were reduced from $30.1+/-15.0$ ha to $17.6+/-9.1$ ha after giving birth (Henry et al., 2002). However, the estimated home range of pregnant and lactating female northern long-eared bats in Michigan were not significantly different from that of males and nonreproductive females (Swingen et al., 2018). Though results vary, it appears that some reproductive females and several bat species regardless of sex and reproductive status tend to travel $<1 \mathrm{~km}$ from their roosts to reach foraging habitat.

While recognizing the many uncertainties and the variation surrounding distances that bats travel between roosts and foraging grounds, it is recommended that artificial gaps be created within 1 $\mathrm{km}$ of suitable roosting habitat to accomodate the needs of reproductive females during their most sensitive life stage. As discussed in Chapter 2, large snags $>50 \mathrm{~cm}$ DBH are favored as roosts by most forest-dwelling bat species in the Pacific Northwest region (Erickson \& West, 2003; Christy, 1993; Campbell, 1993). Unfortunately, the application of a recommendation regarding proximity of a gap to stands with high densities of large diameter snags can be difficult as reliable spatial snag data is often unavailable. When applying this approach to forests where snag data is unavailable, such as the Siuslaw NF, a proxy for snags may be necessary to identify suitable roosting habitat. While there is variation in the results of regional studies, research shows that bats often roost in late-successional and old-growth stands $\geq 120$ years old (Erickson \& West, 1995; Arnett \& Hayes, 2009; Perkins \& Cross, 1988). This preference for roosting in older stands is most likely driven by a higher availability of optimal, large diameter snags compared to younger stands (Erickson \& West, 1995; Erickson, 1993; Zabel \& Anthony, 2003; Thomas, 1988; Crampton \& Barclay, 1998; Humes et al., 1999; Law, Park, \& Lacki, 2015). 
Many factors influence commuting distances which make it difficult to pinpoint how far an individual bat of a particular species and reproductive status might travel from its roost to foraging grounds, much less to make a generalized statement regarding a diverse bat community such as that found in the Siuslaw NF. As described by Tuttle (1976), acceptable distances between resources are not absolute and will vary depending upon the quality of roosting and foraging habitats with warmer roosts and areas with abundant insect prey facilitating the use of resources further away. Considering that few radio telemetry studies have been conducted in a setting representative of the coastal forests of Oregon, the movement ecology of bats in the Siuslaw NF is largely unexplored. Based upon limited previous research and lack of spatial snag data, it is recommended that artificial forest gaps in the Siuslaw NF be created $<1 \mathrm{~km}$ of stands $\geq 120$ years old. However, if reliable snag data is made available, this recommendation should be updated accordingly.

\section{Proximity to Source of Drinking Water}

As discussed above, for a resource such as a forest gap to be frequented, it must be a reasonable distance from other habitat needs (Zabel \& Anthony, 2003, Tuttle, 1976). One such habitat need, in addition to roosting habitat, is drinking water; though their water-laden insect prey provides the majority of required water for insectivorous bats, all bats require additional drinking water. Drinking water availability is especially important to bats in arid regions where they may lose up to $30 \%$ of their bodies' water content in only 12 hours (Webb, Speakman, \& Racey, 1995). Accessible drinking water is also highly important for reproductive females. Just as food requirements are higher for pregnant and lactating females than males and nonreproductive females, so are drinking water requirements (Kurta, Kunz, \& Nagt, 1990; McLean \& Speakman, 1999; Adams \& Hayes, 2008). Studies have shown that around $20 \%$ of lactating bats' water intake must come from drinking water (McLean \& Speakman, 1999).

Bats use echolocation to identify water bodies (Greif \& Siemers, 2010) and drink while flying low over the water's surface (Seibold et al., 2013; Korine et al., 2016). Bats typically drink from lentic waters such as ponds and lakes or slow-moving lotic waters including rivers, streams, pools, back channels, and wetlands (Johnson et al., 2010; Korine et al., 2016). Despite the importance of suitable sources of drinking water, only a small body of research has been dedicated to quantifying drinking site parameters required by bats. However, it is known that water body size is one factor that influences drinking activity; agile clutter-adapted species are capable of drinking from smaller water bodies than less maneuverable open-adapted species (Razgour, Korine \& Saltz, 2010; Cross, 1988). Cross (1986) observed that small Myotis species are capable of drinking water from pools only several centimeters in diameter. Though unable to identify bats to the species level, Tuttle, Chambers and Theimer (2006) documented both small and large bat species drinking from $4.7 \mathrm{~m}^{2}$ water troughs in northern Arizona. A study of drinking activity of insectivorous bats within the Central Negev Desert of Israel found that ponds $\geq 15 \mathrm{~m}$ in length supported a higher diversity of bat species than smaller ponds, though drinking activity was observed at smaller ponds only $6.2 \mathrm{~m}$ in length (Razgour, Korine \& Saltz, 2010). While further research regarding the influence of water body size on drinking activity is needed to characterize preferences of Pacific Northwest bat species specifically, existing literature indicates that bats can utilize relatively small bodies of water for drinking.

While studies indicate that bats prefer to drink from and forage over calm waters as opposed to fast-moving or turbulent waters (Mackey \& Barclay, 1989; Seidman \& Zabel, 2001), few studies have quantified the effect of flow and turbulence. A study conducted in riparian areas of northwestern 
Georgia found that water body features including flow, turbidity, and depth were only minimally correlated with bat activity (Johnson et al., 2010). Though streamflow was not actually quantified, Adams and Simmons (2002) noted that bats approached drinking water sites in the opposite direction of streamflow and consistently drank from sources with "mild streamflow". Even fast-moving streams and rivers often contain calm pools or back flow areas that can be used by bats for drinking purposes (Seidman \& Zabel, 2001; Adams \& Simmons, 2002). While other features of water bodies that influence whether a site is suitable for drinking also require additional research, streamflow appears to be an especially important parameter in need of future study to enable the identification of suitable drinking sites for bats.

Interestingly, while bats require water sources for drinking and many species are known to forage over water (see discussion in Chapter 2), there are mixed results regarding the importance of the proximity of roosting and foraging habitat to water. Some results from North American studies have concluded that bat activity is positively correlated with proximity to water (Brooks, 2009; Ford et al., 2006; Menzel et al., 2005; Gellman \& Zielinski, 1996; Weller \& Zabel, 2001; Ormsbee \& McComb, 1998; Starbuck, Considine \& Chambers, 2020) while other studies have found that water proximity had the opposite or no effect on bat activity (Hein, Castleberry, \& Miller, 2009; Yates \& Muzika, 2006; Betts 1998b; Waldien, Hayes, \& Arnett, 2000; Campbell, Hallett \& O'Connell, 1996; Mattson et al., 1996; Brooks et al., 2017). Though not well-studied, documentented maternity roosts in some areas of Colorado and Scotland are concentrated near water sources (Adams \& Thibault, 2006; Speakman et al., 1991).

Even within the Pacific Northwest region specifically there are disparities among results of several studies exploring this facet of bat ecology. A survey of fringed myotis roosting sites in northern California revealed that used roosts were significantly closer to stream channels than random sites (Weller \& Zabel, 2001). Roosts were an average of $43.7 \mathrm{~m}$ from stream channels and $117.4 \mathrm{~m}$ from perennial water sources (Weller \& Zabel, 2001). Another study in northern California quantified the amount of bat guano at roost trees and discovered that the weights of guano were significantly greater at roosts close to perennial water sources with available surface water (Gellman \& Zielinski, 1996). However, a study of long-eared myotis roosting habits in the western Cascades of Oregon found that significantly more roosts were located $>100 \mathrm{~m}$ away from water sources than $<100 \mathrm{~m}$ (Waldien, Hayes, \& Arnett, 2000). Similarly, a study of silver-haired bats in northeast Washington found that all roost sites were $>100 \mathrm{~m}$ away from riparian zones with available water though the species was only ever caught in mist nets set above water bodies (Campbell, Hallett, \& O'Connell, 1996).

While the results of the above studies give insight into roosting preferences in relation to water, little is known about the preferred spatial context of forest gaps in relation to water. However, as discussed above in the previous section, bats minimize distances between roosting and foraging habitat to reduce energy expenditure and all habitat needs of bats must be within a reasonable distance of one another (Zabel \& Anthony, 2003; Tuttle, 1976). Thus, it is a reasonable assumption that it would be beneficial for artificial gaps to be created in relatively close proximity to drinking water. Research from North American regions other than the Pacific Northwest have revealed that a wide diversity of species choose to forage in areas <100 m from water (Tuttle, 1976; Racey \& Swift, 1985; Wilkinson \& Barclay, 1997) though these studies were not conducted specifically in forest gaps.

However, to validate this assumption and to quantify preferential distances between forest gaps and water bodies, additional research in the Pacific Northwest region is required. There is a particular need to better understand the limitations of lactating females in commuting between maternal roosts, foraging grounds, and drinking water sources. As with most facets of bat ecology, preferences and needs 
are likely to be species-specific and may be influenced by favored foraging ground types. While some species including the Yuma myotis, little brown bat, and silver-haired bat are known to frequently forage over water (Herd \& Fenton, 1983; Lunde \& Harestand, 1986; Brigham, Aldridge \& Mackey, 1992; Campbell, Hallett \& O'Connell, 1996), other species such as the big brown bat, hoary bat, and northern long-eared bat are not tightly associated with aquatic habitat (Brigham, 1991; Furlonger, Deward \& Fenton, 1987; Waldien \& Hayes, 2001).

The issue of where to position artificial gaps in relation to water bodies to ensure the gap can be utilized by an entire bat community is clearly complex and is in need of additional research. Even among several studies regarding the preferred distances of roosting habitat to water, a similar but more thoroughly studied topic, results are conflicting. However, a thorough review of bat ecology in western coniferous forests suggested that prime roosting habitat is located within 2-3 km of water sources (Zabel \& Anthony, 2003). Based upon the limited available research and the knowledge that all resources must be a reasonable distance from one another, it is recommended that forest gaps be created within 2-3 km of water sources. This tentative recommendation should be reevaluated frequently as the results of pertinent research, especially pertaining to the needs of reproductive females, become available in the future. Similarly, this recommendation should be adjusted accordingly as more information becomes available regarding the influence of streamflow on the viability of drinking sites.

Due to the lack of information needed to utilize streamflow as a parameter to identify suitable drinking sites and due to the inability to obtain spatial data to map pools and backchannels of streams, all streams, ponds, and lakes are considered to be suitable drinking sites within the Siuslaw NF though it is likely that some portions of streams may be too fast-flowing to allow for drinking. Considering the vast and sinuous stream system through the mesic forest along with the 30 natural lakes (USDA Forest Service, n.d.a), it is unlikely that drinking site availability and accessibility is a limiting factor for bats in the Siuslaw NF. Meeting the recommendation of creating gaps within 2-3 km from a water source would likely be an easy task in any location on the west side of the Cascade Range where precipitation is abundant. However, in more arid locations of the Pacific Northwest region, this recommendation could be more constraining in terms of finding suitable locations for gap creation. The identification of suitable drinking sites should be a high priority for future research and the availability of drinking sites should be considered if this approach is applied to other forests.

\section{Proximity to Highways}

Traffic on major roads and highways dampen nearby bat activity (Kites \& Merenlender, 2014; Berthinussen \& Altringham, 2012; Berthinussen, 2013; Medinas et al., 2019; Claireau et al., 2019) and can cause mortality of bats by vehicle collision (Lesiński, Sikora, \& Olszewski, 2011; Berthinussen \& Altringham, 2012; Fensome \& Mathews, 2016). Studies on the Indiana bat (Myotis sodalis) have shown that individuals flying near roads display avoidance behaviors as vehicles approach and ultimately turn around to avoid crossing the road (Zurcher et al., 2010; Bennett \& Zurcher, 2013). An acoustic study in California revealed that bat activity of all detected species was approximately two-fold greater at locations $300 \mathrm{~m}$ from roads with annual average daily traffic (AADT) volumes of 33,500-86,000 than at the roads themselves (Kitzes \& Merenlender, 2014). However, bat activity was recorded at locations a maximum of only $300 \mathrm{~m}$ away from roads but did not explore potentially further reaching road effects and only open-adapted species were detected in the study. 
Some research has revealed that roads negatively impact the activity of certain morphogroups more than others. A study conducted in Portugal examined the effect of roads with low to medium traffic volumes (277-1,210 vehicles/night) on bat activity in agricultural and woodland areas (Medinas et al., 2019). Results showed that roads negatively impacted overall bat activity up to $310 \mathrm{~m}$ from the road and that clutter- and edge-adapted species were more sensitive to roads than open-adapted species (Medinas et al., 2019). A study in France examined the impact of major roads (16,218-33,800 AADT) running through agricultural areas, grasslands, and woodlands (Claireau et al., 2019). While open- and edge- adapted bat activity was decreased near roads, only activity of clutter-adapted species was significantly affected and negative impacts spanned $5 \mathrm{~km}$ from the road into adjacent habitats (Claireau et al., 2019). Unlike previous studies, these results showed that roads negatively impacted clutter-adapted bat activity at the landscape scale and Claireau et al. (2019) suggested that the road effect zone could be even wider than $5 \mathrm{~km}$.

Researchers in the UK recorded bat activity (Pipistrellus spp., Nyctalus spp., and Myotis spp.) at eight distances from a rural section of a major road with variable traffic volumes (30-40,000 AADT) and found that bat passes increased with distance from the road with passes being 3-5 times greater at the furthest distance, $1.6 \mathrm{~km}$ from the road, compared to $0 \mathrm{~m}$ (Berthinussen \& Altringham, 2011). Even between sites at $1.2 \mathrm{~km}$ and $1.6 \mathrm{~km}$, models showed a relatively large difference in number of bat passes; at $1.2 \mathrm{~km}$, there were only approximately 11 passes while at $1.6 \mathrm{~km}$, there were approximately 16.5 passes (Berthinussen \& Altringham, 2011). Species richness increased significantly with distance from the road as the odds of detecting a higher number of species was 2-5 times higher at locations 1.6 $\mathrm{km}$ from the road than at $0 \mathrm{~m}$ (Berthinussen \& Altringham, 2011). While noise is known to disrupt foraging behavior (Schaub, Ostwald \& Siemers 2008; Siemers \& Schaub 2011), sound levels from traffic remained the same beyond $100 \mathrm{~m}$ from the road suggesting that bats chose habitat further away from the road for reasons other than noise (Berthinussen \& Altringham, 2011). Similar results came from a nearby study at a different major road (25-90,000 AADT) where the number of overall bat passes was 3 times greater at $1.6 \mathrm{~km}$ from the road than at the road (Berthinussen, 2013).

Based upon the results of previous research, it is clear that all bats avoid roads with high traffic volumes to some degree, though it is highly likely that clutter-adapted and possibly edge-adapted species are more sensitive than open-adapted species. Thus, to accommodate the needs of all three morphogroups, it is recommended that artificial gaps be created more than $1.6 \mathrm{~km}$ away from any major roads or highways with high traffic volumes. This recommendation takes a cautious approach to ensure that gaps are utilized by sensitive clutter- and edge-adapted species and to avoid bat mortalities that could occur if bats try to cross roads to reach artificial gaps. However, this recommendation to create gaps more than $1.6 \mathrm{~km}$ away from major roads may not be feasible in all circumstances. At a minimum, gaps should be created more than $350 \mathrm{~m}$ away from major roads to accommodate the activity of openand perhaps edge-adapted species. While the studies informing these recommendations do provide insight into the impact of high traffic roads on bats, recommendations should be updated accordingly as results of future studies originating in the Pacific Northwest better characterize the behaviors of the region's bat communities. 
Additionally, more research is needed to understand how roads with low traffic volumes impact bats as most of the existing research concentrates on only roadways with high traffic volumes. However, it is unlikely that there are significant negative impacts. As discussed in Chapter 2, small, infrequently traveled forest roads can even be used by bats for foraging and commuting (Fenton \& Bell, 1979; Brigham, Aldridge \& Mackey, 1992; Grindal \& Brigham, 1998; Krusic et al., 1996; Menzel et al., 2002; Brooks, 2009; Wai-Ping \& Fenton, 1989). Therefore, it is not recommended that artificial forest gaps be created any certain distance away from low traffic roadways. As with all recommendations suggested in this document, recommendations regarding both high and low traffic roadways should be revisited periodically as more information becomes available and should be updated accordingly.

In the Siuslaw NF specifically, several major roadways run through the forest, including Highways $101,126,38,229,18,130$, and 22 . These highways support medium to high traffic volumes and the roadways themselves are 2- 4 lanes wide. The most traveled major roadway, Highway 101, runs roughly parallel to the coastline cutting through substantial portions of the Siuslaw NF and has the highest traffic volumes in the region. Traffic census data from 2019 shows that between the northernmost and southernmost boundaries of the Siuslaw NF, Highway 101 experiences 2,900-27,100 vehicles per day (Oregon Department of Transportation, 2019). Traffic volumes on the other above-mentioned highways are less than that of Highway 101 but are still likely to negatively impact bat activity. Therefore, it is recommended that gaps be created at least $350 \mathrm{~m}$ away from major roadways but that locations more than $1.6 \mathrm{~km}$ from major roadways should be favored. This recommendation does not extend to smaller, less traveled roads.

\section{Regenerating Plant Structure}

The functional longevity of artificial forest gaps is of both ecological and managerial concern. Over time, after the initial creation of an artificial gap, the gap will become more and more cluttered with regenerating vegetation and will eventually no longer function as foraging grounds for open- and edge-adapted species. Of course, it would be most beneficial to bats for artificial gaps to have extended lives to serve as long-lasting locations for foraging. Additionally, it is in the interest of forest managers to have long-lived gaps to minimize the need for upkeep and perhaps decrease the frequency at which artificial forest gaps must be created.

To ensure that gaps remain functional for as long as possible, the structure of the plant community that is expected to colonize the gap post-disturbance should be considered. From both an ecological and managerial standpoint, dense shrubs are likely the most beneficial type of regenerating vegetation in a newly created forest gap. Dense shrub species are capable of shading and crowding out regenerating trees for a certain amount of time (Hemstrom \& Logan, 1986) effectively lengthening the life of an artificial gap. Additionally, as discussed in Chapter 2, bats regularly forage over shrubs (Furlonger, Deward \& Fenton, 1987; Froidevaux et al., 2016; Ober \& Hayes, 2008; Morris, Miller \& Kalcounis-Rueppell, 2010) and this type of vegetative growth may even promote high levels of insect availability (Ober \& Hayes, 2008). Thus, it is recommended that artificial forest gaps be created in locations where dense shrub species are expected to be early colonizers post-gap creation to extend the life of the gap without requiring intervention from management and to provide high quality foraging 
habitat for bats. To determine which shrub species are present and capable of suppressing tree growth in a specific forest, research on local plant species is required.

In the Siuslaw NF and many coastal forests of the Pacific Northwest region, there are several shrub species capable of suppressing tree growth. Salmonberry is an especially competitive species in post-disturbance areas whose growth can outstrip that of Douglas fir and western hemlock and effectively block light causing seedling mortality (Hemstrom \& Logan, 1986). One year post-disturbance, salmonberry can reach a height of more than $2 \mathrm{ft}$ and a height of $4 \mathrm{ft}$ by year three (Hemstrom \& Logan, 1986). Test plots within the Siuslaw NF showed that in post-disturbance salmonberry-associated locations, crop trees were generally absent after 3-5 years and could even suppress tree growth for up to 15 years (Hemstrom \& Logan, 1986). Other shrub species including salal and Oregon grape can suppress tree growth, although competition of these species is not as intense as that of salmonberry. It is suggested that, in the Siuslaw NF, artificial forest gaps be created in locations where salmonberry, salal, or Oregon grape are expected to be one of the early colonizing species after gap creation. The prevalence of these shrub species within the Siuslaw NF can be seen above in Table 1.

\section{Elevation}

Results of several studies suggest that overall bat activity decreases with increasing elevation (Grindal, Morissette, \& Brigham, 1999; Thomas, 1988; Barclay, 1991; Erickson \& West, 2003; Grindal \& Brigham, 1999; Krusic et al., 1996; Baker \& Lacki, 2004; Brooks et al., 2017) and that a higher abundance and diversity of bat species can be found at lower elevations (Grindal, 1995, 1996). A survey of sites across western Oregon and Washington revealed that bat activity was negatively associated with increasing elevation (Erickson \& West, 2003). A study in southeastern British Columbia found that foraging activity at low elevations $(540-1,000 \mathrm{~m})$ was significantly higher than at elevations $>1,000 \mathrm{~m}$ (Grindal, Morissette, \& Brigham, 1999). An earlier study in the same area found a significantly greater abundance of bats at sites $<500 \mathrm{~m}$ than at higher elevations (Fenton et al., 1980). This general trend is seen outside of the Pacific Northwest region as well. In New Hampshire, researchers recorded greater overall bat activity in stands at $<533 \mathrm{~m}$ than in stands at $>838 \mathrm{~m}$ (Krusic et al., 1996). Results of an acoustic study in Pennsylvania showed significantly greater bat activity at low elevations $(<335 \mathrm{~m})$ than at high elevations (457-579 m) (Wolbert, Zellner, \& Whidden, 2014).

Several factors are responsible for this phenomenon. Perhaps the most important is that nightly temperatures drop with increasing elevation. As bats are limited by thermoregulatory constraints, cold nightly temperatures negatively impact bat activity (McCain 2007; Cryan, Bogan, \& Altenbach, 2000; Wolbert, Zellner, \& Whidden, 2014). High elevations also experience higher levels of precipitation. Bat activity in Washington is known to decrease significantly due to rainfall and highest detection rates of bats generally occur in rainshadow zones (Erickson \& West, 2002). Grindal et al. (1992) observed similar patterns in southern British Columbia and found decreased proportions of reproductive female little brown bats and Yuma myotis during years with high levels of precipitation.

Not only can environmental conditions associated with elevation affect bats directly, it can also influence their insect prey. Grindal and Brigham (1999) found that insect biomass and abundance decreased with increasing elevation, although not significantly, in southern British Columbia. A study in North Carolina also found that insect abundance decreased with increasing elevation (Brooks et al., 2017). Aerial insect activity decreases with dropping temperatures (Wolbert, Zellner \& Whidden, 2014; 
Brooks et al., 2017; Racey \& Speakman, 1987). Use of habitat with warmer temperatures can result in greater availability of insect prey, particularly that of aquatic insects (Grindal, 1996; Hoying \& Kunz, 1998) as well as improve feeding productivity (Cryan, Bogan, \& Altenbach, 2000).

As discussed in Chapter 1, temperature is an influential factor in roost selection and reproductive females exhibit different preferences than their nonreproductive counterparts, males, and juveniles (Cryan, Bogan, \& Altenbach, 2000; Fenton et al., 1980; Sasse, 1995). Reproductive females generally utilize warm, low elevation roosts to avoid using torpor as means of energy conservation (Cryan, Bogan, \& Altenbach, 2000; Fenton et al., 1980; Baker \& Lacki, 2004; Sasse, 1995) which benefits their young (Hoying \& Kunz, 1998; Racey, 1973, 1982; Racey \& Swift, 1981). In contrast, males, adult nonreproductive females, and juveniles often seek out cooler roosts at higher elevations than reproductive females to better facilitate torpor and hibernation states to lower energy expenditure (Grindal, Morissette, \& Brigham, 1999; Baker \& Lacki, 2004; Barclay, 1991; Hamilton \& Barclay, 1994).

Researchers in the eastern Cascades of Washington found that females were significantly more likely to be detected in low elevation watersheds (760-1260 $\mathrm{m}$ ) as opposed to high elevation watersheds $(1,000-1,400 \mathrm{~m})$ while a greater proportion of males were found in high elevation watersheds (Baker \& Lacki, 2004). Similarly, in British Columbia, Grindal et al. (1999) found significantly more females in low elevation zones (540-1,000 m) as opposed to mid- (1,000-1,400 m) and high- (1,400-1,800 m) elevation zones while males were found most often in mid-elevation zones. A study in the western Cascades of Washington found no reproductive females at elevations $>300 \mathrm{~m}$ but reproductive females were found at elevations $<700 \mathrm{~m}$ within the Oregon Coast Range and eastern Washington Cascades (Thomas, 1988). Outside of the Pacific Northwest, a study in the Black Hills of South Dakota found that reproductive females were negatively correlated with increasing elevation with almost no reproductive females roosting at $>1,400 \mathrm{~m}$ (Cryan, Bogan, \& Altenbach, 2000).

Based upon the results of previous research conducted specifically in the Pacific Northwest region, it is recommended that artificial forest gaps be created at elevations $<700 \mathrm{~m}$. As reproductive females are generally found roosting at warm, low elevation sites, it is more likely that artificial forest gaps will benefit this subset of the population if gaps are created at similar elevations. Though most existing research has examined roosting habits, Grindal et al. (1999) discovered significantly greater levels of overall foraging activity at elevations $<1,000 \mathrm{~m}$. It is likely that this parameter recommendation will still support foraging activity of males, nonreproductive females, and juveniles as well as reproductive females. Additional research specifically examining the influence of elevation on foraging activity rather than roosting in the Pacific Northwest would help refine this recommendation.

As the highest point in the Siuslaw NF and the entire Oregon Coast Range is Mary's Peak at an elevation of 1,249 m (USDA Forest Service, n.d.a) and much of the Siuslaw NF is at much lower elevations, this recommendation is easily achieved. However, the elevation at which gaps are created even in the Siuslaw NF where there isn't dramatic topographic relief, could be highly important. Strong orographic effects occur within the Coast Range with prominent ridges experiencing much higher levels of precipitation than neary be valley bottoms (Hemstrom \& Logan, 1986) which could negatively impact foraging activity of bats. 


\section{Additional Managerial Concerns for the Siuslaw NF}

In addition to the parameter recommendations discussed in the above sections of Chapter 3 , there are several managerial concerns specific to the Siuslaw NF in regards to artificial gap creation. As the Siuslaw NF is managed according to the Late-Successional Reserve Guidelines, as dictated by the NWFP (USDA Forest Service \& Bureau of Land Management, 1994), trees can only be cut in stands $<80$ years old for several predetermined purposes. Though this guideline is highly restrictive in terms of diversifying available habitat for wildlife and creating openings that can be used as foraging grounds for bats specifically, this limitation promotes the continuation and creation of late-successional habitat used by a suite of late-successional obligate species. One of the designated purposes for creating gaps in stands $<80$ years old is to increase the diversity of forest flora and fauna to which the creation of gaps to promote bat diversity applies.

Also in accordance with the NWFP and Late-Successional Reserve Guidelines, gaps must be created $>122 \mathrm{~m}$ from fish-bearing streams. The streams themselves and buffers extending to $122 \mathrm{~m}$ from each side of the stream ( $244 \mathrm{~m}$ wide in total including both sides of the stream) are a part of protected Riparian Reserves. These tracts of land alongside streams, wetlands, ponds, and lakes are set aside for the following purposes as dictated by the USDA US Forest Service (USDA Forest Service \& Bureau of Land Management, 1994).

"The main purpose of the reserves is to protect the health of the aquatic system and its dependent species; the reserves also provide incidental benefits to upland species. These reserves will help maintain and restore riparian structures and functions, benefit fish and riparian-dependent non-fish species, enhance habitat conservation for organisms dependent on the transition zone between upslope and riparian areas, improve travel and dispersal corridors for terrestrial animals and plants, and provide for greater connectivity of late-successional forest habitat."

Beyond restrictions set forth by the NWFP, US Forest Service managers have further concerns regarding gap creation within the Siuslaw NF that require additional consideration. As with most forest managers, the threat of invasive plant species is particularly concerning. Many invasive species are already prevalent within the Siuslaw NF including shining geranium (Geranium lucidum), European beachgrass (Ammophila arenaria), purple foxglove (Digitalis purpurea), bull thistle (Cirsium vulgare), and Himilayan blackberry (Rubus armeniacus) among others. The current extent and location of these species has been mapped by the US Forest Service. Therefore, any location that is already known to be invaded was not considered suitable for artificial gap creation.

Though there is no specific recommendation for creating artificial gaps a certain distance away from low traffic roadways based upon ecological benefits for bats, creating gaps away from all roadways will help prevent the spread of invasive species. Research shows that small forest roads can be hotspots for invasive plant species and can advance invasion (Mortensen al., 2009). Recently disturbed areas, like artificial forest gaps, present ideal conditions for the invasion of many nonnative species as there are oftentimes fewer native plants in a disturbed area to compete with (Nuzzo, 1999; Humber, 2009). Therefore, it is common practice for the US Forest Service to create gaps $>30 \mathrm{~m}$ from forest roads to avoid unnecessary spread of nonnative plant species (pers. comm.).

The US Forest Service has also mapped landslide risk throughout the entire Siuslaw NF. Landslide risk ratings include low, moderate, high, and very high. As the removal of vegetation can increase the probability of landslides, especially in future rainfall events (Sidle \& Terry, 1992), areas categorized as 
having a high or very high risk of landslides were not considered suitable for gap creation. Areas categorized as having a low landslide risk were prioritized.

Though the Siuslaw NF itself is a protected Late-Successional Reserve where tree harvest activity is highly limited, the public and private forest lands surrounding the Siuslaw NF are actively logged and many large clear-cut patches are in close proximity to the boundaries of the Siuslaw NF. It can be assumed that bats dwelling near boundaries of the Siuslaw NF can access these forest gaps and it is more beneficial for gaps to be created toward the interior of the forest rather than at its boundaries. Therefore, it is suggested that gaps be created $>1 \mathrm{~km}$ from Siuslaw NF boundaries that are abutted by actively logged forest lands.

\section{Siuslaw NF Gap Parameter Table}

Based upon the above findings from existing literature and communications with forest managers of the Siuslaw NF, a final gap parameter table was created for the case study (Table 3). This table was used to guide the identification of ideal locations for gap creation in the Siuslaw NF discussed below in Chapter 4. Though parameter recommendations and their rationale are brief in Table 3, complete discussions of each parameter can be found in the above sections of Chapter 3 . Influential references are cited in Table 3 though more can also be found in the above sections.

Table 5: Important gap parameters identified through review of literature and specific recommendations and rationale for each parameter specific to the Siuslaw NF.

\begin{tabular}{|c|c|c|c|c|}
\hline \multicolumn{5}{|c|}{ Siuslaw NF Gap Parameter Table } \\
\hline $\begin{array}{c}\text { Gap } \\
\text { Parameter }\end{array}$ & Concern & Recommendation & Rationale & References \\
\hline Gap Size & Ecological & $\begin{array}{l}\text { Forest gaps should be } \\
\text { between } 0.075-0.5 \text { ha } \\
\text { in size. }\end{array}$ & $\begin{array}{l}\text { Previous research shows that open- } \\
\text { adapted bat activity is low in very small } \\
\text { gaps }(<0.1 \text { ha) and that clutter-adapted } \\
\text { bat activity is low in large gaps ( }>0.5 \mathrm{ha}) \text {. } \\
\text { Gaps within this size range should } \\
\text { accommodate all morphogroups. }\end{array}$ & $1,2,3,4,5$ \\
\hline Gap Shape & Ecological & $\begin{array}{l}\text { Forest gaps should be } \\
\text { elongate in shape when } \\
\text { possible to maximize } \\
\text { availability of edge } \\
\text { habitat. }\end{array}$ & $\begin{array}{l}\text { While forest gaps can be utilized by all } \\
\text { three morphogroups for foraging and } \\
\text { commuting activity, gap edges are often } \\
\text { where this activity is concentrated for } \\
\text { clutter- and edge-adapted species. }\end{array}$ & 2,3 \\
\hline Forest Type & Ecological & $\begin{array}{l}\text { Not applicable to the } \\
\text { Siuslaw NF. }\end{array}$ & $\begin{array}{l}\text { There is no clear evidence that bats } \\
\text { specifically select for or against any } \\
\text { forest type while foraging in coastal } \\
\text { forests of Oregon. }\end{array}$ & $6,7,8,9$ \\
\hline Proximity to & Ecological & Forest gaps should be & Regional studies show that bats & $10,11,12$ \\
\hline
\end{tabular}




\begin{tabular}{|c|c|c|c|c|}
\hline $\begin{array}{l}\text { Roosting } \\
\text { Habitat }\end{array}$ & & $\begin{array}{l}\text { created }<1 \mathrm{~km} \text { from } \\
\text { stands with high } \\
\text { densities of snags }>50 \\
\mathrm{~cm} \text { DBH to } \\
\text { accommodate pregnant } \\
\text { and lactating females. }\end{array}$ & $\begin{array}{l}\text { preferentially roost in snags }>50 \mathrm{~cm} \\
\mathrm{DBH} \text {. If spatial snag data is unavailable, } \\
\text { late-successional and old-growth stands } \\
\text { ( } \geq 120 \text { years old) that often contain high } \\
\text { densities of large diameter snags may be } \\
\text { considered as suitable roosting habitat. } \\
\text { Commuting distances between day } \\
\text { roosts and foraging sites are mostly } \\
\text { restricted to }<1 \mathrm{~km} \text { for reproductive } \\
\text { females. }\end{array}$ & $\begin{array}{l}13,14,15 \\
16,17,18 \\
19,20,21 \\
22,23\end{array}$ \\
\hline \multirow[t]{2}{*}{$\begin{array}{l}\text { Proximity to } \\
\text { Source of } \\
\text { Drinking } \\
\text { Water }\end{array}$} & Ecological & $\begin{array}{l}\text { Forest gaps should be } \\
\text { created between } 100 \mathrm{~m} \\
\text { and } 3 \mathrm{~km} \text { to the nearest } \\
\text { water source. }\end{array}$ & $\begin{array}{l}\text { Bat species that prefer to forage over } \\
\text { water are less likely to utilize forest gaps } \\
\text { and research shows that several species } \\
\text { regularly forage in openings }>100 \mathrm{~m} \\
\text { from water. Gaps }>3 \mathrm{~km} \text { from a water } \\
\text { source may be too far away for bats to } \\
\text { regularly use while also having access to } \\
\text { drinking water. }\end{array}$ & $\begin{array}{l}4,10,11 \\
24,25,26 \\
27,28\end{array}$ \\
\hline & Managerial & $\begin{array}{l}\text { Forest gaps must be } \\
\text { created }>122 \mathrm{~m} \text { from } \\
\text { any fish-bearing } \\
\text { stream. }\end{array}$ & $\begin{array}{l}\text { Dictated by the Northwest Forest Plan } \\
\text { USDA Late-Successional Reserve } \\
\text { Guidelines. }\end{array}$ & 48 \\
\hline \multirow[t]{2}{*}{$\begin{array}{l}\text { Proximity to } \\
\text { Roads }\end{array}$} & Ecological & $\begin{array}{l}\text { Forest gaps should be } \\
\text { created a minimum of } \\
350 \mathrm{~m} \text { from major } \\
\text { roadways (all highways } \\
\text { and scenic byways) } \\
\text { though locations }>1.6 \\
\mathrm{~km} \text { should be favored. }\end{array}$ & $\begin{array}{l}\text { Studies have shown that roads } \\
\text { negatively affect bat activity and species } \\
\text { richness as well as cause direct mortality } \\
\text { through vehicle collisions. Road edge } \\
\text { effects extend at least } 350 \mathrm{~m} \text { from the } \\
\text { roadway and may pervade up to } 1.6 \mathrm{~km} \\
\text { into forest stands. }\end{array}$ & $\begin{array}{l}29,30,31 \\
32,33,34\end{array}$ \\
\hline & Managerial & $\begin{array}{l}\text { Forest gaps should be } \\
\text { created }>30 \mathrm{~m} \text { from all } \\
\text { roads. }\end{array}$ & $\begin{array}{l}\text { US Forest Service ecologists recommend } \\
\text { this } 30 \mathrm{~m} \text { buffer to avoid the spread of } \\
\text { invasive plant species. }\end{array}$ & $\begin{array}{l}\text { pers. } \\
\text { comm. }\end{array}$ \\
\hline \multirow{2}{*}{$\begin{array}{c}\text { Regenerating } \\
\text { Plant } \\
\text { Structure }\end{array}$} & Ecological & $\begin{array}{l}\text { Forest gaps should } \\
\text { preferentially be } \\
\text { created in salmonberry, } \\
\text { salal, or rhododendron } \\
\text { plant association zones. }\end{array}$ & $\begin{array}{l}\text { As dense shrubs such as salmonberry, } \\
\text { salal, and rhododendrons will be the } \\
\text { colonizing species after gap creation, } \\
\text { this will delay the regeneration of trees } \\
\text { and prolong the life of the gap. }\end{array}$ & $\begin{array}{c}35,36,37 \\
38\end{array}$ \\
\hline & Managerial & $\begin{array}{l}\text { Forest gaps should } \\
\text { preferentially be } \\
\text { created in salmonberry, } \\
\text { salal, or rhododendron } \\
\text { plant association zones. }\end{array}$ & $\begin{array}{l}\text { Forest gaps will not be maintained by } \\
\text { management. As described above, the } \\
\text { dense shrubs will delay tree } \\
\text { regeneration and prolong the life of the } \\
\text { gap. }\end{array}$ & 48 \\
\hline Elevation & Ecological & $\begin{array}{l}\text { Forest gaps should be } \\
\text { created at elevations } \\
<700 \mathrm{~m} \text { to minimize } \\
\text { distances between }\end{array}$ & $\begin{array}{l}\text { Regional studies have shown that } \\
\text { reproductive females roost at lower } \\
\text { elevations than males and } \\
\text { nonreproductive females. Research has }\end{array}$ & $\begin{array}{l}1,18,23 \\
39,40,41 \\
42,43,44 \\
45,46,47\end{array}$ \\
\hline
\end{tabular}




\begin{tabular}{|c|c|c|c|c|}
\hline & & $\begin{array}{l}\text { maternity roosts and } \\
\text { foraging grounds. }\end{array}$ & $\begin{array}{l}\text { also shown that foraging activity is } \\
\text { greater at elevations }<1,000 \mathrm{~m} \text {. }\end{array}$ & \\
\hline Stand Age & Managerial & $\begin{array}{l}\text { Forest gaps may only be } \\
\text { created within stands } \\
<80 \text { years old. }\end{array}$ & $\begin{array}{l}\text { Dictated by the Northwest Forest Plan } \\
\text { USDA Late-Successional Reserve } \\
\text { Guidelines. }\end{array}$ & 48 \\
\hline $\begin{array}{l}\text { Invasive } \\
\text { Species }\end{array}$ & Managerial & $\begin{array}{l}\text { Forest gaps should not } \\
\text { be created in areas } \\
\text { known to contain } \\
\text { invasive plant species. }\end{array}$ & $\begin{array}{l}\text { By avoiding areas already invaded, the } \\
\text { chance of spreading invasive plant } \\
\text { species is decreased. }\end{array}$ & $\begin{array}{l}\text { pers. } \\
\text { comm. }\end{array}$ \\
\hline $\begin{array}{l}\text { Landslide } \\
\text { Potential }\end{array}$ & Managerial & $\begin{array}{l}\text { Forest gaps should be } \\
\text { created in areas with } \\
\text { low or moderate } \\
\text { landslide potential. } \\
\text { Areas with high or very } \\
\text { high landslide potential } \\
\text { should be avoided. }\end{array}$ & $\begin{array}{l}\text { Creating forest gaps in areas with } \\
\text { greater soil stability will avoid } \\
\text { unintentional triggering of landslides. }\end{array}$ & $\begin{array}{l}\text { pers. } \\
\text { comm. }\end{array}$ \\
\hline $\begin{array}{l}\text { Proximity to } \\
\text { Forest } \\
\text { Boundaries }\end{array}$ & Ecological & $\begin{array}{l}\text { Forest gaps should be } \\
\text { created }>1 \mathrm{~km} \text { from } \\
\text { forest boundaries that } \\
\text { abut actively harvested } \\
\text { forest lands. }\end{array}$ & $\begin{array}{l}\text { Many public and private lands adjacent } \\
\text { to the Siuslaw NF are actively harvested } \\
\text { and forest gaps within reasonable } \\
\text { distance are available to bats residing } \\
\text { around forest boundaries. Gaps created } \\
\text { in the interior of the Siuslaw NF are } \\
\text { better positioned to promote bat } \\
\text { activity. }\end{array}$ & $\begin{array}{c}\text { pers. } \\
\text { comm. }\end{array}$ \\
\hline \multicolumn{5}{|c|}{$\begin{array}{l}\text { References: (1) Grindal \& Brigham, } 1998 \text { (2) Brooks, Loeb \& Gerard, } 2017 \text { (3) Menzel et al., } 2002 \text { (4) Ford et al., } \\
2005 \text { (5) Fukui et al., } 2011 \text { (6) Patriquin \& Barclay, } 2003 \text { (7) Hogberg, Patriquin \& Barclay, } 2002 \text { (8) Luszcz \& } \\
\text { Barclay, } 2016 \text { (9) Kalcounis et al., 1999 (10) Zabel \& Anthony, } 2003 \text { (11) Geggie \& Fenton, } 1985 \text { (12) Kurta \& } \\
\text { Baker, } 1990 \text { (13) Brigham \& Fenton, } 1985 \text { (14) Swingen et al., } 2018 \text { (15) Tuttle, } 1976 \text { (16) Henry et al., } 2002 \text { (17) } \\
\text { Rainho \& Palmeirim, } 2011 \text { (18) Erickson \& West, } 2003 \text { (19) Fellers \& Pierson, } 2002 \text { (20) Erickson \& West, } 1995 \\
\text { (21) Arnett \& Hayes, } 2009 \text { (22) Perkins \& Cross, } 1988 \text { (23) Thomas, } 1988 \text { (24) Brooks, } 2009 \text { (25) Menzel et al., } \\
2005 \text { (26) Weller \& Zabel, 2001 (27) Gellman \& Zielinski, } 1996 \text { (28) Racey \& Swift, } 1985 \text { (29) Kitzes \& } \\
\text { Merenlender, } 2014 \text { (30) Medinas et al., 2019) (31) Claireau et al., 2019 (32) Berthinussen \& Altringham, } 2011 \\
\text { (33) Berthinussen, 2013 (34) Fensome \& Mathews, } 2016 \text { (35) Hemstrom \& Logan, } 1986 \text { (36) Furlonger, Deward } \\
\text { \& Fenton, } 1987 \text { (37) Froidevaux et al., } 2016 \text { (37) Ober \& Hayes, } 2008 \text { (38) Morris, Miller \& Kalcounis-Rueppell, } \\
2010 \text { (39) Grindal, Morissette, \& Brigham, 1999 (40) Barclay, } 1991 \text { (41) Krusic et al., 1996 (42) Baker \& Lacki, } \\
2004 \text { (43) Brooks et al., } 2017 \text { (44) Grindal, } 1995 \text { (45) Grindal } 1996 \text { (46) Fenton et al., 1980 (47) Cryan, Bogan, \& } \\
\text { Altenbach, } 2000 \text { (48) USDA Forest Service, } 1994\end{array}$} \\
\hline
\end{tabular}

\section{Parameters in Need of Further Research}

The above list of gap parameters is by no means comprehensive; there are other potentially influential gap parameters that require additional consideration to understand how they impact bat activity. The above gap parameters were prioritized due to their influence on habitat structure and their importance in coastal forests of the Pacific Northwest. Several high priority parameters in need of future investigation are discussed below. While these parameters were not included in the case study of the 
Siuslaw NF, they may be important to consider when planning the creation of artificial gaps in the future when more information regarding these parameters is made available.

\section{Insect Availability}

While the impact of certain gap parameters on insect availability and bat activity has been discussed throughout this document, there are still many questions regarding insect-bat dynamics of the Pacific Northwest that require additional attention and study. Perhaps the most important area of research is to better understand the strength of influence that prey availability has over bat behavior. As noted in Chapter 2, results of several studies conducted in the Pacific Northwest region have been conflicting; some results show that bat activity is positively correlated with insect availability (Kalcounis \& Brigham, 1995; Tibbels \& Kurta, 2003; Brooks et al., 2017) while others have found no effect (Grindal \& Brigham, 1999; Obrist et al., 2011; Lunde \& Harestad, 1986). Better characterization of how insect availability impacts foraging behavior of bats would provide insight as to how much preference should be given to optimizing gap parameters according to insect needs when planning artificial gap creation for the benefit of bats.

When assuming that bats adhere to the optimal foraging theory (Stephen \& Krebs, 1986) and that prey availability does play a role in determining their selection of foraging grounds, more questions regarding insect communities arise. For example, little is known about how gap size influences insect availability other than results from Brooks, Loeb, and Gerard (2017) and Grindal and Brigham (1988). Future research should also explore how forest type shapes insect communities and whether this has any impacts on bat habitat selection as suggested by Kalcounis et al. (1999). A couple additional questions regarding the impact of gap parameters on insect availability are addressed in the remainder of this section. Better characterization of the relative influence of insect availability on bat behavior as well as the impact of gap parameters on insect communities is necessary in order to utilize insect availability as a measure to guide artificial gap creation.

\section{Wind}

Several studies have shown that high winds can negatively impact bat activity. A study conducted in Delaware at woodland and farmland sites found that overall bat activity was negatively correlated with wind speed (Wolcott \& Vulinec, 2012). Research conducted in Mexico found that activity of some Phyllostomidae spp. was significantly lower on nights with strong winds. The activity of a small nectivorous species, Godman's long-tailed bat (Choeroniscus godmani), was high on nights when wind speeds were $<24 \mathrm{~km}$ per hour but activity was significantly decreased when wind speeds reached 29-38 km per hour (Santos-Moreno, Velásquez, \& Martinez, 2010). However, the activity of three larger-bodied, frugivorous Artibeus spp. was not impacted by wind speeds (Santos-Moreno, Velásquez, \& Martinez, 2010). Mist netting surveys in Utah captured California myotis individuals on nights when wind speeds were $<6 \mathrm{~km}$ per hour, while pallid bats (Antrozous pallidus) and spotted bats were active on nights with wind speeds $13-15 \mathrm{~km}$ per hour (Ruffner et al., 1979).

As discussed briefly in Chapter 2, one of the many theories explaining why bats forage around treelines at the edges of forest gaps is that the edges shield bats from wind and can decrease energy 
expenditure when foraging (Norberg \& Rayner, 1987; Norberg, 1990; Verboom \& Spoelestra, 1999; Racey and Swift 1985; Verboom 1998; Walsh \& Harris, 1996). As demonstrated by the results of previous research, it is highly possible that bats may avoid foraging in open areas that experience high wind speeds to conserve energy. Thus, it may be important to create artificial gaps in areas that are normally devoid of strong winds. This parameter could be especially important in coastal areas like the Siuslaw NF where strong winds can be prevalent (Hemstrom \& Logan, 1986).

However, more research is needed to understand the impacts of wind on bats in order to use this parameter to guide artificial gap creation. Another hypothesis as to why bats forage at gap edges is that wind may push insects to congregate at leeward gap edges making these edges particularly dense in prey (Lewis, 1970; Whitaker, Carroll \& Montevecchi, 2000); however, this phenomenon has not been documented in some studies (Thomas, 1988; Furlonger, Deward \& Fenton, 1987). It is possible that bats do not avoid gaps that experience strong winds for energy conservation purposes but because there is no insect prey available within these gap interiors, only at gap edges.

No studies have been conducted in the Pacific Northwest region to characterize how regional bat communities respond to wind. It is likely that smaller-bodied clutter-adapted species are more sensitive to high winds than heavier open-adapted species like the hoary bat and silver-haired bat as was seen in results of Santos-Moreno, Velásquez, \& Martinez (2010). Additionally, very few existing studies have quantified thresholds at which wind speeds negatively impact bat activity. Future research may show that wind speed is a highly important parameter necessary for the planning of artificial gap creation for the benefit of bats.

\section{Plant Composition, Slope Aspect, and Soil Type}

While the structure of plant communities is already known to influence bat activity, less is known about the impacts of plant community composition in forest gaps. Studies exploring the impact of forest type largely consider only dominant tree species and do not quantify impacts of shrub and understory community composition. A study conducted within riparian areas of the Coast Range of Oregon demonstrated that riparian plant composition affected insect abundance and community composition as well as bat activity (Ober, 2006). As was discovered by Ober (2006), it is likely that plant composition in artificial forest gaps would influence bat activity and that different bat species would respond in a varied manner.

The structure and composition of plant communities are influenced by a whole suite of environmental factors. As such, there can be interplay between many different potential gap parameters. Among those already discussed, elevation, forest type, and regenerating plant structure are all intertwined; elevation can influence forest type and forest type can influence regenerating plant structure. However, other potentially important and related parameters including slope aspect and soil type were not highlighted by the above discussion. Slope aspect can have a significant influence over the amount of solar insolation received by an area impacting soil moisture and temperature which can have dramatic implications for plant communities (Qin et al., 2019). Properties of different soil types including nutrient availability and porosity can influence where certain plant species can grow and compete 
against other vegetation (Quan \& Liang, 2016). Future research is needed to first understand the impacts of plant community composition on bat activity as well as the relative importance of additional environmental factors such as slope aspect and soil type.

\section{Connectivity via Commuting Pathways}

While the proximity of resources is addressed in the discussion of gap parameters above, connectivity of resources also likely impacts how frequently bats utilize forest gaps. As previously mentioned in Chapter 2, forest roads with infrequent vehicular activity (Fenton \& Bell, 1979; Brigham, Aldridge \& Mackey, 1992; Grindal \& Brigham, 1998; Krusic et al., 1996; Menzel et al., 2002; Brooks, 2009; Wai-Ping \& Fenton, 1989) and open space above streams (Grindal, Morissette, \& Brigham, 1999; Brooks, 2009; Thomas, 1988; Menzel et al., 2005; Owen et al., 2004; Anthony \& Kunz, 1977; Racey \& Swift, 1985; Jones \& Rayner, 1988; Brigham, 1991; Saunders \& Barclay, 1992; Barclay \& Brigham, 1994; Rautenbach, Whiting \& Fenton. 1996; Walsh \& Harris, 1996; Vaughan, Jones \& Harris, 1997; Wilkinson \& Barclay, 1997) act as movement corridors. Bats have been documented regularly using the same commuting pathways on a nightly basis (Wai-Ping \& Fenton, 1989; Audet, 1990). Thus, it is possible that positioning artificial forest gaps near small roadways and stream corridors could be beneficial; bats may more readily discover and use a newly created forest gap situated nearby regular commuting corridors and known landmarks.

The assumption that bat activity would be greater in gaps placed in close proximity to commuting pathways has not been tested and specific distances at which gaps should be from commuting pathways that will be most beneficial for bats have not been identified. Additionally, existing literature does not provide a definitive description of what types of forest roads are beneficial to bats (e.g. road width, traffic volumes, road surface type, etc.) or thresholds at which different species are either attracted to or repelled from these roads. Future research characterizing roads used as commuting pathways and quantifying bat activity within forest gaps at varied distances from known commuting pathways is necessary to understand if resource connectivity should be taken into consideration when planning artificial gap creation.

\section{CHAPTER 4: Case Study of the Siuslaw NF: Identifying Locations for Gap Creation}

\section{Methods}

Once important gap parameters and their associated recommendations have been determined for a forest in question, ideal locations for gap creation must be identified using geospatial data and tools. The weighted overlay approach is a relatively simple and highly accessible method for quantifying site suitability by combining weighted raster data layers. This section lists the methods for how the weighted overlay approach was applied to the case study of the Siuslaw NF. Analysis was conducted 
using Esri ArcGIS Pro 2.6.0; the following methods reflect language used in this program, though these methods can easily be adapted for alternative GIS programs. Datasets and their sources used in the case study of the Siuslaw NF can be seen in Table 6.

Table 6: Datasets and their sources used to conduct a weighted overlay analysis of the Siuslaw NF to identify ideal locations for artificial gap creation for the benefit of bats.

\begin{tabular}{|c|c|c|c|c|}
\hline Dataset & Data Type & Source & Online Access & Use \\
\hline $\begin{array}{l}\text { National } \\
\text { Forest System } \\
\text { Land Units }\end{array}$ & $\begin{array}{c}\text { Vector } \\
\text { (polygons) }\end{array}$ & $\begin{array}{l}\text { FSGeodata } \\
\text { Clearinghouse }\end{array}$ & $\begin{array}{l}\text { https://data.fs.usda.gov/g } \\
\text { eodata/edw/datasets.php } \\
\text { ?dsetCategorv=boundaries }\end{array}$ & $\begin{array}{l}\text { Used to isolate the boundaries of the } \\
\text { Siuslaw NF. }\end{array}$ \\
\hline $\begin{array}{c}\text { Oregon } \\
\text { Statewide } \\
\text { Habitat Map } \\
\text { (2018) }\end{array}$ & Raster & $\begin{array}{l}\text { Oregon } \\
\text { Explorer }\end{array}$ & $\begin{array}{l}\underline{\text { https://spatialdata.oregon }} \\
\text { explorer.info/geoportal/de } \\
\underline{\text { tails;id=4f271c43605a48f3 }} \\
\underline{\text { b1edf89f35f0db29 }}\end{array}$ & $\begin{array}{l}\text { Used to identify locations of suitable } \\
\text { roosting habitat (late- successional } \\
\text { and old-growth stands } \geq 120 \text { years } \\
\text { old). }\end{array}$ \\
\hline $\begin{array}{l}\text { Oregon } \\
\text { Hydrography } \\
\text { (2012) }\end{array}$ & $\begin{array}{l}\text { Vector } \\
\text { (lines and } \\
\text { polygons) }\end{array}$ & $\begin{array}{l}\text { Oregon } \\
\text { Explorer }\end{array}$ & $\begin{array}{l}\frac{\text { https://spatialdata.oregon }}{\text { explorer.info/geoportal/de }} \\
\underline{\text { tails;id=c56af1d4a19040e }} \\
\underline{\text { 98e25c05abc5e690f }}\end{array}$ & $\begin{array}{l}\text { Used to create buffers around all } \\
\text { water bodies according to NWFP } \\
\text { guidelines to avoid creating gaps } \\
\text { within Riparian Reserves. Used to } \\
\text { identify potential sources of drinking } \\
\text { water. }\end{array}$ \\
\hline $\begin{array}{l}\text { Oregon } \\
\text { Transportation } \\
\text { Network } \\
\text { (2019) }\end{array}$ & $\begin{array}{l}\text { Vector } \\
\text { (lines) }\end{array}$ & $\begin{array}{l}\text { Oregon } \\
\text { Explorer }\end{array}$ & $\begin{array}{l}\frac{\text { https://spatialdata.oregon }}{\text { explorer.info/geoportal/de }} \\
\underline{\text { tails;id=161c9568b5584a6 }} \\
\underline{\underline{\text { d9ff9b019da09f034 }}}\end{array}$ & $\begin{array}{l}\text { Used to create buffers around } \\
\text { highways and all other road types to } \\
\text { avoid negative road effects on bat } \\
\text { activity and to avoid the unnecessary } \\
\text { spread of invasive plant species in } \\
\text { gaps. }\end{array}$ \\
\hline $\begin{array}{l}\text { Oregon Coast } \\
\text { Plant } \\
\text { Association } \\
\text { Groups }\end{array}$ & Raster & $\begin{array}{l}\text { Ecoshare } \\
\text { (USDA Forest } \\
\text { Service/BLM) }\end{array}$ & $\begin{array}{l}\frac{\text { https://ecoshare.info/200 }}{9 / 12 / 07 / \text { or-coast-plant-ass }} \\
\frac{\text { n-groups/ }}{\text { gros }}\end{array}$ & $\begin{array}{l}\text { Used to identify areas where dense } \\
\text { shrubs are expected to be early } \\
\text { colonizers after gap creation in order } \\
\text { to maximize the life of the gap. }\end{array}$ \\
\hline $\begin{array}{l}\text { Digital } \\
\text { Elevation } \\
\text { Model }\end{array}$ & Raster & $\begin{array}{l}\text { The National } \\
\text { Map (USGS) }\end{array}$ & $\begin{array}{l}\text { https://viewer.nationalma } \\
\text { p.gov/basic/\#/ }\end{array}$ & $\begin{array}{l}\text { Used to characterize elevation in } \\
\text { order to prioritize areas at low } \\
\text { elevations for gap creation. }\end{array}$ \\
\hline $\begin{array}{l}\text { Siuslaw NF } \\
\text { Stand Age }\end{array}$ & $\begin{array}{c}\text { Vector } \\
\text { (polygons) }\end{array}$ & $\begin{array}{l}\text { USDA Forest } \\
\text { Service }\end{array}$ & $\begin{array}{c}\mathrm{N} / \mathrm{A} \\
\text { (pers. comm.) }\end{array}$ & $\begin{array}{l}\text { Used to identify stands }<80 \text { years } \\
\text { old; the only stand age that a gap } \\
\text { can be created in. }\end{array}$ \\
\hline $\begin{array}{l}\text { Siuslaw NF } \\
\text { Invasive Plants }\end{array}$ & $\begin{array}{l}\text { Vector } \\
\text { (polygons) }\end{array}$ & $\begin{array}{l}\text { USDA Forest } \\
\text { Service }\end{array}$ & $\begin{array}{c}\mathrm{N} / \mathrm{A} \\
\text { (pers. comm.) }\end{array}$ & $\begin{array}{l}\text { Used to identify areas invaded by } \\
\text { non-native plants that should be } \\
\text { avoided when planning gap creation. }\end{array}$ \\
\hline $\begin{array}{l}\text { Siuslaw NF } \\
\text { Landslide } \\
\text { Potential }\end{array}$ & $\begin{array}{l}\text { Vector } \\
\text { (polygons) }\end{array}$ & $\begin{array}{l}\text { USDA Forest } \\
\text { Service }\end{array}$ & $\begin{array}{c}\mathrm{N} / \mathrm{A} \\
\text { (pers. comm.) }\end{array}$ & $\begin{array}{l}\text { Used to prioritize locations with low } \\
\text { landslide risk and to avoid gap } \\
\text { creation in high risk areas. }\end{array}$ \\
\hline
\end{tabular}




\begin{tabular}{|c|c|c|c|c|}
\hline $\begin{array}{l}\text { GNN LEMMA } \\
\text { (2017) }\end{array}$ & Raster & $\begin{array}{c}\text { Oregon State } \\
\text { University }\end{array}$ & $\begin{array}{l}\text { https://lemmadownload.f } \\
\underline{\text { orestry.oregonstate.edu/in }} \\
\underline{\text { dex }}\end{array}$ & $\begin{array}{l}\text { Used to identify areas with }<10 \% \\
\text { canopy cover which likely already } \\
\text { function as forest gaps. }\end{array}$ \\
\hline
\end{tabular}

\section{Dataset Preparation}

The below methods describe the preparation of datasets used to address each important gap parameter in the same order as they are listed in Table 5. Methods for dataset preparation varied depending upon whether the original dataset was a raster or vector. In order to be useful in the weighted overlay approach, most rasters had to be reclassified using the "reclassify" tool to isolate categories important to gap creation and to assign those categories unique numerical values. It was necessary that these important categories be distinguishable from other categories so that they could be weighted accordingly in the "weighted overlay" tool. Vector datasets had to be converted to rasters using the "polygon to raster" tool and most of these newly converted rasters also had to be reclassified.

Please note that gap size, gap shape, and forest type parameters were not given any special consideration in the analysis of Siuslaw NF. These parameters may require additional attention if this approach is applied to another forest. Though not by design, all original raster datasets used in this analysis had a resolution of $30 \times 30 \mathrm{~m}$, a common cell size for environmental data. This was fortuitous as a $30 \times 30 \mathrm{~m}$ forest gap is of ecologically relevant size for bats. Therefore, when any vector dataset was converted to a raster, cell size was specified to be $30 \times 30 \mathrm{~m}$ and no further analysis was needed to address the gap size parameter. As raster cells are square and a gap of any preferred shape can be created within that area, gap shape was not given any further consideration. As there are no clearly defined forest type preferences of bats in coastal forests of Oregon, the forest type parameter was not considered in this analysis.

To start the analysis, polygons representing the shape of the Siuslaw NF were obtained from the National Forest System Land Units dataset. As reliable spatial snag data was unavailable for the Siuslaw $\mathrm{NF}$, late-successional and old-growth forest stands $\geq 120$ years old were used as a proxy to represent suitable roosting habitat. The Oregon Statewide Habitat Map raster was first clipped to the extent of the Siuslaw NF using the "clip raster" tool. Then the raster was reclassified using the "reclassify" tool so that late-successional and old-growth stands $\geq 120$ years old were assigned an identifiable numerical value while forested stands $<120$ years old and all other habitat types were assigned a different value.

After suitable roosting habitat had been isolated from all other habitat types in the Oregon Statewide Habitat Map raster, forested areas within the Siuslaw NF $>1 \mathrm{~km}$ from roosting habitat needed to be identified. To achieve this, the newly reclassified roosting habitat raster was converted into polygons using the "raster to polygon" tool then a $1 \mathrm{~km}$ buffer was drawn around the polygons using the "buffer" tool. Upon visual inspection, no forested location within the Siuslaw NF fell outside of the $1 \mathrm{~km}$ buffers. Thus, it was determined that the creation of an artificial forest gap within any forested portion of the Siuslaw NF would accommodate the suggested recommendation of gaps being created $<1 \mathrm{~km}$ away from suitable roosting habitat. As such, the polygon buffers were not converted back to a raster dataset 
and used in the final weighted overlay analysis. However, if this approach were to be applied to a different forest, this data layer should be incorporated into a weighted overlay analysis if any forested location within the boundaries of the study area in question are $>1 \mathrm{~km}$ away from suitable roosting habitat.

In order to avoid creating artificial gaps in Riparian Reserves protected by the NWFP, a $122 \mathrm{~m}$ buffer polygon was drawn around all water bodies represented in the Oregon Hydrography vector dataset. The $122 \mathrm{~m}$ waterbody buffer polygons were converted to a raster dataset and then clipped to the extent of the Siuslaw NF. The $122 \mathrm{~m}$ waterbody buffer raster was reclassified to assign cells associated with the buffers an identifiable numerical value.

To avoid creating gaps in too close proximity to roadways that could negatively impact bat activity and could cause the unnecessary spread of invasive plant species, buffers were drawn around roadway data provided by the Oregon Transportation Network (2019) vector dataset according to road type. Highways and scenic byways were isolated from all other road types then a $350 \mathrm{~m}$ buffer polygon and a $1.6 \mathrm{~km}$ buffer polygon were drawn around line vectors representative of the major roadways. These highway buffer polygons were then converted to a raster and reclassified to assign cells within the $350 \mathrm{~m}$ buffer and cells within the $1.6 \mathrm{~km}$ buffer identifiable numerical values. A second set of buffer polygons, only $30 \mathrm{~m}$ wide, was drawn around all remaining road types. These polygons were also converted to a raster and reclassified to assign cells within the $30 \mathrm{~m}$ buffer an identifiable numerical value.

To prioritize locations where dense shrub species are expected to be early colonizers after gap creation and lengthen the functional life of the gap for bats, the Oregon Coast Plant Association Groups raster dataset was used. Shrub species given highest priority include salmonberry, salal, and Oregon grape while Rhododendron spp. and red huckleberry were given medium priority. The Oregon Coast Plant Association Groups raster was clipped to the extent of the Siuslaw NF. As each plant association category was already assigned a unique value according to the plant association it represented, no further manipulation was necessary.

In order to prioritize locations at low elevations for gap creation to accommodate the needs of reproductive females, Digital Elevation Models (DEM) from the US Geological Survey were used. Six individual DEM raster datasets were required to cover the entire extent of the Siuslaw NF. All six of the DEMs were mosaicked together to form one raster using the "mosaic" tool. This raster was then clipped to the extent of the Siuslaw NF. The elevation raster was reclassified into three different categories $(<700$ $\mathrm{m}, 700-1,000 \mathrm{~m}$, and >1,000 m) and each category was assigned a unique identifiable numerical value.

To identify forest stands aged $<80$ years old, the only stands in which artificial gaps can be created in Late Successional Reserves according to the NWFP, a vector dataset showing all such stands in the Siuslaw NF as polygons was obtained from the USDA Forest Service. The polygons were converted into a raster dataset and then clipped to the extent of the Siuslaw NF. The raster dataset was reclassified to assign cells associated with stands $<80$ years old an identifiable numerical value. 
To avoid the unnecessary spread of invasive plant species when creating artificial gaps, a second shapefile was obtained from the USDA Forest Service that showed locations in the Siuslaw NF known to be invaded by nonnative plants. The invasive plant polygons were converted to a raster dataset then reclassified to assign cells associated with nonnative plants an identifiable numerical value. As the original shapefile was already specific to the Siuslaw NF, it did not need to be clipped to the extent of the forest's boundaries.

To prevent gaps from being created in areas prone to landslides, a third shapefile showing landslide risk as polygons was obtained from the USDA Forest Service. The landslide polygons were converted to a raster dataset then clipped to the extent of the Siuslaw NF. The landslide risk raster was not reclassified and all cells retained original values that corresponded with designated levels of landslide risk.

To prioritize locations within the interior of the Siuslaw NF for gap creation rather than locations near the boundaries of the forest, another buffer was created. Using the Siuslaw NF boundaries polygon, a $1 \mathrm{~km}$ buffer polygon was drawn only within the inside of forest boundaries. At locations where the Siuslaw NF abuts the Pacific Ocean and where it abuts outside forested land devoid of clear-cut gaps, the buffer was removed using editing tools. The edited buffer polygon was then converted to a raster and reclassified to assign cells within the $1 \mathrm{~km}$ buffer an identifiable numerical value.

Though not addressed in Table 3, one final parameter was taken into consideration. To avoid prioritizing areas devoid of tree canopies that already function as forest gaps, a canopy cover layer from the 2017 Gradient Nearest Neighbor Landscape Ecology, Modeling, Mapping and Analysis (GNN LEMMA) dataset was evaluated. The canopy cover raster was reclassified to assign cells with $<10 \%$ canopy cover an identifying numerical value while all other cells with $\geq 10 \%$ canopy cover were assigned a separate value.

\section{Weighted Overlay Analysis}

After all data layers were prepared they were fed into the "weighted overlay" tool. Each layer was assigned an overall weight and each category within the layer was assigned a score of " 1 ", " 2 ", " 3 ", or "restricted". The overall weights and category scores for each data layer used in the analysis of the Siuslaw NF can be seen below in Table 5. If a category's conditions were ideal, moderate, or poor for artificial gap creation, it was assigned a score of " 3 ", " 2 ", or " 1 " respectively. For example, the elevation category of " $<700 \mathrm{~m}$ " is ideal for gap creation and was assigned a score of " 3 " while the category of "700-1,000 m" is of moderate suitability and was assigned a score of " 2 " and the category of " $>1,000 \mathrm{~m}$ " is of poor suitability and was assigned a score of " 1 ". If the category's condition was completely unsuitable for gap creation, it was given a score of "restricted". For example, artificial gaps cannot be created in stands $\geq 80$ years old so the stand age category of " $\geq 80$ years old" was given a score of "restricted". These scores were determined according to gap parameter recommendations in Table 3.

However, the overall weight of each data layer was not necessarily dictated by information in Table 3. Some data layers including "Proximity to Water Bodies", "Proximity to Highways", "Proximity to 
Other Roads", and "Tree Canopy Presence" were all assigned an overall weight of $1 \%$. Categories for these data layers were only assigned scores of "1" or "restricted" (Table 7); there was no gradient of suitability among these categories. As such, as long as the data layer was assigned an overall weight of at least $1 \%$, it was included in the analysis and cells with conditions that were assigned a score of "restricted" were considered completely unsuitable for gap creation. Therefore, these layers assigned an overall weight of $1 \%$ served their purpose and heavier overall weights could be given to layers that contained a range of suitabilities to yield a more accurate site suitability assessment.

The overall weight of data layers including "Landslide Risk", "Expected Regenerating Plant Species", "Elevation", "Invasive Plants", and "1 km Interior Forest Boundary Buffer" were assigned overall weights $>1 \%$. Categories within these data layers had a range of suitability and, as such, these data layers were assigned an overall weight according to their importance as indicated by Table 5 . The sum of overall weights for each data layer must add to 100.

Table 7: All data layers used for the final weighted overlay analysis of the Siuslaw NF and their respective overall weights as well as their corresponding categories and assigned values. A score of " 3 " represents ideal conditions for gap creation, a score of " 2 " represents moderate conditions, a score of " 1 " represents poor conditions, and a score of "restricted" represents unsuitable conditions.

\begin{tabular}{|c|c|c|c|c|c|}
\hline \multicolumn{3}{|c|}{ Landslide Risk Layer } & \multicolumn{3}{|c|}{ Plant Association Layer } \\
\hline \multicolumn{2}{|r|}{ Overall Weight: } & $15 \%$ & \multicolumn{2}{|r|}{ Overall Weight } & \multirow{2}{*}{$\begin{aligned} 28 \% \\
\text { Score }\end{aligned}$} \\
\hline Value & Layer Categories & Score & Value & Layer Categories & \\
\hline 1 & Low Risk & 3 & 901 & Sitka spruce/salal, mesic & 3 \\
\hline 2 & Moderate Risk & 2 & 902 & Sitka spruce/oxalis-swordfern, moist & 1 \\
\hline 3 & High Risk & 1 & 903 & Sitka spruce/salmonberry, wet & 3 \\
\hline 4 & Very High Risk & 1 & 991 & Sitka spruce/nonforest-wet & 1 \\
\hline 5 & Blank & 1 & \multirow{2}{*}{1407} & \multirow{2}{*}{ Douglas-fir/poison oak-warm often low elevation } & \multirow{2}{*}{1} \\
\hline NODATA & & 1 & & & \\
\hline \multicolumn{3}{|c|}{ Proximity to Water Bodies Layer } & 1452 & Douglas fir-black oak/poison oak (SW Oregon) & 1 \\
\hline & Overall Weight: & $1 \%$ & 1471 & Douglas-fir/nonforest-dry & 1 \\
\hline Value & Layer Categories & Score & \multirow{2}{*}{1609} & \multirow{2}{*}{$\begin{array}{l}\text { Grand fir/ocean spray-poison oak-westside low } \\
\text { elevation }\end{array}$} & \multirow{2}{*}{1} \\
\hline 0 & $<122 \mathrm{~m}$ & Restricted & & & \\
\hline 9 & $>122 \mathrm{~m}$ & 1 & \multirow{2}{*}{1903} & \multirow{2}{*}{$\begin{array}{l}\text { Western hemlock-warm (transitional to DFZ in } \\
\text { Oregon) }\end{array}$} & \multirow{2}{*}{1} \\
\hline NODATA & & Restricted & & & \\
\hline \multicolumn{3}{|c|}{ Elevation Layer } & & \multirow{2}{*}{$\begin{array}{l}\text { Western hemlock/swordfern-Oregongrape- salal, } \\
\text { mesic }\end{array}$} & \multirow[b]{2}{*}{3} \\
\hline & Overall Weight: & $15 \%$ & 1906 & & \\
\hline
\end{tabular}




\begin{tabular}{|c|c|c|c|c|c|}
\hline Value & Layer Categories & Score & 1907 & Western hemlock/swordfern, moist & 1 \\
\hline 1 & $<700 \mathrm{~m}$ & 3 & 1908 & Western hemlock/salmonberry, wet & 2 \\
\hline 2 & $700-1,000 \mathrm{~m}$ & 2 & 1909 & Western hemlock/Alaska huckleberry/oxalis & 2 \\
\hline 3 & $>1,000 \mathrm{~m}$ & 1 & \multirow{2}{*}{1910} & \multirow{2}{*}{$\begin{array}{l}\text { Western hemlock/devils club or skunk cabbage, } \\
\text { very wet }\end{array}$} & \multirow{2}{*}{1} \\
\hline NODATA & & 1 & & & \\
\hline \multicolumn{3}{|c|}{ Proximity to Highway Layer } & \multirow{2}{*}{1915} & \multirow{2}{*}{$\begin{array}{l}\text { Western hemlock/rhododendron, (Oregon Coast } \\
\text { Range) }\end{array}$} & \multirow{2}{*}{3} \\
\hline & Overall Weight: & $27 \%$ & & & \\
\hline Value & Layer Categories & Score & 1971 & Western hemlock/nonforest-dry & 1 \\
\hline 1 & $<350 \mathrm{~m}$ & Restricted & 1991 & Western hemlock/nonforest-wet & 1 \\
\hline 2 & $350-1,600 \mathrm{~m}$ & 1 & 2208 & Pacific silver fir/oxalis, high precipitation & 1 \\
\hline NODATA & $>1,600 \mathrm{~m}$ & 3 & 2291 & Pacific silver fir/nonforest-wet & 1 \\
\hline \multicolumn{3}{|c|}{ Stand Age Layer } & NODATA & & 1 \\
\hline & Overall Weight: & $1 \%$ & \multicolumn{3}{|c|}{ Tree Canopy Presence Layer } \\
\hline Value & Layer Categories & Score & & Overall Weight: & $5 \%$ \\
\hline 0 & $<80$ years old & 1 & Value & Layer Categories & Score \\
\hline 9 & $>80$ years old & Restricted & 0 & $>10 \%$ tree canopy & 3 \\
\hline \multicolumn{3}{|c|}{ Proximity to Other Roads Layer } & 1 & $<10 \%$ tree canopy & 1 \\
\hline & Overall Weight: & $1 \%$ & NODATA & & 3 \\
\hline Value & Layer Categories & Score & \multicolumn{3}{|c|}{1 km Perimeter Buffer Layer } \\
\hline 1 & $<30 \mathrm{~m}$ & Restricted & & Overall Weight: & $5 \%$ \\
\hline NODATA & $>30 \mathrm{~m}$ & 1 & Value & Layer Categories & Score \\
\hline \multicolumn{3}{|c|}{ Invasive Plants Layer } & 1 & Within $1000 \mathrm{~m}$ buffer & 1 \\
\hline & Overall Weight: & $1 \%$ & NODATA & Outside of $1000 \mathrm{~m}$ buffer & 3 \\
\hline Value & Layer Categories & Score & & & \\
\hline 1 & Invasives Present & Restricted & & & \\
\hline 2 & Invasives Not Present & 1 & & & \\
\hline NODATA & & 1 & & & \\
\hline
\end{tabular}




\section{Results and Discussion}

Resulting site suitability for the Hebo Ranger District can be seen below in Figure 7 and for the Central Coast Ranger District in Figure 8. Site suitability scores range from 0-3. Sites received a score of 0 where at least one data layer category was assigned as "restricted" (see Table 7); sites with a score of 0 represent areas that a gap absolutely cannot be created in. Sites with a score of 1 represent areas of poor suitability for gap creation but do not violate any management requirements. Sites with a score of 2 represent areas of moderate suitability for gap creation and sites with a score of 3 represent areas of ideal suitability. As previously mentioned, each cell is a size of $30 \times 30 \mathrm{~m}$ and a gap of ecologically relevant size for bats could be created in even a single cell (see Chapter 3 ).

$2.822 \%$ of the Siuslaw NF (approx. 17,894 acres) is suitable for gap creation; $0.4 \%$ of suitable locations received a score of $1,79.5 \%$ of suitable locations received a score of 2 , and $20.1 \%$ of suitable locations received a score of 3 (Table 8 ). The primary site characteristic which lowered suitability scores from 3 to 2 was plant association. Sites associated with salal, rhododendron, and salmonberry typically received a score of 3 while sites associated with oxalis and swordfern received a score of 2 (Figure 9). The distribution of the suitable sites among plant association groups is similar to that of the entire Siuslaw NF (Figure 10). Though not a prioritized plant association group, the greatest proportion of suitable sites were concentrated in the "Western hemlock/swordfern, moist" group due to the prominence of this particular plant association group within the forest (Figure 10). The greatest proportion of sites that received a score of 2 were located within the "Western hemlock/swordfern, moist" group (Figure 9). However, the greatest proportion of ideal sites (score of 3) were located within the "Western hemlock/swordfern-Oregon grape-salal, mesic" group which only makes up approximately $10 \%$ of the Siuslaw NF (Figure 9, Figure 10).

Table 8: Site suitability results of the weighted overlay analysis of the Siuslaw NF.

\begin{tabular}{|c|c|c|c|c|}
\hline Suitability for Gap Creation & Score & Map Color & Area of Siuslaw NF (acres) & \% of Siuslaw NF \\
\hline Not Suitable & 0 & & 616,366 & $97.18 \%$ \\
\hline Poor & 1 & & 74 & $0.012 \%$ \\
\hline Moderate & 2 & & 14,218 & $2.242 \%$ \\
\hline Ideal & 3 & & 3,602 & $0.568 \%$ \\
\hline
\end{tabular}




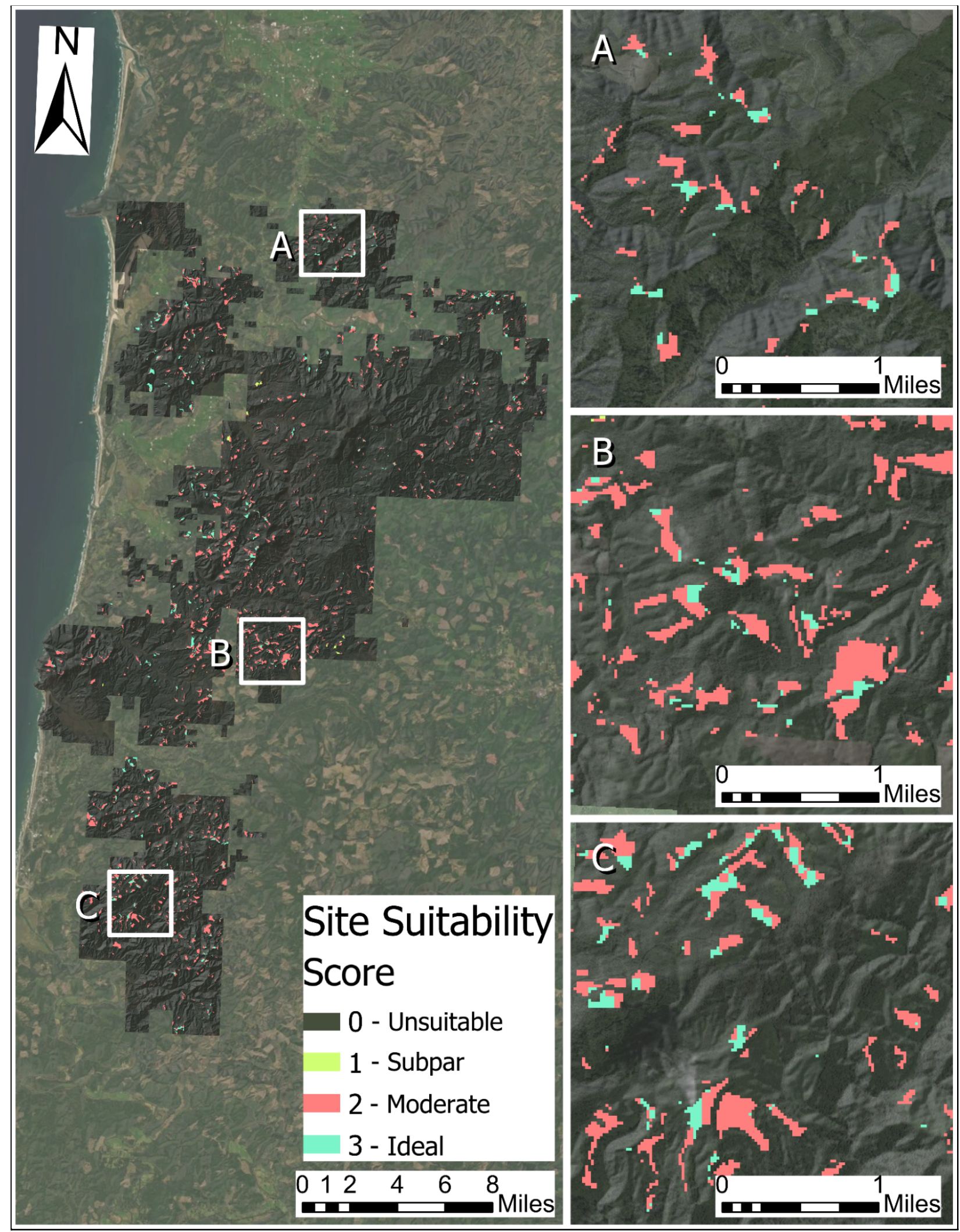

Figure 7: Results of the Siuslaw NF weighted overlay analysis for the Hebo Ranger District with three areas of interest for gap creation highlighted on the right. 


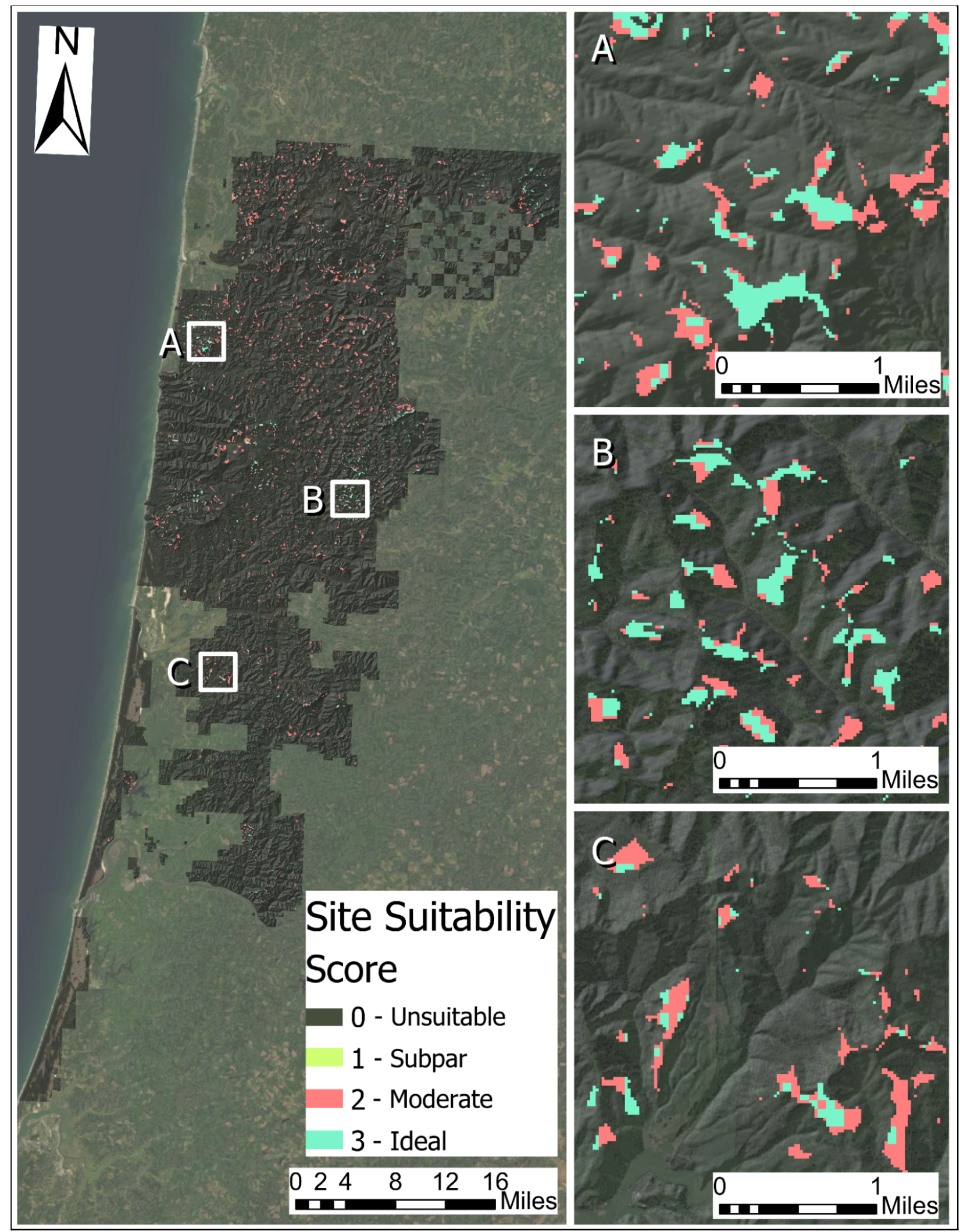

Figure 8: Results of the Siuslaw NF weighted overlay analysis for the Central Coast Ranger District with three areas of interest for gap creation highlighted on the right. 


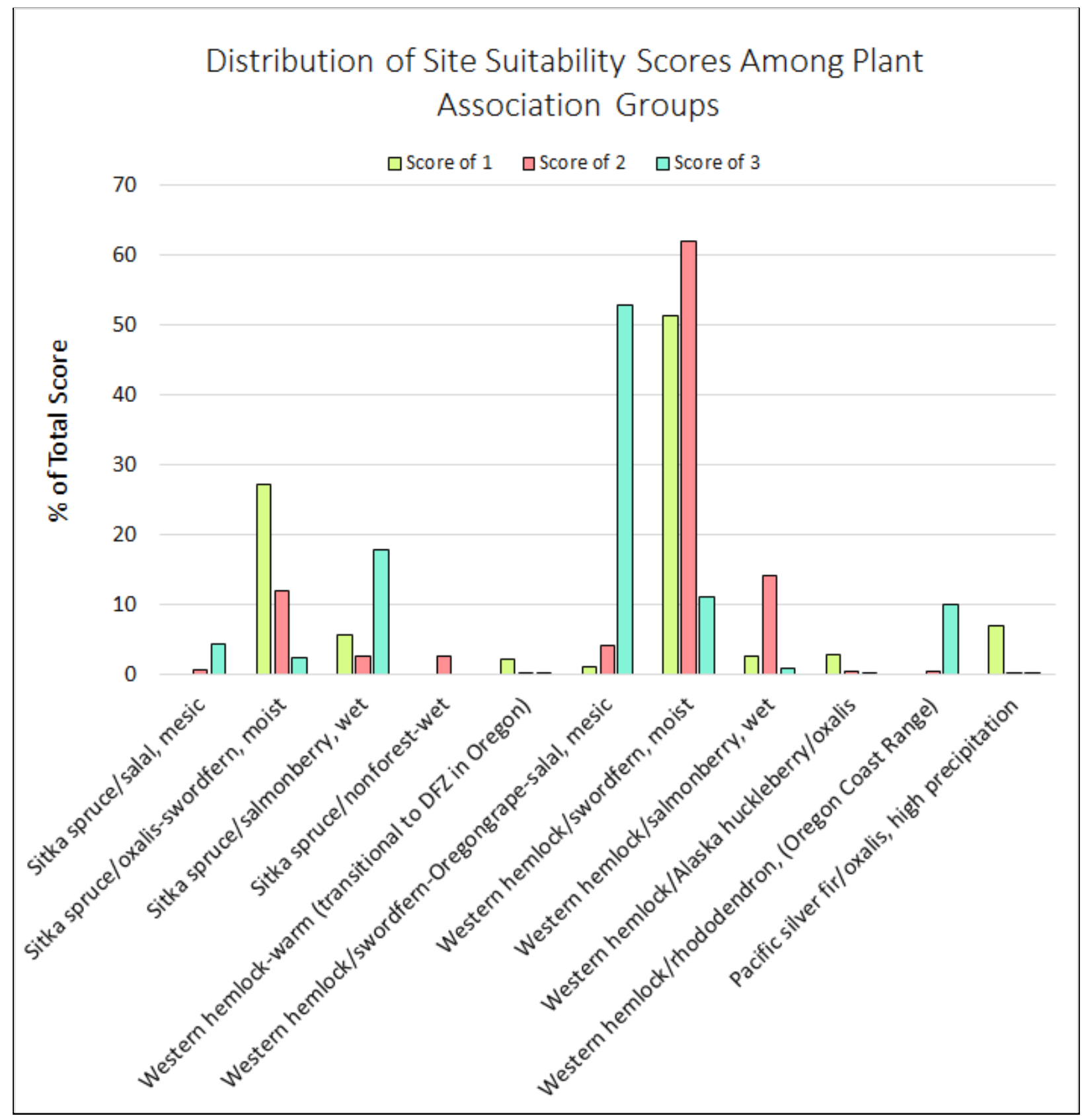

Figure 9: Distribution of suitable sites of gap creation scored as a 1, 2, or 3 according to their related plant association group. Plant association groups which made up $<1 \%$ of suitable sites excluded. 


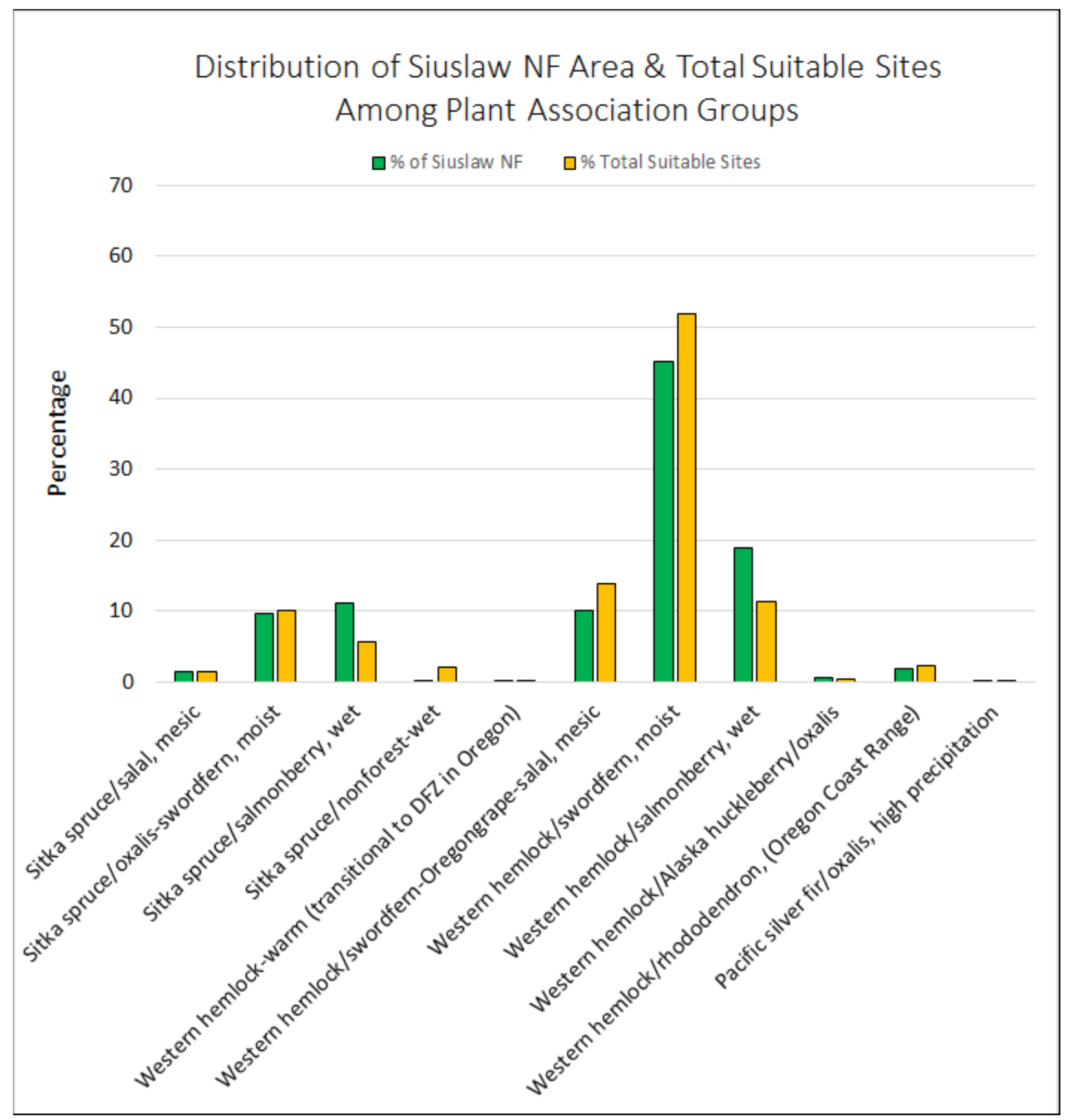

Figure 10: Distribution of the total area of the Siuslaw NF and total sites suitable for gap creation according to plant association groups. Plant association groups which made up $<1 \%$ of total suitable sites excluded.

A secondary site characteristic which had moderate influence over site suitability scores was elevation. Sites at elevations $<700 \mathrm{~m}$ typically received a suitability score of 3 while sites at elevations $>700 \mathrm{~m}$ typically received a suitability score of $2 ; 90.5 \%$ of all sites were at elevations $<700 \mathrm{~m}$. Another secondary site characteristic which lowered site suitability scores was landslide risk. Sites with a "low risk" of landslides generally received a score of 3 while sites with a "moderate risk" or "high risk" received a score of 2 . An additional secondary site characteristic influential to site suitability score was 
proximity to highways. Sites $<1.6 \mathrm{~km}$ from highways typically received lower scores than sites $>1.6 \mathrm{~km}$ away from highways. A final secondary site characteristic which had a moderate impact on site suitability scores was whether the site was within $1 \mathrm{~km}$ of the forest perimeter. Sites $<1 \mathrm{~km}$ from the perimeter typically received a lower score than sites $>1 \mathrm{~km}$. $<1 \%$ of all suitable sites received a score of 1 . Sites received a score of 1 only if associated with a subpar plant group and a combination of the following characteristics: elevation of $>1,000 \mathrm{~m}$, "very high risk" of landslides, $<1.6 \mathrm{~km}$ of highways, or $<1 \mathrm{~km}$ of the forest's perimeter.

Based upon this analysis, $97.18 \%$ of the Siuslaw NF (approx. 616,366 acres) is unsuitable for artificial gap creation for the benefit of bats (Table 8). By far the two most restricting site characteristics were proximity to water bodies and stand age. Any sites within $<144 \mathrm{~m}$ of a water body or within a forest stand $\geq 80$ years old were unsuitable for gap creation. With just these two site characteristics in consideration, only $3.98 \%$ of the Siuslaw NF is suitable for gap creation. Thus, the addition of the other 8 site characteristics reduced suitable sites by an additional $1.16 \%$. Among these additional 8 site characteristics, the next most limiting were proximity to highways $(<350 \mathrm{~m})$, proximity to other roads $(<30 \mathrm{~m})$, and invasive plants.

Locations suitable for gap creation are distributed relatively evenly across the Siuslaw NF with often $<1 \mathrm{~km}$ separating suitable patches. However, there are some areas lacking in sites suitable for gap creation such as much of the southern portion of the Central Coast District, simply due to the lack of stands $<80$ years old which are also $>122 \mathrm{~m}$ away from water bodies. As the majority of suitable sites are $<1 \mathrm{~km}$ away from one another, there is an opportunity to create a matrix of highly connected foraging grounds throughout the Siuslaw NF. Though distances traveled between roosts, foraging grounds, and drinking water sites are constrained for lactating females (Campbell, Hallett \& O'Connell, 1996; Tuttle, 1976; Barclay, 1989; Henry et al., 2002; Roadhouse \& Hyde, 2014), distances <1 km between gaps are not likely to deter reproductive females (see Chapter 3 for more details). These short distances between suitable sites for gap creation are especially within the flight range of non-lactating bats. For example, open-adapted big brown bats have been documented traveling around $4 \mathrm{~km}$ up to $18.8 \mathrm{~km}$ between roosts and foraging grounds (Brigham \& Fenton, 1986; Everett et al., 2001). Even clutter-adapted species such as Townsend's bat can travel from $5 \mathrm{~km}$ to $13 \mathrm{~km}$ between roosts and foraging grounds (Adam et al., 1994; Brown, Berry \& Brown, 1994; Clark, Leslie \& Carter, 1993; Fellers \& Pierson, 2002). In areas such as the southern portion of the Central Coast District, there is less of an opportunity for creating well-connected foraging grounds. However, as demonstrated by the previously mentioned studies, some bats can travel $>4 \mathrm{~km}$ in a single night.

Though there is not an overwhelming abundance of locations highly suitable for gap creation in the Siuslaw NF, there are several areas of interest throughout the forest that could serve as ideal foraging grounds for open- and edge-adapted species (Figures $7 \& 8$ ). Even the creation of a few strategically placed gaps within the even-aged closed canopy stands of the Siuslaw NF could promote bat diversity and activity. If this approach were to be applied to a forest which is not designated as a Late-Successional Reserve it is likely that this approach would yield a greater availability of sites suitable for gap creation than what was seen in the case study of the Siuslaw NF. Policies preventing gap creation in stands $\geq 80$ years old and within $122 \mathrm{~m}$ of water bodies are highly limiting but ensure that the forest serves its 
designated purposes as a Late Successional Reserve (see Chapter 1). Regardless, if this approach were to be applied to a forest which is not a Late Successional Reserve, it is recommended that the creation of artificial gaps in mature stands with high availability of large diameter snags be avoided to preserve optimal roosting habitat.

As previously mentioned, some of the parameters used in this analysis, notably gap size, proximity to drinking water, and proximity to roads, are in need of additional research originating from the Pacific Northwest region. As new pertinent research becomes available, parameter recommendations should be updated and new weighted overlay analyses should be conducted periodically. As spatial data regarding snag availability was unavailable for use in this analysis and a proxy was used to identify suitable roosting habitat, a new weighted overlay analysis should be conducted when snag data becomes available. Similarly, as the GNN LEMMA dataset from 2017 was used to identify locations with $<10 \%$ tree canopy which likely already function as forest gaps, a new weighted overlay analysis should be conducted to reflect more current canopy conditions of the Siuslaw NF.

The weighted overlay method used to conduct this analysis is a readily accessible tool available in most geospatial programs. The weighted overlay and other tools utilized in this analysis such as the clip, buffer, and reclassify tool require only minimal to moderate user experience as opposed to complex modeling efforts which require extensive training. However, as a highly simplified method, absolute thresholds were required to determine site suitability. As criteria and thresholds used in the weighted overlay were obtained from the culmination of the results of previous studies, there is a high amount of uncertainty surrounding site suitability thresholds which cannot be incorporated into this method. The weighted overlay method is just one of many methods that could be utilized to identify sites suitable for gap creation. Other approaches used in Ecological Niche Modeling (ENM) or Classification and Regression Tree (CART) analyses which incorporate uncertainty may present a more flexible approach that would result in a wider range of sites considered suitable for gap creation.

\section{Conclusions}

This document provides the first comprehensive approach to artificial forest gap creation for the benefit of bats in the Pacific Northwest region. By using information from existing literature regarding regional bat biology and ecology, key gap parameters have been identified and informed recommendations regarding each parameter have been formulated. In addition, parameters in need of additional research have been highlighted throughout the document. With the help of geospatial data and tools, these recommendations can be used by forest and wildlife managers to identify ideal locations for gap creation in any forest to promote bat diversity and foraging activity of open- and edge-adapted bat species.

However, if this approach were to be applied to a forest other than the Siuslaw NF, it is recommended that each gap parameter discussed in this document be reevaluated and additional potentially influential parameters be considered. As mentioned in several previous chapters, responses 
of bats to many factors are species-dependent and the importance of certain gap parameters may change depending upon the composition of bat communities. Based upon the location of the forest in question, climatic variables such as temperature and precipitation may play an important role in determining what gap parameters are most influential for bats. Additionally, it is important that the gap parameters and recommendations in this document be updated accordingly as new research becomes available. It is especially detrimental that parameters in need of further research, like those discussed at the end of Chapter 3, be investigated and that future findings be included in this approach. By updating gap parameters and their recommendations, best management practices regarding artificial gap creation for bats are more likely to be achieved.

Though recommendations for gap parameters suggested in this document were informed by literature that originated from the Pacific Northwest region when available, future acoustic monitoring studies conducted at sites identified as being suitable for gap creation prior to and post gap creation could be used to validate this approach. Long-term acoustic monitoring would provide a unique view of how bat activity changes in gaps over time and through various stages of forest succession. These types of studies could be expanded to also monitor the effects of the artificial gaps on other wildlife species. The creation of forest gaps could provide an opportunity to support the activity of many wildlife species including invertebrate pollinators, mustelids, rodents, birds, and ungulates in addition to bats (Roberts, King \& Milam, 2017; Muscolo et al., 2004; Menzel et al., 1999; Kie, Bowyer \& Stewart, 2003). 


\section{References}

Adams, M.D., \& Hayes, J.P. (2000). Use of bridges as night roosts by bats in the Oregon Coast Range. Journal of Mammalogy. 81(2): 402-407. https://doi.org/10.1644/1545-1542(2000)081<0402:UOBANR>2.0.CO;2

Adams, M.D., Lacki, M.J. \& Barnes, T.G. (1994). Foraging areas and habitat use of the Virginia big-eared bat in Kentucky. Journal of Wildlife Management. 58(3): 462-469. https://doi.org/10.2307/3809317

Adams, M.D., Law, B.S., \& French, K.O. (2009). Vegetation structure influences the vertical stratification of open- and edge-space aerial-foraging bats in harvested forests. Forest Ecology and Management. 258(9): 2090-2100. https://doi.org/10.1016/j.foreco.2009.08.002

Adams, R.A. \& Hayes, M.A. (2008). Water availability and successful lactation by bats as related to climate change in arid regions of western North America. Journal of Animal Ecology. 77(6): 1115-1121. https://doi.org/10.1111/j.1365-2656.2008.01447.x

Adams, R.A. \& Simmons, J.A. (2002). Directionality of drinking passes by bats at water holes: is there cooperation? Acta Chiropterologica. 4(2): 195-199. https://doi.org/10.3161/001.004.0211

Adams, R.A. \& Thibault, K.M. (2006). Temporal resource partitioning by bats at water holes. Journal of Zoology. 270(3): 466-472. https://doi.org/10.1111/i.1469-7998.2006.00152.x

Adams, Rick A, \& Hayes, M.A. (2008). Water Availability and Successful Lactation by Bats as Related to Climate Change in Arid Regions of Western North America. Journal of Animal Ecology, 77(6): 1115-1121. https://doi.org/10.1111/i.1365-2656.2008.01447.x

Agee, J.K. (1991). Fire history of Douglas fir forests in the pacific Northwest. In: Ruggiero, L.F., Aubry, K.B., Carey, A.B. \& Huff, M.H. (eds), Wildlife and vegetation of unmanaged Douglas fir forests. General Technical Report PNW-GTR-285. Portland, Oregon: USDA Forest Service, Pacific Northwest Research Station. https://doi.org/10.2737/PNW-GTR-285

Aldridge, H.D.J.N. \& Rautenbach, I.L. (1987). Morphology, echolocation and resource partitioning in insectivorous bats. Journal of Animal Ecology. 56(3): 763-778. https://doi.org/10.2307/4947

Altringham, J. \& Kerth, G. (2016). Bats and roads. In: Voigt, C.C. \& Kingston, T. (eds). Bats in the Anthropocene: Conservation of Bats in a Changing World. Springer International Publishing.

Anthony, E.L.P., \& Kunz, T.H. (1977). Feeding strategies of the little brown bat, Myotis lucifugus, in southern New Hampshire. Ecology. 58(4): 775-786. https://doi.org/10.2307/1936213 
Anthony, E.L.P., Stack, M.H., \& Kunz, T.H. (1981). Night roosting and the nocturnal time budget of the little brown bat, Myotis lucifugus: Effects of reproductive status, pred density, and environmental conditions. Oecologia. 51: 151-156. https://doi.org/10.1007/BF00540593

Arnett, E.B., \& Hayes, J.P. (2003). Presence, relative abundance, and resource selection of bats at multiple spatial scales in western Oregon. Unpublished final report to USGS-BRD ,Cooperative Forest Ecosystem Research Program, Oregon State University.

Arnett, E.B., \& Hayes, J.P. (2009). Use of conifer snags as roosts by female bats in western Oregon. Journal of Wildlife Management, 73(2): 214-225. https://doi.org/10.2193/2007-532

Aubry, K.B., \& Raley, C.M. (2002). The pileated woodpecker as a keystone habitat modifier in the Pacific Northwest Cascades Carnivore Project View project. General Technical Report PSW-GTR-181. Portland, Oregon: USDA Forest Service, Pacific Northwest Research Station.

Audet, D. (1990). Foraging behavior and habitat use by a gleaning bat, Myotis myotis (Chiroptera: Vespertilionidae). Journal of Mammalogy. 71(3): 420-427. https://doi.org/10.2307/1381955

Baker, M.D., \& Lacki, M.J. (2004). Forest bat communities in the East Cascade Range, Washington. Northwest Science. 78(4): 234-241.

Barbour, R.W., \& Davis, W.H. (1969). Bats of America. University Press of Kentucky.

Barclay, R.M.R. (1989). The effect of reproductive condition on the foraging behavior of female hoary bats, Lasiurus cinereus. Behavioral Ecology and Sociobiology. 24: 31-37. https://doi.org/10.1007/BF00300115

Barclay, R.M.R. (1991). Population structure of temperate zone insectivorous bats in relation to foraging behaviour and energy demand. Journal of Animal Ecology. 60(1): 165-178.

https://doi.org/10.2307/5452

Barclay, R.M.R. \& Brigham, R.M. (1994). Constraints on optimal foraging: a field test of prey discrimination by echolocaing insectivorous bats. Animal Behavior. 48(5): 1013-1021. https://doi.org/10.1006/anbe.1994.1334

Barclay R.M.R. \& Kurta, A. (2007). Ecology and behavior of bats roosting in tree cavities and under bark. In: Lacki, M.J., Hayes, J.P. \& Kurta, A. (eds). Bats in Forests: Conservation and Management. John Hopkins University Press.

Bell, G.P., \& Fenton, M.B. (1984). The use of Doppler-shifted echoes as a flutter detection and clutter rejection system: the echolocation and feeding behavior of Hipposideros ruber (Chiroptera: Hipposideridae). Behavioral Ecology and Sociobiology. 15(2): 109-114. https://doi.org/10.1007/BF00299377 
Bender, M.J., Castleberry, S.B., Miller, D.A. \& Wigley T.B. (2015). Site occupancy of foraging bats on landscapes of managed pine forest. Forest Ecology and Management. 336: 1-10. https://doi.org/10.1016/i.foreco.2014.10.004

Bennett, V.J. \& Zurcher, A.A. (2012). When corridors collide: Road-related disturbance in commuting bats. Journal of Wildlife Management. 77(1): 93-101. https://doi.org/10.1002/iwmg.467

Berthinussen, A. (2013). The effect of roads on bats in the UK: a model for evidence based conservation. [Unpublished Doctoral Dissertation, University of Leeds]. Semantic Scholar.

Berthinussen, A. \& Altringham, J. (2012). The effect of a major road on bat activity and diversity. Journal of Applied Ecology. 49(1): 82-89. https://doi.org/10.1111/j.1365-2664.2011.02068.x

Betts, B.J. (1998a). Roosts used by maternity colonies of silver-haired bats in Northeastern Oregon. Journal of Mammalogy. 79(2): 643-650.https://doi.org/10.2307/1382994

Betts, B.J. (1998b). Variation in roost fidelity among reproductive female silver-haired bats in northeastern Oregon. Northwestern Naturalist. 79(2): 59-63. https://doi.org/10.2307/3536702

Bevis, K.R., \& Martin, S.K. (2002). Habitat Preferences of Primary Cavity Excavators in Washington's East Cascades. General Technical Report PSW-GTR-181. Olympia, Washington: USDA Forest Service, Pacific Northwest Research Station.

Black, B.A., Shaw, D.C., \& Stone, J.K. (2010). Impacts of Swiss needle cast on overstory Douglas fir forests of the westnern Oregon Coast Range. Forest Ecology and Management. 259(8): 1673-1680. https://doi.org/10.1016/i.foreco.2010.01.047

Blakey, R.V., Webb, E.B., Kesler, D.C., Siegel, R.B., Corcoran, D., \& Johnson, M. (2019). Bats in a changing landscape: Linking occupancy and traits of a diverse montane bat community to fire regime. Ecology and Evolution, 9(9): 5324-5337. https://doi.org/10.1002/ece3.5121

Blanco, C.M. \& Garrie, J. (2020). Species specific effects of prescribed burns on bat occupancy in northwest Arkansas. Forest Ecology and Management. 460(15): e117890. https://doi.org/10.1016/i.foreco.2020.117890

Boyd, R.T. (1999). Indians, Fire and the Land in the Pacific Northwest. Oregon State University Press.

Boyles, J.G. \& Aubrey, D.P. (2006). Managing forests with prescribed fire: Implications for a cavity-dwelling bat species. Forest Ecology and Management. 222(1-3): 108-115. https://doi.org/10.1016/i.foreco.2005.09.024

Boyles, J.G., McGuire, L.P., Boyles, E., Reimer, J.P., Brooks, C.A.C., Rutherford, R.W., Rutherford, T.A., Whitaker, J.O. \& McCracken. (2016). Physiological and behavioral adaptations in bats living at high latitudes. Physiology \& Behavior. 165(15): 322-327. https://doi.org/10.1016/i.physbeh.2016.08.016 
Brigham, R.M., Grindal, S.D., Firman, M.C., \& Morissette, J.L. (1997). The influence of structural clutter on activity patterns of insectivorous bats. Canadian Journal of Zoology. 75(1): 131-136. https://doi.org/10.1139/z97-017

Brigham, R.M. (1991). Flexibility in foraging and roosting behaviour by the big brown bat (Eptesicus fuscus). Canadian Journal of Zoology. 69(1): 117-121. https://doi.org/10.1139/z91-017

Brigham, R.M., Aldridge, H.D.J.N. \& Mackey, R.L. (1992). Variation in habitat use and prey selection. Journal of Mammalogy. 73(3): 640-645. https://doi.org/10.2307/1382036

Brigham, R.M. \& Fenton, M.B. (1986). The influence of roost closure on the roosting and foraging behaviour of Eptesicus fuscus (Chiroptera: Vespertilionidae). Canadian Journal of Zoology. 64(5): 1128-1133. https://doi.org/10.1139/z86-169

Brigham, R.M. \& Fenton, M.B. (1991). Convergence in foraging strategies by two morphologically and phylogenetically distinct nocturnal aerial insectivores. Journal of Zoology. 223(3): 475-489. https://doi.org/10.1111/j.1469-7998.1991.tb04778.x

Brooks, J. D., Loeb, S. C., \& Gerard, P. D. (2017). Effect of forest opening characteristics, prey abundance, and environmental factors on bat activity in the Southern Appalachians. Forest Ecology and Management. 400: 19-27. https://doi.org/10.1016/i.foreco.2017.05.045

Brooks, R.T. (2009). Habitat-associated and temporal patterns of bat activity in a diverse forest landscape of southern New England, USA. Biodiversity and Conservation. 18(3): 529-545. https://doi.org/10.1007/s10531-008-9518-x

Brown, P.E., Berry, R. \& Brown, C. (1994). Foraging behavior of Townsend's big-eared bats (Plecotus townsendii) on Santa Cruz Island. In: Halvorson, W.L. \& Maender, G.J. (eds). Fourth California islands symposium: update on the status of resources. Santa Barbara Museum of Natural History.

Buchalski, M.R., Fontaine, J.B., Heady, P.A., Hayes, J.P. \& Frick, W.F. (2013). Bat response to differing fire severity in mixed-conifer forest California, USA. PLOS ONE. 8(3): e57884. https://doi.org/10.1371/journal.pone.0057884

Campbell, L.A. (1993). Bat diversity and habitat use in managed forests of northeastern Washington. [Unpublished Master's Thesis, Washington State University]. Libraries Research Exchange.

Campbell, L.A., Hallett, J.G., \& O'Connell, M.A. (1996). Conservation of bats in managed forests: Use of roosts by Lasionycteris noctivagans. Journal of Mammalogy. 77(4): 976-984. https://doi.org/10.2307/1382778

Capellini, I., Venditti, C. \& Barton, R.A. (2010). Phylogeny and metabolic scaling in mammals. Ecology. 91(9): 2783-2793. https://doi.org/10.1890/09-0817.1 
Carey, A.B. (1989). Wildlife associated with old-growth forests in the Pacific Northwest. Natural Areas Journal. 9: 152-262.

Carr, A., Weatherall, A. \& Jones, G. (2020). The effects of thinning management on bats and their insect prey in temperate broadleaved woodland. Forest Ecology and Management. 457(1): e117682. https://doi.org/10.1016/i.foreco.2019.117682

Childs, T.W. \& Shea, K.R. (1967). Annual losses from disease in Pacific Northwest forests. Resource Bulletin PNW-RB-020. Portland, Oregon: USDA Forest Service, Pacific Northwest Forest and Range Experiment Station.

Christy, R. E., \& West, S. D. (1993). Biology of Bats in Douglas fir Forests. General Technical Report PNW-GTR-308. Portland, Oregon: USDA Forest Service, Pacific Northwest Research Station. (Huff, Mark H.; Holthausen, Richard M.; Aubry, Keith B., Tech. coords. Biology and management of old-growth forests) https://doi.org/10.2737/PNW-GTR-308

Claireau, F., Bas, Y., Pauwels, J., Barré, K., Machon, N., Allegrini, B., Puechmaille, S.J. \& Kerbiriou, C. (2019). Major roads have important negative effects on insectivorous bat activity. Biological Conservation. 235: 53-62. https://doi.org/10.1016/j.biocon.2019.04.002

Clark, B.S., Leslie, D.M. \& Carter, T.S. (1993). Foraging activity of adult female Ozark big-eared bats (Plecotus townsendii ingens) in summer. Journal of Mammalogy. 74(2): 422-427. https://doi.org/10.2307/1382398

Confederate Tribe of Siletz Indians. (n.d.) A Siletz History. http://www.ctsi.nsn.us/chinook-indian-tribe-siletz-heritage/our-history/part-i

Constantine, D.G. (1966). Ecological observations on Lasiurine bats in lowa. Journal of Mammalogy. 47(1): 34. https://doi.org/10.2307/1378064

Crome, F.H.J., \& Richards, G.C. (1988). Bats and gaps: Microchiropteran community structure in a Queensland rain forest. Ecology. 69(6): 1960-1969. https://doi.org/10.2307/1941173

Cross, S.P. (1986). Bats. Pp. 297-519. In: Cooperrider, A.Y., Boyd, R.J. \& Stuart, H.R. (eds). Inventory and monitoring of wildlife habitat. United States Department of Interior, Bureau of Land Management, Denver, Colorado.

Cross, S.P. (1988). Riparian systems and small mammals and bats. In: Raedeke, K.J. (eds). Streamside management: riparian wildlife and forestry interactions. University of Washington Press.

Crampton, L.H. \& Barclay, R.M.R. (1996). Habitat selection by bats in fragmented and unfragmented aspen mixedwood stands of different ages. In: Barclay, R.M.R. \& Brigham, R.M. (eds). Bats and Forests Symposium. British Columbia Ministry of Forests. 
Crampton, L.H. \& Barclay, R.M.R. (1998). Selection of roosting and foraging habitat by bats in different-aged aspen mixedwood stands. Conservation Biology. 12(6): 1347-1358.

https://doi.org/10.1111/i.1523-1739.1998.97209.x

Cryan, P.M., Bogan, M.A., \& Altenbach, S.J. (2000). Effect of elevation on distribution of female bats in the Black Hills, South Dakota. Journal of Mammalogy. 81(3): 719-725. https://doi.org/10.1644/1545-1542(2000)081<0719:eoeodo>2.3.co;2

Curtis, R.O., Debell, D.S., Miller, R.E., Newton, M., St. Claire, J.B., \& Stein, W.I. (2007). Silvicultural research and the evolution for forest practices in the Douglas fir region. General Technical Report PNW-GTR-696. Portland, Oregon: USDA Forest Service Pacific Northwest Research Station. https://doi.org/10.2737/PNW-GTR-696

Decker, D. (2018). Tillamook Burn. The Oregon Encyclopedia. https://oregonencyclopedia.org/articles/tillamook burn/\#.XantCchKics

de Jong, J. (1994). Habitat use, home-range and activity pattern of the northern bat, Eptesicus nilssoni, in a hemiboreal coniferous forest. Mammalia. 58(4): 535-548. https://doi.org/10.1515/mamm.1994.58.4.535

Denzinger, A. \& Schnizler, H.U. (2013). Bat guilds, a concept to classify the highly diverse foraging and echolocation behaviors of microchiropteran bats. Frontiers in Physiology. 4: 164. https://doi.org/10.3389/fphys.2013.00164

Donato, D.C., Campbell, J.L. \& Franklin, J.F. (2012). Multiple successional pathways and precocity in forest development: can some forests be born complex? Journal of Vegetation Science. 23(3): 576-584.https://doi.org/10.1111/j.1654-1103.2011.01362.x

Duchamp, J.E., Sparks, D.W. \& Swihart, R.K. (2010). Exploring the "nutrient hot spot" hypothesis at trees used by bats. Journal of Mammalogy. 91(1): 48-53. https://doi.org/10.1644/08-MAMM-A-308R2.1

Duvergé, P.L., Jones, G.J., Rydell, J. \& Ransome, R.D. (2008). Functional significance of emergence timing in bats. Ecography. 23(1): 32-40. https://doi.org/10.1111/j.1600-0587.2000.tb00258.x

Ellis, A.M., Patton, L.L. \& Castleberry, S.B. (2002). Bat activity in upland and riparian habitats in the Georgia Piedmont. Proceedings Annual Conference Southeastern Association of Fish and Wildlife Agencies. 56: 210-218.

Erickson, J.L. (1993). Bat activity in managed forests of the Western Cascade Range. Bat Research News. 34: 56.

Erickson, J.L., \& West, S.D. (1995). Managed forests in the Western Cascades: The effects of seral stage on bat habitat use patterns. In: Barclay, R.M.R. \& Brigham, R.M. (eds). Bats and Forests Symposium (pp. 215-227). 
Erickson, J.L., \& West, S.D. (2003). Associations of bats with local structure and landscape features of forested stands in western Oregon and Washington. Biological Conservation. 109(1): 95-102. https://doi.org/10.1016/S0006-3207(02)00141-6

Everette, A.L., O'Shea, T.J., Ellison, L.E., Stone, L.A. \& McCance, J.L. (2001). Bat use of a high-plains urban wildlife refuge. Wildlife Society Bulletin. 29(3): 967-973. https://doi.org/10.2307/3784424

Faure, P.A., \& Barclay, R.M.R. (1994). Substrate-gleaning versus aerial-hawking: plasticity in the foraging and echolocation behaviour of the long-eared bat, Myotis evotis. Journal of Comparative Physiology A. 174: 651-660. https://doi.org/10.1007/BF00217386

Fellers, G.M. \& Pierson, E.D. (2002). Habitat use and foraging behavior of Townsend's big-eared bat (Corynorhinus townsendii) in coastal California. Journal of Mammalogy. 83(1): 167-177. https://doi.org/10.1644/1545-1542(2002)083<0167:HUAFBO>2.0.CO;2

Fensome, A.G. \& Mathews, F. (2016). Roads and bats: a meta-analysis and review of the evidence on vehicle collisions and barrier effects. Mammal Review. 46(4): 311-323.

https://doi.org/10.1111/mam.12072

Fenton, M.B. (1990). The foraging behaviour and ecology of animal-eating bats. Canadian Journal of Zoology, 68, 411-422. https://doi.org/10.1139/290-061

Fenton, M.B. \& Bell, G.P. (1979). Echolocation and feeding behaviour in four species of Myotis (Chiroptera). Canadian Journal of Zoology, 57(6): 1271-1277. https://doi.org/10.1139/279-163

Fenton, M.B., de Jong, C.G.V.Z., Bell, G.P., Campbell, D.B. \& Laplante, M. (1980). Distribution, parturition dates, and feeding of bats in south-central British Columbia. Canadian Field-Naturalist. 94(3): 416-420.

Fenton, M.B. \& Rautenbach, I.L. (1986). A comparison of the roosting and foraging behavior of three species of African insectivorous bats (Rhinolophidae, Vespertilionidae, and Molossidae). Canadian Journal of Zoology. 64(12): 2860-2867. https://doi.org/10.1139/z86-412

Ford, W.M., Menzel, J.M., Menzel, M.A., Edwards, J.W. \& Kilgo, J.C. (2006). Presence and absence of bats across habitat scales in the Upper Coastal Plain of South Carolina. Journal of Wildlife Management. 70(5): 1200-1209.

Ford, W.M., Menzel, M.A., Rodrigue, J.L., Menzel, J.M., \& Johnson, J.B. (2005). Relating bat species presence to simple habitat measures in a central Appalachian forest. Biological Conservation. 126(4): 528-539. https://doi.org/10.1016/i.biocon.2005.07.003

Forest Conference Executive Committee. (1993). Forest Ecosystem Management: An Ecological, Economic, and Social Assessment. https://www.blm.gov/or/plans/nwfpnepa/FEMAT-1993/1993 \%20FEMAT Report.pdf 
Franklin, J.F., Hoir, W.H., Douglas, G.W. \& Wiberg, C. (1971). Invasion of subalpine meadows by trees in the Cascade Range, Washington and Oregon. Arctic \& Alpine Research. 3(3): 215-224. https://doi.org/10.1080/00040851.1971.12003612

Froidevaux, J.S.P., Zellweger, F., Bollmann, K., Jones, G., \& Obrist, M.K. (2016). From field surveys to LiDAR: Shining a light on how bats respond to forest structure. Remote Sensing of Environment. 175: 242-250. https://doi.org/10.1016/i.rse.2015.12.038

Fukui, D., Hirao, T., Murakami, M. \& Hirakawa, H. (2011). Effects of treefall gaps created by windthrow on bat assemblages in a temperate forest. Forest Ecology and Management. 261(9): 1546-1552. https://doi.org/10.1016/i.foreco.2011.02.001

Fullard, J.H. (1987). Sensory ecology and neuroethology of moths and bats: interactions in a global perspective. In: Fenton, M.B., Racey, P.A. \& Raynor, J.M.V (eds), Recent Advances in the Study of Bats (pp. 244-272). Cambridge University Press.

Funk, C. \& Croteau, R. (1994). Diterpenoid resin acid biosynthesis in conifers: Characterization of two cytochrome P450-dependent monooxygenases and an aldehyde dehydrogenase involved in abietic acid biosynthesis. Biochemistry and Biophysics. 308(1): 258-266.

https://doi.org/10.1006/abbi.1994.1036

Furlonger, C.L., Dewar, H.J. \& Fenton, M.B. (1987). Habitat use by foraging insectivorous bats. Canadian Journal of Zoology. 65(2): 284-288. https://doi.org/10.1139/z87-044

Geggie, J.F. \& Fenton, M.B. (1985). A comparison of foraging by Eptesicus fuscus (Chiroptera: Vespertilionidae) in urban and rural environments. Canadian Journal of Zoology. 63(2): 263-266. https://doi.org/10.1139/z85-040

Geiser, F. (2004). Metabolic rate and body temperature reduction during hibernation and daily torpor. Annual Review of Physiology, 66, 239-274. https://doi.org/10.1146/annurev.physiol.66.032102.115105

Gellman, S. T., \& Zielinski, W. J. (1996). Use by bats of old-growth redwood hollows on the north coast of California. Journal of Mammalogy, 77(1): 255-265. https://academic.oup.com/imammal/article/77/1/255/883384

Ghanem, S. J., \& Voigt, C. C. (2012). Increasing Awareness of Ecosystem Services Provided by Bats. In Brockman, H.J., Roper, T.J., Naguib, M., Mitani, J.C., Simmons, L.W. (eds), Advances in the Study of Behavior. 44: 279-302. Academic Press Inc. https://doi.org/10.1016/B978-0-12-394288-3.00007-1

Goheen, E.M. \& Willhite, E.A. (2006). Field Guide to Common Diseases and Insect Pests of Oregon and Washington Conifers. Portland, OR: USDA Forest Service, Pacific Northwest Region. 
Grief, S. \& Siemers, B.M. (2010). Innate recognition of water bodies in echolocating bats. Nature Communications. 1(107). https://doi.org/10.1038/ncomms1110

Grindal, S.D. (1995). Habitat use by bats in fragmented forests. Bat Research News. 36: 26.

Grindal, S.D. (1996). Impacts of forest harvesting on habitat use by foraging bats in southern British Columbia. [Unpublished Master's Thesis, University of Regina]. eLibrary.ru

Grindal, S.D., \& Brigham, M.R. (1999). Impacts of forest harvesting on habitat use by foraging insectivorous bats at different spatial scales. Ecoscience. 6(1): 25-34. https://doi.org/10.1080/11956860.1999.11682526

Grindal, S.D., Collard, T.S., Brigham, R.M. \& Barclay, R.M.R. (1992). The influence of precipitation on reproduction by Myotis bats in British Columbia. American Midland Naturalist. 128(2): 339-344. https://doi.org/10.2307/2426468

Grindal, S.D., Morissette, J.L., \& Brigham, R.M. (1999). Concentration of bat activity in riparian habitats over an elevational gradient. Canadian Journal of Zoology. 77(6): 972-977. https://doi.org/10.1139/cjz-77-6-972

Grindal, S.D, \& Brigham, R.M. (1998). Short-term effects of small-scale habitat disturbance on activity by insectivorous bats. The Journal of Wildlife Management, 62(3): 996-1003.

https://doi.org/10.2307/3802552

Hackett, T. D., Korine, C., \& Holderied, M. W. (2014). A whispering bat that screams: bimodal switch of foraging guild from gleaning to aerial hawking in the desert long-eared bat. The Journal of Experimental Biology. 217(17): 3028-3032. https://doi.org/10.1242/jeb.100362

Hadfield, J.S. (1985). Laminated root rot: a guide for reducing and preventing losses in Oregon and Washington forests. Portland, Oregon: USDA Forest Service Forest Pest Management, Pacific Northwest Region.

Hagle, S. K. (2009). Laminated root rot ecology and management. Chapter 11.2 Forest insect and disease management guide for the northern and central Rocky Mountains. USDA Forest Service, Northern Region, State and Private Forestry.

Hamilton, I.M. \& Barclay, R.M.R. (1994). Patterns of daily torpor and day-roost selection by male and female big brown bats (Eptesicus fuscus). Canadian Journal of Zoology. 72(4): 744-749. https://doi.org/10.1139/z94-100

Hansen, E. M. (1976). Twenty year survival of Phellinus (Poria) weirii in Douglas fir stumps. Canadian Journal of Forest Research. 6: 123-128. https://doi.org/10.1139/x76-015 
Harmon, M.E. \& Pabst, R.J. (2019). The long-term effects of wind disturbance on a Sitka spruce-western hemlock forest. Forests. 10(2): 1-19. https://doi.org/10.3390/f10020119

Hayes, J.P. (1997). Temporal variation in activity of bats and the design of echolocation-monitoring studies. Journal of Mammalogy. 78(2): 514-524. https://doi.org/10.2307/1382902

Hayes, J. P. (2003). Habitat ecology and conservation of bats in western coniferous forests. In Mammal Community Dynamics (pp. 81-119). Cambridge University Press. https://doi.org/10.1017/cbo9780511615757.005

Hayes, J. P., \& Loeb, S. (2007). The Influences of Forest Management on Bats in North America. In Lacki, M.J., Hayes, J.P, \& Kurta, A. (eds), Bats in Forests (pp. 207-235). John Hopkins University Press.

Hein, C.D., Castleberry, S.B., \& Miller, K.V. (2009). Site-occupancy of bats in relation to forested corridors. Forest Ecology and Management. 257(4): 1200-1207. https://doi.org/10.1016/j.foreco.2008.09.054

Hemstrom, M.A. \& Logan S.E. (1986). Plant association and management guide - Siuslaw National Forest. R6-Ecol 220-1986. Portland Oregon: USDA Forest Service, Pacific Northwest Region 6.

Henry, M., Thomas, D.W., Vaudry, R. \& Carrier, M. (2002). Foraging distances and home range of pregnant and lactating little brown bats (Myotis lucifugus). Journal of Mammalogy. 83(3): 767-774. https://doi.org/10.1644/1545-1542(2002)083<0767:FDAHRO>2.0.CO;2

Henderson, J. \& McCain, C. (2011). Modeled plant association groups Oregon Coast dataset. USDA Forest Service. https://ecoshare.info/2009/12/07/or-coast-plant-assn-groups/

Henderson, L.E. \& Broders, H.G. (2008). Movements and resource selection of the Northern long-eared Myotis (Myotis septentrionalis) in a forest-agriculture landscape. Journal of Mammalogy. 89(4): 952-963. https://doi.org/10.1644/07-MAMM-A-214.1

Herd, R.M. \& Fenton, M.B. (1983). An electrophoretic, morphological, and ecological investigation of a putative hybrid zone between Myotis lucifugus and Myotis yumanensis (Chiroptera: Vespertilionidae). Canadian Journal of Zoology. 61(9): 2029-2050. https://doi.org/10.1139/z83-268

Hogberg, L. K., Patriquin, K. J., \& Barclay, R. M. R. (2002). Use by Bats of Patches of Residual Trees in Logged Areas of the Boreal Forest. Source: The American Midland Naturalist, 148(2), 282-288. https://doi.org/10.1644/1545-1410(2001)670<0001:MC>2.0.CO;2

Holloway, G.L. \& Barclay, R.M.R. (2001). Myotis ciliolabrum. Mammalian Species. 670: 1-5. https://doi.org/10.1644/1545-1410(2001)670<0001:MC>2.0.CO;2

Hoying, K.M. \& Kunz, T.H. (1998). Variation in size at birth and post-natal growth in the insectivorous bat Pipistrellus subflavus (Chiroptera: Vespertilionidae). Journal of Zoology. 245(1): 15-27. https://doi.org/10.1111/j.1469-7998.1998.tb00067.x 
Humber, J.M. (2009). Non-native plant invasion of boreal forest gaps: implications for stand regeneration in a protected areas shaped by hyperabundant herbivores. [Master's thesis, Memorial University of Newfoundland.] Memorial University Research Repository.

Humes, M. L. (1996). Activity of Bats in Thinnined, Unthinned, and Old-growth Forests in the Oregon Coast Range. [Unpublished master's thesis, Oregon State University].

Humes, M.L., Hayes, J.P. \& Collopy, M.W. (1999). Bat activity in thinned, unthinned, and old-growth forests in western Oregon. Journal of Wildlife Management. 63(2): 553-561. https://doi.org/10.2307/3802642

Impara, P.C. (1997). Spatial and Temporal Patterns of Fire in the Forests of the Central Oregon Coast Range. [Unpublished doctoral dissertation, Oregon State University]. Oregon State University Scholars Archive.

Janzten, M.K. \& Fenton, M.B. (2013). The depth of edge influence among insectivorous bats at forest-field interfaces. Canadian Journal of Zoology. 91(5): 287-292. https://doi.org/10.1139/cjz-2012-0282

Jemison, M., Lumsden, L., Nelson, J., Scroggie, M. \& Chick, R. (2009). Assessing the impact of the 2009 Kilmore East-Murrindindi Complex fire on microbats. Department of Sustainability and Environment, Heidelberg, Victoria.

Johnson, J.B., Ford, W.M., Edwards, J.W. \& Menzel, M.A. (2010). Bat community structure within riparian areas of northwestern Georgia, USA. Folia Zoologica. 59(3): 192-202. https://doi.org/10.25225/fozo.v59.i3.a4.2010

Jonasson, K.A., \& Willis, C.K.R. (2012). Hibernation energetics of free-ranging little brown bats. Journal of Experimental Biology, 215(12): 2141-2149. https://doi.org/10.1242/jeb.066514

Jones, K.E. \& MacLarnon, A. (2001). Bat life histories: Testing models of mammalian life-history evolution. Evolutionary Ecology Research. 3: 465-476

Jones, G. \& Rayner, J.M.V. (1988). Flight performance, foraging tactics and echolocation in free-living Daubenton's bats Myotis daubentoni (Chiroptera: Vespertilionidae). Journal of Zoology. 215(1): 113-132. https://doi.org/10.1111/i.1469-7998.1988.tb04888.x

Jones, G. \& Rayner, J. M. V. (1991). Flight performance, foraging tactics and echolocation in the trawling insectivorous bat Myotis adversus (Chiroptera: Vespertilionidae). Journal of Zoology. 225(3): 393-412. https://doi.org/10.1111/i.1469-7998.1991.tb03824.x

Jones, G., Jacobs, D.S., Kunz, T.H., Willig, M.R. \& Racey, P.A. (2009). Carpe noctem: the importance of bats as bioindicators. Endangered Species Research. 8: 93-115. https://doi.org/10.3354/esr00182 
Jönsson, K.I. (1997). Capital and income breeding as alternative tactics of resource use in reproduction. Oikos, 78(1), 57-66.

Jung, K., Kaiser, S., Böhm, S., Nieschulze, J. \& Kalko, E.K.V. (2012). Moving in three dimensions: effects of structural complexity on occurrence and activity of insectivorous bats in managed forest stands. Journal of Applied Ecology. 49(2): 523-531. https://doi.org/10.1111/i.1365-2664.2012.02116.x

Jung, T.S., Thompson, I.D., \& Titman, R.D. (1999). Habitat selection by forest bats in relation to mixed-wood stand types and structure in Central Ontario. Journal of Wildlife Management. 63(4): 1306-1319. https://www.jstor.org/stable/3802849

Jürgens, K.D., Bartels, H. \& Bartels, R. (1981). Blood oxygen transport and organ weights of small bats and small non-flying mammals. Respiration Physiology. 45(3): 234-260.

https://doi.org/10.1016/0034-5687(81)90009-8

Kalcounis-Rüppell, M.C., Psyllakis, J.M. \& Brigham, R.M. (2005). Tree roost selection by bats: an empirical synthesis using meta-analysis. Wildlife Society Bulletin. 33(3): 1123-1132.

https://doi.org/10.2193/0091-7648(2005)33[1123:trsbba]2.0.co;2

Kalcounis-Rüppell, M.C., Briones, K.M., Homyack, J.A., Petric, R., Marshall, M.M. \& Miller, D.A. (2013). Hard forest edges act as conduits, not filters, for bats. Wildlife Society Bulletin, 37(3): 571-576. https://doi.org/10.1002/wsb.289

Kalcounis, M.C. \& Brigham, R.M. (1995). Intraspecific variation in wing loading affects habitat use by little brown bats (Myotis lucifugus). Canadian Journal of Zoology. 73(1): 89-95. https://doi.org/10.1139/z95-011

Kalcounis, M. \& Hecker, K. (1996). Intraspecific variation in roost site selection in little brown bats (Myotis lucifugus). In: Barclay, R.M.R. \& Brigham, R.M. (eds). Bats and Forests Symposium. Research Branch, British Columbia Ministry of Forests.

Kalcounis, M.C., Hobson, K.A., Brigham, R.M., \& Hecker, K.R. (1999). Bat activity in the boreal forest: Importance of stand type and vertical strata. Journal of Mammalogy, 80(2), 673-682. https://doi.org/10.2307/1383311

Kalko, E.K.V. \& Schnizler, H.U. (1993). Plasticity in echolocation signals of European pipistrelle bats in search flight: implications for habitat use and prey detection. Behavioral Ecology and Sociobiology. 33:415-428. https://doi.org/10.1007/BF00170257

Kastner, W.W., Goheen, D.J. \& Edmonds, R.L. (1994). Relationship between occurrence of laminated root rot and site characteristics in Douglas-fir forests of the northern Oregon Coast Range. Western Journal of Applied Forestry. 9(1): 14-17. https://doi.org/10.1093/wiaf/9.1.14

Kie, J.G., Bowyer, R.T. \& Stewart, K.M. (2013). Ungulates in western forests: habitat requirements, population dynamics, and ecosystem processes. In: Zabel, C.J. \& Anthony, R.G. (eds). Mammal 
Community Dynamics: Management and Conservation in the Coniferous Forests of Western North America. Cambridge University Press. https://doi.org/10.1017/CBO9780511615757.010

Kitzes, J. \& Merenlender, A. (2014). Large roads reduce bat activity across multiple species. PLos ONE. 9(5): e96341. https://doi.org/10.1371/iournal.pone.0096341

Korine, C., Adams, R., Russo, D., Fisher-Phelps, M. \& Jacobs, D. (2016). Bats and water: Anthropogenic alterations threaten global bat populations. In: Voigt, C.C. \& Kingston, T. (eds). Bats in the Anthropocene: Conservation of Bats in a Changing World. Springer International Publishing.

Krusic, R.A., Yamasaki, M., Neefus, C.D., \& Pekins, P.J. (1996). Bat habitat use in White Mountain National Forest. Journal of Wildlife Management. 60(3): 625-631. https://doi.org/10.2307/3802081

Kunz, T.H. (1974). Feeding ecology of a temperate insectivorous bat (Myotis velifer). Ecology. 55(4): 693-711. https://doi.org/10.2307/1934408

Kunz, T.H. (1982). Lasionycteris noctivagans. Mammalian Species. 172: 1-5. https://doi.org/10.2307/3504029

Kunz, T. H., Whitaker, J.O.., Wadanoli, M.D. (1995). Dietary energetics of the insectivorous Mexican free-tailed bat (Tadarida brasiliensis) during pregnancy and lactation. Oecologia. 101: 407-415. https://doi.org/10.1007/BF00329419

Kurta, A., Bell, G. P., Nagy, K. A. \& Kunz, T. H. (1989). Energetics of pregnancy and lactation in free ranging little brown bats (Myotis lucifugus). Physiological Zoology. 62(3): 804-818. https://www.jstor.org/stable/30157928

Kurta, A. (1986). Factors affecting the resting and postflight body temperature of little brown bats, Myotis lucifugus. Physiological Zoology. 59(4): 429-438. https://doi.org/10.1086/physzool.59.4.30158596

Kurta, A. \& Baker, R.H. (1990). Eptesicus fuscus. Mammalian Species. 356: 1-10. https://doi.org/10.2307/3504258

Kurta, A., Bell, G.P., Nagy, K.A. \& Kunz, T.H. (1989). Energetics of pregnancy and lactation in freeranging little brown bats (Myotis lucifugus). Physiological Zoology. 62(3): 804-818. https://www.jstor.org/stable/30157928

Kurta, A., Kunz, T.H., \& Nagt, K.A. (1990). Energetics and water flux of freeranging big brown bats (Eptesicus fuscus) during pregnancy and lactation. Journal of Mammalogy. 71(1): 59-65. https://doi.org/10.2307/1381316

Lacki, M.J., Cox, D.R., Dodd, L.E., \& Dickinson, M.B. (2009). Response of northern bats (Myotisseptentrionalis) to prescribed fires in eastern Kentucky forests. Journal of Mammalogy. 90(5): 1165-1175. https://doi.org/10.1644/08-MAMM-A-349.1 
Lacki, M.J., Amelon, S.K. \& Baker, M.D. (2007). Foraging ecology of bats in forests. In: Lacki, M.J., Hayes, J.P. \& Kurta, A. (eds). Bats in Forests: Conservation and Management. John Hopkins University Press.

La Follette, C. \& Deur, D. (2020). Cape Perpetua. The Oregon Encyclopedia. https://oregonencyclopedia.org/articles/cape-perpetua/\#.Xqxk2chKics

Lauzon, A. (2019). Long-Term Effects of Forest Harvesting on Habitat Use by Insectivorous Bats. [Unpublished Master's Thesis, University of Regina]. oURspace Institutional Repository.

Law, B., \& Chidel, M. (2002). Tracks and riparian zones facilitate the use of Australian regrowth forest by insectivorous bats. Journal of Applied Ecology. 39(4): 605-617. https://doi.org/10.1046/j.1365-2664.2002.00739.x

Law, B., Doty, A., Chidel, M. \& Brassil. (2018). Bat activity before and after a severe wildfire in Pilliga forests: Resilience influenced by fire extent and landscape mobility? Austral Ecology. 43(6): 706-718. https://doi.org/10.1111/aec.12617

Law, B., Park, K. \& Lacki, M. (2015). Insectivorous bats and silviculture: balancing timber production and bat conservation. In: Voigt, C. \& Kingston, T. (eds). Bats in the Anthropocene: Conservation of Bats in a Changing World. Springer International Publishing.

Lawson, T.T., Berg, A.B. \& Hansen, E.M. (1983). Damage from laminated root rot at the Black Rock forest management area in western Oregon. Research Note 75. Oregon State University, Forest Research Laboratory.

LaVal, R. K., Clawson, R. L., Laval, M. L., \& Caire, W. (1977). Foraging behavior and nocturnal activity patterns of Missouri bats, with emphasis on the endangered species Myotis grisescens and Myotis sodalis. Journal of Mammalogy, 58(4), 592-599. https://doi.org/10.2307/1380007

Lesiński, G., Popczyk, B., \& Olszewski, A. (2011). Forest roads used by commuting and foraging bats in edge and interior zones. Polish Journal of Ecology. 59(3): 611-616.

Lewis, D. G. \& Kentta, R. (2010). Western Oregon Reservations: Two Perspectives on Place. Oregon Historical Quarterly. 111(4): 476-485. https://doi.org/10.5403/oregonhistq.111.4.0476

Lewis, S.E. (1995). Roost fidelity of bats: A review. Journal of Mammalogy. 76(2): 481-496. https://doi.org/10.2307/1382357

Lewis, S.E. (1996). Low roost-site fidelity in pallid bats: associated factors and effect on group stability. Behavioral Ecology Sociobiology. 39: 335-344. https://doi.org/10.1007/s002650050298

Lewis, T. (1970). Patterns of distribution of insects near a windbreak of tall trees. Annals of Applied Biology. 65(2): 213-220. https://doi.org/10.1111/j.1744-7348.1970.tb04581.x 
Lima, S.L. \& O'Keefe, J.M. (2013). Do predators influence the behaviour of bats? Biological Reviews. 88(3): 626-644. https://doi.org/10.1111/brv.12021

Limpens, H.J.G.A., Helmer, W., van Winden, A. \& Mostert, K. (1989). Bats and linear landscape elements. Lutra. 32: 1-20.

Limpens, H.J.G.A. \& Kapteyn, K. (1991). Bats, their behaviour and linear landscape elements. Myotis. 29: 39-48.

Loeb, S.C., \& O'Keefe, J.M. (2006). Habitat use by forest bats in South Carolina in relation to local, stand, and landscape characteristics. Journal of Wildlife Management. 70(5): 1210-1218.

https://www.jstor.org/stable/4128040

Loeb, S. C., \& O'Keefe, J. M. (2011). Bats and gaps: The role of early successional patches in the roosting and foraging ecology of bats. In Greenberg, C., Collins, B. \& Thompson III F. (eds), Sustaining Young Forest Communities. Managing Forest Ecosystems, vol. 21.

https://doi.org/10.1007/978-94-007-1620-9_10

Long, C., Whitlock, C., \& Bartlein, P. (2007). Holocene vegetation and fire history of the Coast Range, western Oregon, USA. Holocene. 17(7): 917-926. https://doi.org/10.1177/0959683607082408

Loy, W.G. (2001). Atlas of Oregon (2nd ed.). Oregon State University Press.

Lunde, R.E. \& Harestad, A.S. (1986). Activity of little brown bats in coastal forests. Northwest Science. 60(4): 206-209.

Luszcz, T.M.J., \& Barclay, R.M.R. (2016). Influence of forest composition and age on habitat use by bats in southwestern British Columbia. Canadian Journal of Zoology. 94(2): 145-153. https://doi.org/10.1139/ciz-2015-0167

Mackey, R.L. \& Barclay, R.M.R. (1989). The influence of physical clutter and noise on the activity of bats over water. Canadian Journal of Zoology. 67(5): 1167-1170. https://doi.org/10.1139/z89-168

Maguire, D.A., Kanaskie, A., Voelker, W., Johnson, R. \& Johnson, G. (2002). Growth of young Douglas fir plantations across a gradient in Swiss needle cast severity. Western Journal of Applied Forestry. 17(2): 86-95. https://doi.org/10.1016/i.foreco.2019.03.063

Makanya, A.N. \& Mortola, J.P. (2007). The structural design of the bat wing web and its possible role in gas exchange. Journal of Anatomy. 211(6): 687-697. https://doi.org/10.1111/i.1469-7580.2007.00817.x

Malison, R.L. \& Baxter, C.V. (2010). The fire pulse: Wildfire stimulates flux of aquatic prey to terrestrial habitats driving increases in riparian consumers. Canadian Journal of Fisheries and Aquatic Sciences. 67(3): 570-579. https://doi.org/10.1139/F10-006 
Maser, C., \& Cross, S.P. (1981). Notes on the Distribution of Oregon Bats. Research Note PNW-RN-379. Portland, Oregon: USDA Forest Service, Pacific Northwest Forest and Range Experiment Station. https://doi.org/10.2737/PNW-RN-379

Maser, C., Mate, B.R., Franklin, J. F., \& Dyrness, C. T. (1981). Natural History of Oregon Coast Mammals. General Technical Report PNW-133. Portland, Oregon: USDA Forest Service, Pacific Northwest Forest and Range Experimental Station. https://doi.org/10.2737/PNW-GTR-133

Mattson, T.A., Buskirk, S.W. \& Stanton, N.L. (1996). Roost sites of the silver-haired bat (Lasionycteris noctivagans) in the Black Hills, South Dakota. Great Basin Naturalist. 56(3): 247-253. http://www.jstor.org/stable/41712941

McCain, C.M. (2006). Could temperature and water availability drive elevational species richness patterns? A global case study for bats. Global Ecology and Biogeography. 16(1): 1-13. https://doi.org/10.1111/i.1466-8238.2006.00263.x

McGuire, L.P., Jonasson, K.A. \& Guglielmo, C.G. (2014). Bats on a budget: Torpor-assisted migration saves time and energy. PLOS ONE. 9(12): e115724. https://doi.org/10.1371/journal.pone.0115724

McLean, J.A., \& Speakman, J.R. (1999). Energy budgets of lactating and non-reproductive brown longeared bats (Plecotus auritus) suggest females use compensation in lactation. Functional Ecology, 13(3), 360-372. https://doi.org/10.1046/j.1365-2435.1999.00321.x

Mcnaughton, D. (2020). Siuslaw and Kuitsh: Native Americans of the Oregon Coast. Lane Community College Library. https://libraryguides.lanecc.edu/c.php?g=598770\&p=4145125

Medinas, D., Ribeiro, V., Marques, J.T., Silva, B., Barbosa, A.M., Rebelo, H. \& Mira, A. (2019). Road effects on bat activity depend on surrounding habitat type. Science of the Total Environment. 660, 340-347. https://doi.org/10.1016/i.scitotenv.2019.01.032

Melis, C., Olsen, C.B., Hyllvang, M., Gobbi, M., Stokke, B.G. \& Røskaft, E. (2010). The effect of traffic intensity on ground beetle (Coleoptera: Carabidae) assemblages in central Sweden. Journal of Insect Conservation. 14: 159-168. https://doi.org/10.1007/s10841-009-9240-3

Menzel, J.M., Menzel, M.A., Kilgo, J.C., Edwards, J.W., \& Mccracken, G.F. (2005). Effect of habitat and foraging height on bat activity in the coastal plain of South Carolina. Journal of Wildlife Management. 69(1): 235-245. https://doi.org/10.2193/0022-541X(2005)069<0235:EOHAFH>2.0.CO;2

Menzel, M.A., Carter, T.C., Menzel, J.M., Ford, W.M., \& Chapman, B.R. (2002). Effects of group selection silviculture in bottomland hardwoods on the spatial activity patterns of bats. Forest Ecology and Management, 162(2-3): 209-218. https://doi.org/10.1016/S0378-1127(01)00516-3 
Menzel, M.A., Ford, W.M., Laerm, J. \& Krishdon, D. (1999). Forest to wildlife opening: habitat gradient analysis among small mammals in the southern Appalachians. Forest Ecology and Management. 114(2-3): 227-232. https://doi.org/10.1016/S0378-1127(98)00353-3

Moeur, M., Spies, T.A., Hemstrom, M., Martin, J.R., Alegria, J., Browning, J., Cissel, J., Cohen, W.B., Demeo, T.E., Healey, S. \& Warbington, R. (2005). Northwest Forest Plan-the first 10 years (1994-2003): status and trend of late-successional and old-growth forest. General Technical Report PNW-GTR-646. Portland, Oregon: USDA Forest Service, Pacific Northwest Research Station. https://doi.org/10.2737/PNW-GTR-646

Morris, A.D., Miller, D.A., \& Kalcounis-Rueppell, M.C. (2010). Use of Forest Edges by Bats in a Managed Pine Forest Landscape. Journal of Wildlife Management. 74(1): 26-34. https://doi.org/10.2193/2008-471

Mortensen, D. A., Rauschert, E. S. J., Nord, A. N., \& Jones, B. P. (2009). Forest roads facilitate the spread of invasive plants. Invasive Plant Science and Management. 2(3): 191-199. https://doi.org/10.1614/ipsm-08-125.1

Mulvey, R.L., Shaw, D.C., Filip, G.M., \& Chastagner, G.A. (2013). Swiss Needle Cast. Forest Insect and Disease Leaflet FIDL-181-13/001. Portland, Oregon: USDA Forest Service Forest Insect \& Disease Leaflet.

Muñoz, P.T., Torres, F.P \& Megías, A.G. (2014). Effects of roads on insects: a review. Biodiversity and Conservation. 24: 659-682. https://doi.org/10.1007/s10531-014-0831-2

Müller, J., Brandl, R., Buchner, J., Pretzsch, H., Seifert, S., Strätz, C., Veith, M. \& Fenton, B. (2013). From ground to above canopy-Bat activity in mature forests is driven by vegetation density and height. Forest Ecology and Management. 306: 179-184. https://doi.org/10.1016/i.foreco.2013.06.043

Murray, S.W. \& Kurta, A. (2006). Nocturnal activity of the endangered Indiana bat (Myotis sodalis). Journal of Zoology. 262(2): 197-206. https://doi.org/10.1017/S0952836903004503

Muscolo, A., Bagnato, S., Sidari, M. \& Mercurio, R. (2014). A review of the roles of forest canopy gaps. Journal of Forestry Research. 25: 725-736. https://doi.org/10.1007/s11676-014-0521-7

Navarro, S. \& Norlander, D. (2018). 2018 Swiss Needle Cast Aerial Survey. Oregon Department of Forestry. http://sncc.forestry.oregonstate.edu/survey-maps

Nelson, J.J. \& Gillam, E.H. (2017). Selection of foraging habitat by female little brown bats (Myotis lucifugus). Journal of Mammalogy. 98(1): 222-231.. https://doi.org/10.1093/imammal/gyw181

Nixon, A.E., Gruver, J.C. \& Barclay, R.M.R. (2009). Spatial and temporal patterns of roost use by western long-eared bats (Myotis evotis). American Midland Naturalist. 162(1): 139-147. https://doi.org/10.1674/0003-0031-162.1.139 
Norberg, U.M. (1990). Vertebrate Flight: Mechanics, physiology, morphology, ecology and evolution (Vol. 27). Springer Berlin Heidelberg. https://doi.org/10.1007/978-3-642-83848-4

Norberg, U.M., \& Rayner, J.M.V. (1987). Ecological Morphology and Flight in Bats (Mammalia; Chiroptera): Wing Adaptations, Flight Performance, Foraging Strategy and Echolocation. Philosophical Transactions of the Royal Society of London. Series B, Biological Sciences, 316(1179), 335-427. https://doi.org/10.1098/rstb.1987.0030

Nuzzo, V. (1999). Invasion pattern of the herb garlic mustard (Alliaria petiolata) in high quality forests. Biological Invasions. 1: 169-179. https://doi.org/10.1023/A:1010009514048

Ober, H.K. (2006). Functional relationships among vegetation, nocturnal insects, and bats in riparian areas of the Oregon Coast Range. [Unpublished Doctoral Dissertation, Oregon State University]. Oregon State University Scholars Archive.

Ober, H.K. \& Hayes, J.P. (2008). Influence of vegetation on bat use of riparian areas at multiple spatial scales. Journal of Wildlife Management. 72(2): 396-404. https://doi.org/10.2193/2007-193

Obrist, M.K., Rathey, E., Bontadina, F., Martinoli, A., Conedera, M., Christe, P. \& Moretti, M. (2011). Response of bat species to sylvo-pastoral abandonment. Forest Ecology and Management. 261(3): 789-798. https://doi.org/10.1016/i.foreco.2010.12.010

ODFW (Oregon Department of Fish and Wildlife). (n.d.) Bats. Oregon Department of Fish and Wildlife. https://myodfw.com/wildlife-viewing/species/bats

Oregon Department of Transportation. (2019). Data \& Maps: Traffic Counting. Oregon Department of Transportation. https://www.oregon.gov/ODOT/DATA/Pages/Traffic-Counting.aspx

O'Keefe, J. (2009). Roosting and foraging ecology for forest bats in the southern Appalachian Mountains. [Unpublished doctoral dissertation, Clemson University]. All Dissertations.

Oregon State University College of Forestry. (n.d.) Swiss Needle Cast Cooperative. Oregon State University. http://sncc.forestry.oregonstate.edu/swiss-needle-cast-summary

Ormsbee, P.C. \& McComb, W.C. (1998). Selection of day roosts by female long-legged myotis in the Central Oregon Cascade Range. Journal of Wildlife Management. 62(2): 596-603. https://doi.org/10.2307/3802335

Otto, M. S., Becker, N. I., \& Encarnação, J. A. (2016). Roost characteristics as indicators for heterothermic behavior of forest-dwelling bats. Ecological Research. 31(3): 385-391.

https://doi.org/10.1007/s11284-016-1348-9 
Owen, S.F., Menzel, M.A., Edwards, J.W., Ford, W.M., Menzel, J.M., Chapman, B.R., Wood, P.B., \& Miller, K.V. (2004). Bat activity in harvested and intact forest stands in the Allegheny Mountains. Northeastern Journal of Applied Forestry, 21(3), 154-159. https://doi.org/10.1093/njaf/21.3.154

Patriquin, K.J., \& Barclay, R.M R. (2003). Foraging by bats in cleared, thinned and unharvested boreal forest. Journal of Applied Ecology. 40(4): 646-657. https://doi.org/10.1046/i.1365-2664.2003.00831.x

Pearson, O.P., Koford, M.R. \& Pearson, A.K. (1952). Reproduction of the lump-nosed bat (Corynorhinus rafinesquii) in California. Journal of Mammalogy. 33(3): 273-320. https://doi.org/10.2307/1375769

Perkins, J. M., Barss, J. M., \& Peterson, J. (1990). Winter Records of Bats in Oregon and Washington. Northwestern Naturalist, 71(2), 59-62. https://doi.org/10.2307/3536594

Perkins, J.M., \& Cross, S.P. (1988). Differential use of some coniferous forest habitats by hoary and silver-haired bats in Oregon. The Murrelet. 69(1): 21-24. https://doi.org/10.2307/3534882

Perry, R.W., Thill, R.E. \& Leslie, D.M. (2007). Selection of roosting habitat by forest bats in a diverse forested landscape. Forest Ecology and Management. 238(1-3): 156-166. https://doi.org/10.1016/i.foreco.2006.10.008

Preisser, E.L., Smith, D.C. \& Lowman, M.D. (1998). Canopy and ground level insect distribution in a temperate forest. Selbyana. 19(2): 141-146. http://www.jstor.org/stable/41759984

Pyke, G.H. (1984). Optimal foraging theory: A critical review. Annual Review of Ecology and Systematics. 15: 523-575. https://doi.org/10.1146/annurev.es.15.110184.002515

Qin, Y., Adamowski, J.F., Deo, R.C., Hu, Z., Cao, J., Zhu, M. \& Feng, Q. (2019). Controlling factors of plant community composition with respect to the slope aspect gradient in the Qilian Mountains. Ecosphere. 10(9): e02851. https://doi.org/10.1002/ecs2.2851

Quan, M. \& Liang, J. (2017). The influences of four types of soil on the growth, physiological and biochemical characteristics of Lycoris aurea (L' Her.) Herb. Scientific Reports. 7: 43284. https://doi.org/10.1038/srep43284

Racey, P.A. (1973). Environmental factors affecting the length of gestation in heterothermic bats. Journal of Reproduction and Fertility. 19: 175-189. PMID: 4522371

Racey, P.A. (1982). Ecology of bat reproduction. In: Kunz T.H. (eds), Ecology of Bats. Springer, Boston. https://doi.org/10.1007/978-1-4613-3421-7_2

Racey, P.A. \& Swift, S.M. (1981). Variations in gestation length in a colony of pipistrelle bats (Pipistrellus pipistrellus) from year to year. Reproduction. 61(1): 123-129. https://doi.org/10.1530/jrf.0.0610123 
Racey, P.A. \& Swift, S.M. (1985). Feeding ecology of Pipistrellus pipistrellus (Chiroptera: Vespertilionidae) during pregnancy and lactation. Foraging behavior. Journal of Animal Ecology. 54(1): 205-215. https://doi.org/10.2307/4631

Racey, P. A., \& Speakman, J. (1987). The energy costs of pregnancy and lactation in heterothermic bats. In Loudon, A. \& Racey, P.A. (eds), Reproductive energetics in mammals. Oxford University Press.

Rainho, A. \& Palmeirim, J.M. (2011). The importance of distance to resources in the spatial modelling of bat foraging habitat. PLoS ONE, 6(4): e19227. https://doi.org/10.1371/journal.pone.0019227

Ratcliffe, J.M., \& Dawson, J.W. (2003). Behavioural flexibility: The little brown bat, Myotis lucifugus, and the northern long-eared bat, M. septentrionalis, both glean and hawk prey. Animal Behaviour. 66(5): 847-856. https://doi.org/10.1006/anbe.2003.2297

Rautenbach, I.L., Whiting, M.J. \& Fenton, M.B. (1996). Bats in riverine forests and woodlands: a latitudinal transect in southern Africa. Canadian Journal of Zoology. 74(2): 312-322. https://doi.org/10.1139/296-039

Razgour, O., Korine, C. \& Saltz, D. (2010). Pond characteristics as determinants of species diversity and community composition of desert bats. Animal Conservation. 13(5): 505-513. https://doi.org/10.1111/j.1469-1795.2010.00371.x

Roberts, H.P., King, D.I. \& Milam, J. (2017). Factors affecting bee communities in forest openings and adjacent mature forest. Forest Ecology and Management. 394: 111-122. https://doi.org/10.1016/i.foreco.2017.03.027

Rodhouse, T.J. \& Hyde, K.J. (2014). Roost and forage site fidelity of western small-footed myotis (Myotis ciliolabrum) in an Oregon desert canyon. Western North American Naturalist. 74(2): 241-248. https://doi.org/10.3398/064.074.0212

Ruffner, G.A., Poche, R.M., Meierkord, M. \& Neal, J.A. (1979). Winter bat activity over a desert wash in southwestern Utah. The Southwestern Naturalist. 24(3): 447-453. https://doi.org/10.2307/3671300

Ruth, R.H. \& Yoder, R.A. (1953). Reducing wind damage in the forests of the Oregon Coast range. USDA Forest Service PNW Old Series Research Paper; No. 7: 1-30.

Santos-Moreno, A., Velasquez, E.R. \& Martinez, A.S. (2010). Effect of the intensity of the moonlight and wind speed in the activity of phyllostomid bats of Mena Nizanda, Oaxaca, Mexico. Revista Mexicana de Biodiversidad. 81: 839-845.

Sasse, D.B. (1995). Summer roosting ecology of cavity-dwelling bats in the White Mountain National Forest. [Unpublished Master's Thesis, University of New Hampshire]. Research Gate. 
Saunders, M.B. \& Barclay, R.M.R. (1992). Ecomorphology of insectivorous bats: A test of predictions using two morphologically similar species. Ecology. 73(4): 1335-1345. https://doi.org/10.2307/1940680

Schaub, A., Ostwald, J. \& Siemers, B.M. (2008). Foraging bats avoid noise. Journal of Experimental Biology. 211(19): 3174-3180. https://doi.org/10.1242/jeb.022863

Seibold, S., Buchner, J., Bässler, C. \& Müllerm, J. (2013). Ponds in acidic mountains are more important for bats in providing drinking water than insect prey. Journal of Zoology. 290(4): 302-308. https://doi.org/10.1111/jzo.12041

Seidman, V.M., \& Zabel, C.J. (2001). Bat activity along intermittent streams in northwestern California. Journal of Mammalogy. 82(3): 738-747. https://doi.org/10.1644/1545-1542(2001)082<0738:BAAISI>2.0.CO;2

Sidle, R.C. \& Terry, P.K.K. (1992). Shallow landslide analysis in terrain with managed vegetation. In: Proceedings of the Chengdu Symposium. IAHS Publication No. 209.

Siemers, B.M. \& Schaub, A. (2011). Hunting at the highway: traffic noise reduces foraging efficiency in acoustic predators. Proceedings of the Royal Society of London B: Biological Sciences. 278: 1646-1652. https://doi.org/10.1098/rspb.2010.2262

Sleep, D.J.H., \& Brigham, R.M. (2003). An experimental test of clutter tolerance in bats. Journal of Mammalogy. 84(1): 216-224. https://doi.org/10.1644/1545-1542(2003)084<0216:aetoct>2.0.c0;2

Sparks, D.W., Ritzi, C.M., Duchamp, J.W. \& Whitaker, J.O. (2005). Foraging habitat of the Indiana bat (Myotis sodalis) at an urban-rural interface. Journal of Mammalogy. 86(4): 713-718. https://doi.org/10.1644/1545-1542(2005)086[0713:FHOTIB]2.0.CO;2

Speakman, J R. (1991a). The impact of predation by birds on bat populations in the British Isles. Mammalogy Reviews. 21(3): 123-142. https://doi.org/10.1111/i.1365-2907.1991.tb00114.x

Speakman, J R. (1991b). Why do insectivorous bats in Britain not fly in daylight more frequently? Functional Ecology. 5(4): 518-524. https://doi.org/10.2307/2389634

Speakman, J.R., Racey, P.A.., Catto, C.M.C., Webb, P.I., Swift, S.M. \& Burnett, A.M. (1991). Minimum summer populations and densities of bats in N.E. Scotland, near the northern borders of their distributions. Journal of Zoology. 225(2) 327-345. https://doi.org/10.1111/i.1469-7998.1991.tb03820.x

Speakman, J.R., \& Rowland, A. (1999). Preparing for inactivity: How insectivorous bats deposit a fat store for hibernation. Proceedings of the Nutrition Society. 58(1): 123-131. https://doi.org/10.1079/pns19990017 
Starbuck, C.A., Considine, E.S. \& Chambers, C.L. (2020). Water and elevation are more important than burn severity in predicting bat activity at multiple scales in a post-wildfire landscape. PLOS ONE. 15(4): e0231170. https://doi.org/10.1371/iournal.pone.0231170

Stephens, D.W. \& Krebss, J.R. (1987). Foraging Theory. Princeton University Press.

Strittholt, J.R., Dellasala, D.A., \& Jiang, H. (2006). Status of mature and old-growth forests in the Pacific Northwest. Conservation Biology. 20(2): 363-374. https://www.jstor.org/stable/3591344

Strobel, S., Roswag, A., Becker, N. I., Trenczek, T. E., \& Encarnação, J. A. (2013). Insectivorous Bats Digest Chitin in the Stomach Using Acidic Mammalian Chitinase. PLOS ONE, 8(9): 72770. https://doi.org/10.1371/journal.pone.0072770

Swengel, A.B. (2001). A literature review of insect responses to fire, compared to other conservation managements of open habitat. Biodiversity and Conservation. 10(7): 1141-1169. https://doi.org/10.1023/A:1016683807033

Swingen, M., Moen, R., Walker, M. Baker, R., Nordquist, G., Catton, T., Kirschbaum, K., Dirks, B., \& Dietz, N. (2018). Bat radiotelemetry in forested areas of Minnesota. University of Minnesota Duluth, Natural Resources Research Institute. https://conservancy.umn.edu/bitstream/handle/11299/204335/NRRI-TR-2018-42.pdf?sequence=1

Swystun, M.B., Psyllakis, J.M. \& Brigham, R.M. (2001). The influence of residual tree patch isolation on habitat use by bats in Central British Columbia. Acta Chiropterologica. 3(2): 197-201.

Thomas, D.W. \& West, S.D. (1991). Forest age associations of bats in the southern Washington Cascade and Oregon Coast Ranges. Olympia, Washington: USDA Forest Service, Pacific Northwest Research Station.

Thomas, D.W. (1988). The distribution of bats in different ages of Douglas-fir forests. Journal of Wildlife Management. 52(4): 619-626.https://doi.org/10.2307/3800920

Tibbels, A.E. \& Kurta, A. (2003). Bat activity is low in thinned and unthinned stands of red pine. Canadian Journal of Forest Research. 33(12): 2436-2442. https://doi.org/10.1139/x03-177

Tuttle, M.D. (1976). Population ecology of the gray bat (Myotis grisescens): Philopatry, timing and patterns of movement, weight loss during migration, and seasonal adaptive strategies. Ecology. 57(3): 587-595. https://doi.org/10.2307/1936443

Tuttle, M. D., \& Ryan, M. J. (1981). Bat predation and the evolution of frog vocalizations in the neotropics. Science, 214(4521), 677-678. https://doi.org/10.1126/science.214.4521.677 
Tuttle, S.R., Chambers, C.L. \& Theimer, T.C. (2010). Potential effects of livestock water-trough modifications on bats in northern Arizona. Wildlife Society Bulletin. 34(3): 602-608. https://doi.org/10.2193/0091-7648(2006)34[602:PEOLWM]2.0.CO;2

USDA Forest Service. (1990). Final Environmental Impact Statement for the Land and Resource Management Plan: Siuslaw National Forest. Portland, Oregon: USDA Forest Service, Pacific Northwest Region.

USDA Forest Service. (2010). Environmental Assessment: Marys Landscape Management Project. Portland, Oregon: USDA Forest Service, Pacific Northwest Region.

USDA Forest Service. (n.d.a). About the Forest. USDA Forest Service. https://www.fs.usda.gov/main/siuslaw/about-forest

USDA Forest Service. (n.d.b). History \& Culture - Timeline through the Decades. USDA Forest Service. https://www.fs.usda.gov/detailfull/siuslaw/learning/history-culture/?cid=fsbdev7 007152\&width=f ull\#decade1

USDA Forest Service. (n.d. c). Cape Perpetua Scenic Area. USDA Forest Service. https://www.fs.usda.gov/recarea/siuslaw/recreation/recarea/?recid=42265

USDA Forest Service. (n.d. d). Oregon Dunes National Recreation Area. USDA Forest Service. https://www.fs.usda.gov/recarea/siuslaw/recreation/recarea/?recid=42465

USDA Forest Service. (n.d. e). Cascade Head Scenic Research Area. USDA Forest Service. https://www.fs.usda.gov/recarea/siuslaw/recreation/recarea/?recid=42717

USDA Forest Service. (n.d.f). Resource Management. USDA Forest Service. https://www.fs.usda.gov/detailfull/siuslaw/landmanagement/resourcemanagement/?cid=stelprdb5 $177211 \&$ width=full

USDA Forest Service \& Bureau of Land Management. (1994). Record of decision for amendments to Forest Service and Bureau of Land Management planning documents within the range of the northern spotted owl. Washington, DC: USDA Forest Service and Bureau of Land Management.

USDA Forest Service \& Bureau of Land Management. (1994a). Standards and Guidelines for Management of Habitat for Late-Successional and Old-Growth Forest Related Species Within the Range of the Northern Spotted OwI Washington, DC: USDA Forest Service and Bureau of Land Management.

U.S. Geological Survey - Gap Analysis Project. (2018). U.S.Geological Survey - Gap Analysis Project Species Range Maps CONUS_2001: U.S. Geological Survey data release, https://doi.org/10.5066/F7081B3R 
van Zyll de Jong. (1985). Handbook of Canadian Mammals: Volume 2: Bats. National Museum of Natural Sciences.

Vaughn, N., Jones, G. \& Harris, S. (1997). Habitat use by bats (Chiroptera) assessed by means of a broad-band acoustic method. Journal of Applied Ecology. 34(3): 716-730.

https://doi.org/10.2307/2404918

Veilleux, J.P., Moosman, P.R., Reynolds, D.S., LaGory, K.E. \& Walston, L.J. (2009). Observations of summer roosting and foraging behavior of a hoary bat (Lasiurus cinereus) in Southern New Hampshire. Northeastern Naturalist. 16(1): 148-152. https://doi.org/10.1656/045.016.0113

Verboom, B. (1998). The use of edge habitats by commuting and foraging bats. [Unpublished Doctoral Dissertation, Wageningen University.] Semantic Scholar.

Verboom, B., Boonman, A.M. \& Limpens, H.J.G.A. (2006). Acoustic perception of landscape elements by the pond bat (Myotis dasycneme). Journal of Zoology. 248(1): 59-66. https://doi.org/10.1111/j.1469-7998.1999.tb01022.x

Verboom, B. \& Huitema, H. (1997). The importance of linear landscape elements for the pipistrelle Pipistrellus pipistrellus and the serotine bat Eptesicus serotinus. Landscape Ecology. 12: 117-125. https://doi.org/10.1007/BF02698211

Verboom, B. \& Spoelstra, K. (1999). Effects of food abundance and wind on the use of tree lines by an insectivorous bat, Pipistrellus pipistrellus. Canadian Journal of Zoology. 77(9): 1393-1401. https://doi.org/10.1139/cjz-77-9-1393

Voigt, C. C., Frick, W. F., Holderied, M. W., Holland, R., \& Kerth, G. (2017). Principles and patterns of bat movements: from aerodynamics to ecology. In The Quarterly Review of Biology. 92(3): 267-287. https://doi.org/10.1086/693847

von Frenckell, B. \& Barclay, M.R.M. (1987). Bat activity over calm and turbulent water. Canadian Journal of Zoology. 65(2): 219-222. https://doi.org/10.1139/z87-035

Vonhof, M.J. \& Barclay, R.M.R. (1996). Roost-site selection and roosting ecology of forest-dwelling bats in southern British Columbia. Canadian Journal of Zoology. 74: 1797-1805. https://doi.org/10.1139/z96-200

Wai-Ping, V., \& Fenton, M.B. (1989). Ecology of spotted bat (Euderma maculatum) roosting and foraging behavior. Journal of Mammalogy. 70(3): 617-622. https://doi.org/10.2307/1381434

Waldien, D. L., \& Hayes, J. P. (2001). Activity areas of female long-eared myotis in coniferous forests in western Oregon. Northwest Science. 75(3): 307-314. https://doi.org/10.2307/3802749 
Waldien, D.L., Hayes, J.P., \& Arnett, E.B. (2000). Day-roosts of female long-eared Myotis in western Oregon. Journal of Wildlife Management. 64(3): 785-796. https://www.jstor.org/stable/3802749

Walsh, A.L. \& Harris, S. (1996). Foraging habitat preferences of Vespertilionid bats in Britain. Journal of Applied Ecology. 33: 508-518. https://doi.org/10.2307/2404980

Webb, P.I., Speakman, J.R. \& Racey, P.A. (1995). Evaporative water loss in two sympatric species of vespertilionid bat, Plecotus auritus and Myotis daubentoni: relation to foraging mode and implications for roost site selection. Journal of Zoology. 235(2): 269-278.

https://doi.org/10.1111/i.1469-7998.1995.tb05143.x

Weller, T.J., Castle, K.T., Liechti, F., Hein, C.D., Schirmacher, M.R. \& Cryan, P.M. (2016). First direct evidence of long-distance seasonal movements and hibernation in a migratory bat. Scientific Reports. 6 : 34585. https://doi.org/10.1038/srep34585

Weller, T.J. \& Zabel, C.J. (2001). Characteristics of fringed myotis day roosts in northern California. Journal of Wildlife Management. 66(3): 489-497. https://doi.org/10.2307/3803102

Whitaker, D.M., Carroll, A.L. \& Montevecchi, W.A. (2000). Elevated numbers of flying insects and insectivorous birds in riparian buffer strips. Canadian Journal of Zoology. 78(5): 740-747. https://doi.org/10.1139/z99-254

Wilkinson, L. (2010). The People Are Dancing Again: The History of the Siletz Tribe of Western Oregon. University of Washington Press.

Wilkinson, L.C. \& Barclay, R.M.R. (1997). Differences in the foraging behavior of male and female big brown bats (Eptesicus fuscus during the reproductive period. Ecoscience. 4(3): 279-285. https://doi.org/10.1080/11956860.1997.11682406

Wimberly, M.C., Spies, T.A., Long, C.J. \& Whitlock, C. (2000). Simulating historical variability in the amount of old forests in the Oregon Coast Range. Conservation Biology. 14(1): 167-180. https://doi.org/10.1046/i.1523-1739.2000.98284.x

Wolbert, S.J., Zellner, A.S. \& Whidden, H.P. (2014). Bat activity, insect biomass, and temperature along an elevational gradient. Northeastern Naturalist. 21(1): 72-85. https://doi.org/10.1656/045.021.0106

Wolcott, K.A. \& Vulinec, K. (2012). Bat activity at woodland/farmland interfaces in central Delaware. Northeastern Naturalist. 19(1): 87-89. https://doi.org/10.1656/045.019.0107

Wunder, L. \& Carey, A.B. (1996). Use of the forest canopy by bats. Northwest Science. 70: 79-85.

Yates, M.D. \& Muzika, R.M. (2006). Effect of forest structure and fragmentation on site occupancy of bat species in Missouri Ozark forests. Journal of Wildlife Management. 70(5): 1238-1248.

https://doi.org/10.2193/0022-541x(2006)70[1238:eofsaf]2.0.c0;2 
Zabel, C.J. \& Anthony, R.G. (2003). Mammal Community Dynamics: Management and Conservation in the Coniferous Forests of Western North America. Cambridge University Press.

Zurcher, A.A., Sparkes, D.W. \& Bennett, V.J. (2010). Why the bat did not cross the road? Acta Chiropterologica. 12(2): 337-340. https://doi.org/10.3161/150811010X537918 